\title{
INEEL Subsurface Disposal Area CERLCA-Based Decision Analysis for Technology Screening and Remedial Alternative Evaluation
}

\author{
G. S. Parnell \\ J. Kloeber \\ D. Westphal \\ V. Fung
}

March 2000 


\title{
INEEL Subsurface Disposal Area (SDA) CERLCA-Based Decision Analysis for Technology Screening and Remedial Alternative Evaluation
}

\author{
Gregory S. Parnell \\ Jack Kloeber, Jr. \\ Deborah Westphal \\ Vicki Fung
}

March 2000

\section{Idaho National Engineering and Environmental Laboratory Idaho Falls, Idaho 83415}

Prepared for the

U.S. Department of Energy

Assistant Secretary for Environmental Management

Under DOE Idaho Operations Office

Contract DE-AC07-99ID13727 


\section{ABSTRACT}

A CERCLA-based decision analysis methodology for alternative evaluation and technology screening has been developed for application at the Idaho National Engineering and Environmental Laboratory WAG 7 OU13/14 Subsurface Disposal Area (SDA). Quantitative value functions derived from CERCLA balancing criteria in cooperation with State and Federal regulators are presented. A weighted criteria hierarchy is also summarized that relates individual value function numerical values to an overall score for a specific technology alternative. 


\section{SPECIAL NOTE}

This report was prepared by Toffler and Associates for the INEEL WAG 7 OU13/14 Subsurface Disposal Area Feasibility Study effort. It summarizes a CERCLA-based decision methodology and presents value functions that were developed jointly by representatives of the Department of Energy Idaho Field Office, State of Idaho Department of Health and Welfare, and United States Environmental Protection Agency (EPA) Region 10. Toffler provided guidance during development of the methodology and value functions, facilitated meetings and documented results in various draft documents and this report. The value functions described in this report have been integrated into an automated computer model which is described in INEEL Subsurface Disposal Area CERCLA-based Technology Screening Model, INEEL/EXT-2000-0158. Together, these reports provide a complete description of the rationale, methodology, and implementation of the FS technology screening tools developed to support the WAG 7 OU13/14 Feasibility Study. 


\section{EXECUTIVE SUMMARY}

\section{INEEL SDA Challenge}

The INEEL Subsurface Disposal Area has radiological waste spread throughout 88 acres in various liquid and solid forms including barrels and other containers. There are also other carcinogenic hazardous wastes, primarily carbon tetrachloride, nitrates, and methylene chloride, spread throughout in various forms and states. There are many pits and trenches containing these wastes (and soil vaults, and Pad A). Different pits and trenches may require different remediation technologies that may cause interactions between adjacent locations, all affecting the success of the remediation effort. Finally, there is concern about the accuracy of the historical records of the SDA contaminants.

\section{Purpose of the CERCLA-Based Decision Analysis}

The Comprehensive Environmental Response, Compensation, and Liability Act (CERCLA) requires that technology screening and evaluation of remedial alternatives be performed for INEEL/ LMITCO, Department of Energy Idaho Field Office (DOE-ID) DOE/ Idaho Operations Office, State of Idaho Department of Health and Welfare (IDHW), and United States Environmental Protection Agency Region 10 decision-makers. In addition, their decisions must be justified to public stakeholders. CERCLA and the EPA guidance identify the criteria and subcriteria for technology screening and remedial alternative evaluation. The goal of this effort is to support CERCLA decision-makers by developing a CERCLA-based decision analysis methodology for screening remedial technologies and evaluating remedial alternatives for the INEEL Waste Area Group (WAG) -7, Operable Unit (OU) 13/14 Subsurface Disposal Area (SDA) Feasibility Study. This report documents the decision model.

\section{CERCLA-Based Decision Analysis Methodology}

Working with INEEL/LMITCO, DOE-ID, State of Idaho, and EPA Region 10 decision-makers, we had previously developed a CERCLA-based multiobjective decision analysis model based on the CERCLA criteria and subcriteria. Beginning at a meeting of key decision-makers in May 1999, we reviewed and refined this decision analysis model. For each criterion, we developed evaluation measures and value functions to capture how well a technology or a remedial alternative meets each of the CERCLA criteria. Next, we reviewed each evaluation measure and value function with the Feasibility Study team to ensure that data could be cost-effectively obtained. We refined the value model based on team feedback. Next, we reviewed the changes with the key decision-makers. This value model will be the decision analysis algorithm for the SDA Site Analysis Model being developed by INEEL. This document describes the CERCLA-based decision analysis model developed for the SDA technology screening and remedial alternative evaluation. Each CERCLA criterion, sub criterion, evaluation measure, and value function is described. The rationale for each measure is also included. The team also used CERCLA and the SDA site specific characteristics to adjust the weights throughout the model reflecting the appropriate relative importance of the criteria, the subcriteria, and the various contaminants.

\section{CERCLA-Based Decision Analysis Value}

The major value of the CERCLA-based multiobjective decision analysis methodology is the direct link of the CERCLA criteria to the ultimate decisions leading to the safest, most cost effective, and successful technology screening and remediation of radiological waste and other hazardous wastes at the INEEL SDA site. Since an objective, systematic process is used to define the value model and score the remedial alternatives; the results are directly traceable and transparent for decision-maker use and stakeholder review. The methodology draws a clear 
line from the existing waste and hazards through transparent decisions clearly aimed at remediation, and to ongoing and final actions to remediate the SDA. The methodology has the following benefits:

1. An Objective, Systematic Process

2. A Robust Analysis Technique

3. Traceable Analysis Results

4. Better Alternatives

5. Sensitivity Analysis

6. Uncertainty Analysis

7. A Framework for Regulator and Public Discourse 


\section{ACKNOWLEDGMENTS}

Many people have provided valuable guidance and support to help develop the CERCLA-based multiobjective decision analysis methodology. The authors would like to especially thank the following individuals for their assistance:

\author{
Mr. Alan Jines \\ Mr. Aran Armstrong \\ Mr. Rick Poeton \\ Mr. Wayne Pierre \\ Mr. Daryl Koch \\ Mr. Gerry Winter \\ Ms. Reva Hyde \\ Mr. John Richardson \\ Mr. Bruce Becker \\ Ms. Joan McDonald \\ Mr. Doug Jorgensen \\ Mr. Dave Nickelson
}

\author{
DOE - Idaho Operations Office \\ DOE - Idaho Operations Office \\ U.S. Environmental Protection Agency, Region 10 \\ U.S. Environmental Protection Agency, Region 10 \\ State of Idaho, IDHW \\ State of Idaho, IDHW \\ Bechtel BWXT Idaho, LLC \\ Bechtel BWXT Idaho, LLC \\ Bechtel BWXT Idaho, LLC \\ Bechtel BWXT Idaho, LLC. \\ Bechtel BWXT Idaho, LLC. \\ Bechtel BWXT Idaho, LLC.
}




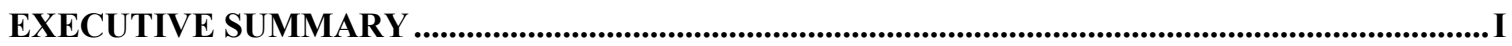

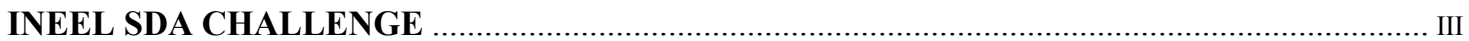

PURPOSE OF THE CERCLA-BASED DECISION ANALYSIS .............................................. III

CERCLA-BASED DECISION ANALYSIS METHODOLOGY ............................................... III

CERCLA-BASED DECISION ANALYSIS VALUE ................................................................. III

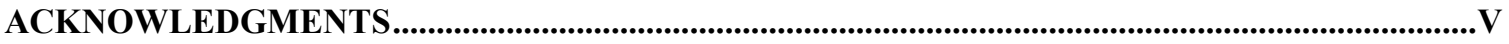

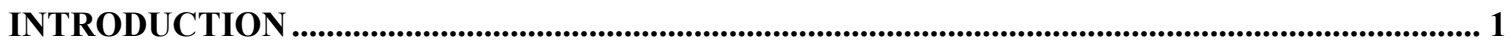

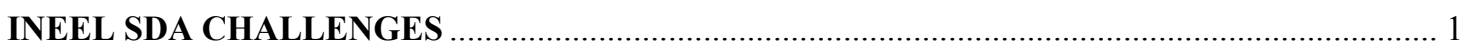

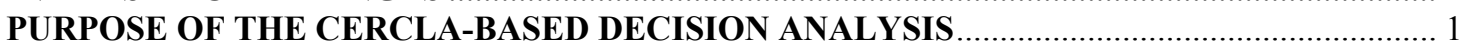

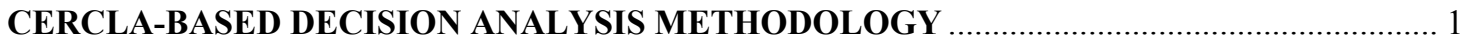

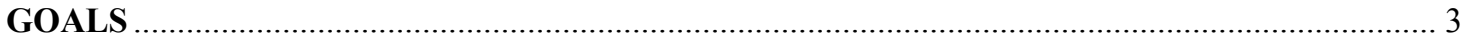

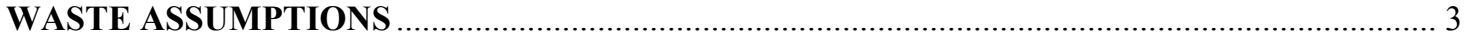

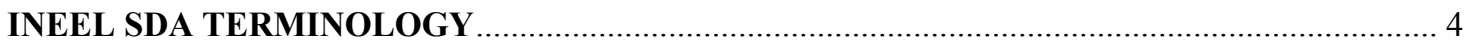

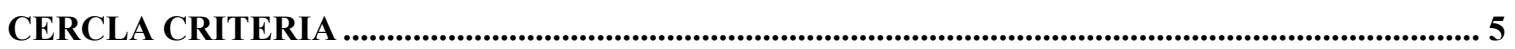

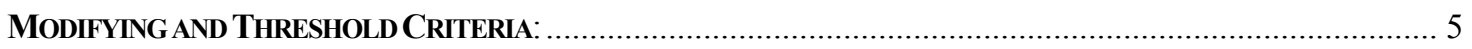

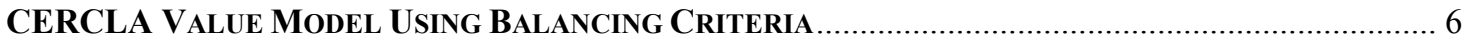

MULTIOBJECTIVE DECISION ANALYSIS............................................................................................... 7

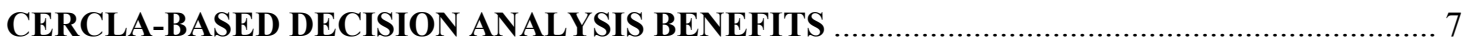

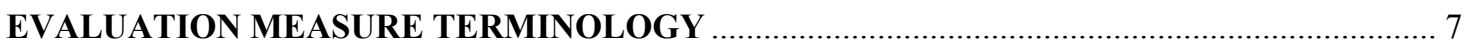

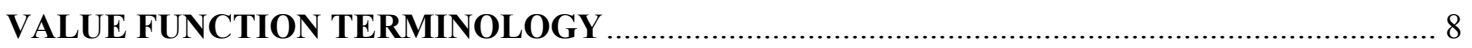

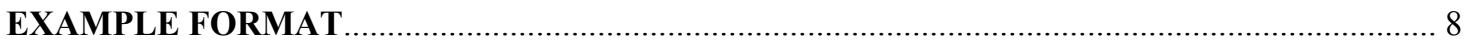

CERCLA HIERARCHY AND EVALUATION MEASURES FOR INEEL SDA ................................ 10

BALANCING CRITERIA 1: LONG TERM EFFECTIVENESS AND PERMANENCE ............................................ 10

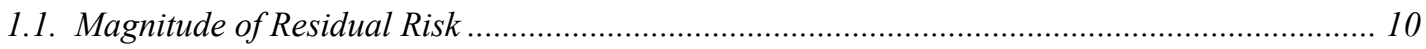

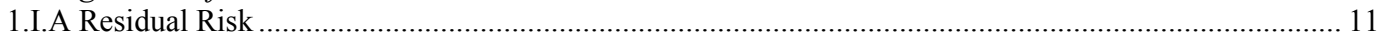

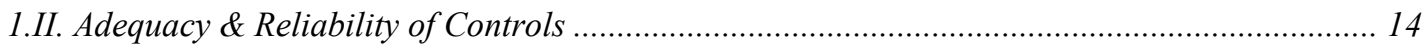

Balancing Criteria 2: Reduction Of Toxicity, Mobility, Or VOlume Through

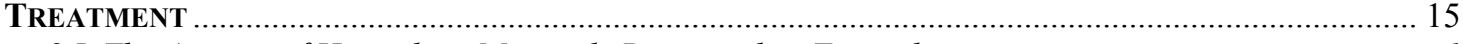

2.I. The Amount of Hazardous Materials Destroyed or Treated ……............................................. 1

2.I.A. The Amount of Carbon Tetrachloride with Reduced Toxicity, Mobility, or Volume ............................... 1

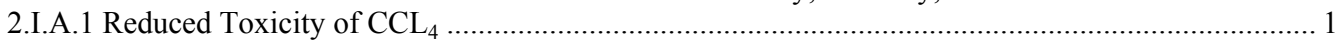

2.I.A.2 Reduced Mobility of CCL4 …………………………………………………………….... 2

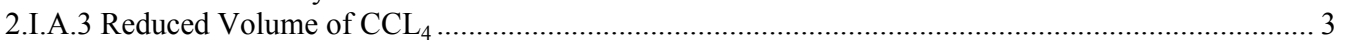

2.I.B. The Amount of Actinides with Reduced Toxicity, Mobility, or Volume ……………………………..... 4

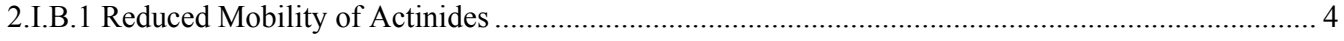

2.1.B.2 Reduced Volume of Actinides............................................................................................. 5

2.I.C. The Amount of Risk-Driving/NPT VOCs with Reduced Toxicity, Mobility, or Volume........................ 6

2.I.C.1 Reduced Toxicity Of Risk-Driving/NPT (Nitrates \& Methylene Chloride)....................................... 6

2.I.C.2 Reduced Mobility of Risk-Driving/NPT VOCs (Nitrates \& Methylene Chloride) ………………..... 7

2.I.C.3 Reduced Volume of Risk-Driving/NPT VOCs (Nitrates \& Methylene Chloride) .............................. 8

2.I.D. The Amount of Risk-Driving/NPT Radiological Contaminants with Reduced Toxicity, Mobility, or Volume.

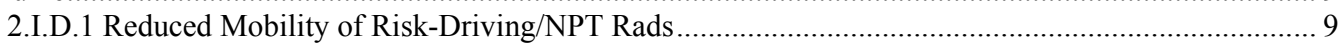

2.I.D.2 Reduced Volume of Risk-Driving/NPT Rads .................................................................... 10

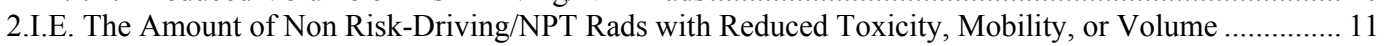

2.I.E.1 Reduced Mobility of Non Risk-Driving Rads ...................................................................... 11

2.I.E.2 Reduced Volume of Non Risk-Driving/Non Principal Threat Rads............................................ 12

2.II. Amount of Principal Threat Treated to Reduce Toxicity, Mobility, or Volume......................... 13

2.II.A. Amount of VOCs Treated to Reduce Toxicity, Mobility, or Volume............................................... 14

2.II.A.1 Reduction of Toxicity of Principal Threat VOCs ............................................................. 14

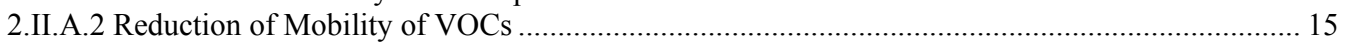


2.II.A.3 Reduction of Volume of Principal Threat VOCs

2.II. B. Amount of Actinides Treated to Reduce Toxicity, Mobility, or Volume ……....................................... 17

2.II.B.1 Reduction of Mobility of Principal Threat - Actinides ......................................................... 17

2.II.B.2 Reduction of Volume of Principal Threat - Actinides ........................................................... 18

2.III. Irreversibility of Treatment of Contaminants of Principal Concern...................................... 19

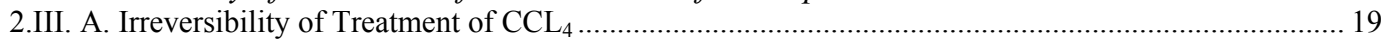

2.III.A.1 Irreversibility of Reduction of Toxicity of Carbon tetrachloride $\left(\mathrm{CCL}_{4}\right)$............................... 19

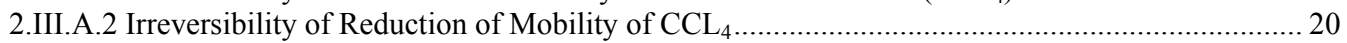

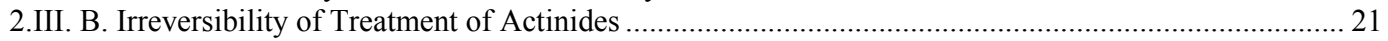

2.III.B.1 Irreversibility of Reduction of Mobility of Actinides ............................................................. 21

2.III. C. Irreversibility of Treatment of VOCs (Nitrates \& Methylene Chloride)............................................ 22

2.III.C.1 Irreversibility of Reduction of Toxicity of Risk Driving/NPT VOCs.................................... 22

2.III.C.2 Irreversibility of Reduction of Mobility of Risk-Driving NPT VOCs ..................................... 23

2.III. D. Irreversibility of Treatment of Other COPC Radiological Contaminants........................................ 24

2.III.D.1 Irreversibility of Reduction of Mobility of Other COPC Rads.............................................. 24

2.IV. Amount of Treatment Residuals Remaining After Treatment ................................................ 25

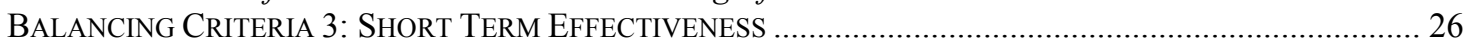

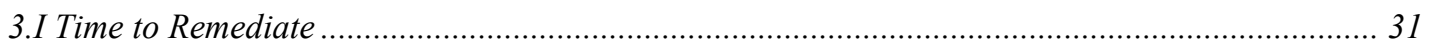

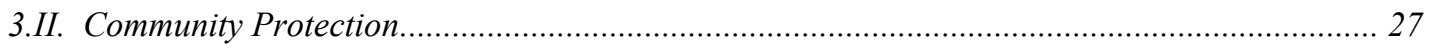

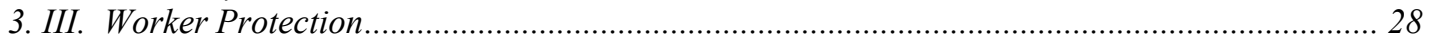

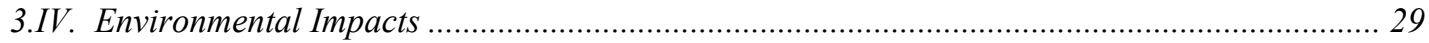

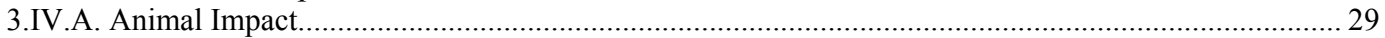

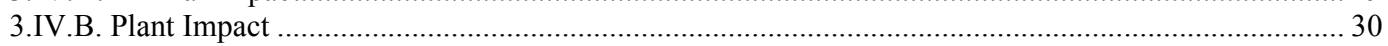

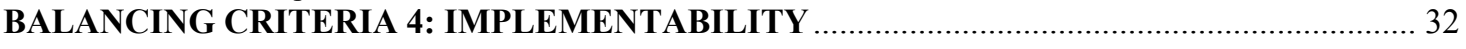

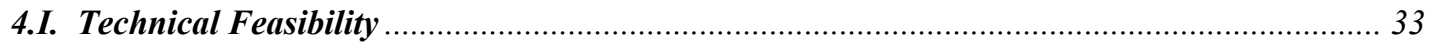

4.I.A. Technical Difficulties and Unknowns Associated with the Construction and Operation of a

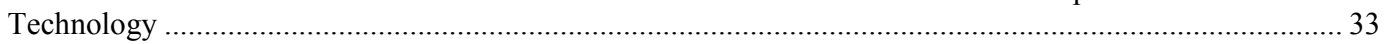

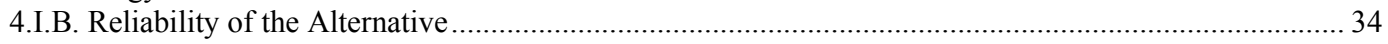

4.I.C. Ease of Additional Remedial Actions (if required) ............................................................ 35

This measure addresses how difficult it would be to perform additional remedial actions if required. For each

TPO in Phase 2, the experts will assign one of the above categories. In Phase 3, each train will be evaluated as the lowest value of the TPOs that comprise the train. The likely future interim remedial actions will have

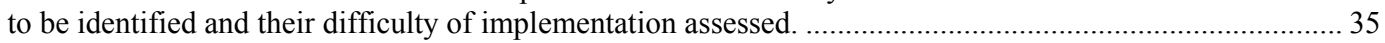

4.I.D. Ability to Monitor the Effectiveness of the Remedy ........................................................... 36

4.II. Administrative Feasibility ......................................................................................... 37

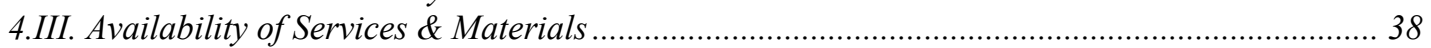

4.III.A. Availability of Storage and Disposal Facilities.................................................................... 38

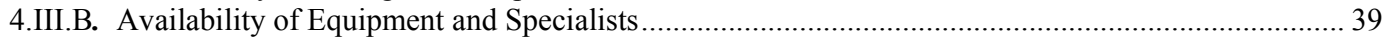

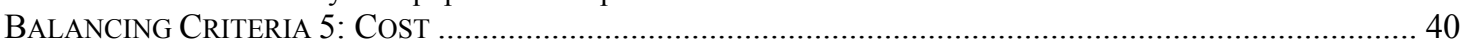

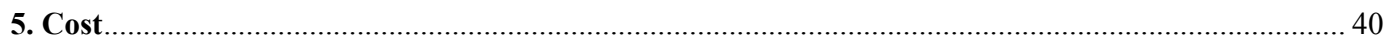

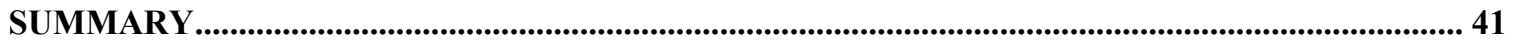

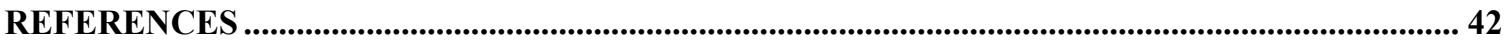




\section{INTRODUCTION}

\section{INEEL SDA Challenges}

The INEEL Subsurface Disposal Area has radiological waste spread throughout 88 acres in various liquid and solid forms including barrels and other containers. There are also other carcinogenic hazardous wastes, primarily carbon tetrachloride, nitrates, and methylene chloride, spread throughout in various forms and states. There are many pits and trenches containing these wastes (and soil vaults, and Pad A). Different pits and trenches may require different remediation technologies that may cause interactions between adjacent locations, all affecting the success of the overall remediation effort. Finally, there is concern about the accuracy of the historical records of the contaminants present at the SDA.

\section{Purpose of the CERCLA-Based Decision Analysis}

The Comprehensive Environmental Response, Compensation, and Liability Act (CERCLA), as amended, regulates the cleanup of hazardous waste disposal sites. CERCLA outlines the remedial investigation and feasibility study (RI/FS) process used by environmental decision-makers at all Superfund sites. DOE must comply with the CERCLA requirements in its cleanup activities. The FS describes three types of remedial alternative analyses: the screening analysis, the detailed analysis of alternatives, and the cost-effectiveness analysis. In addition, CERCLA requires site decision-makers to document their remedial alternative analyses in the Proposed Plan and Record of Decision.

CERCLA requires that technology screening and evaluation of remedial alternatives be performed. The decision makers for selecting the remedial alternatives are INEEL/ LMITCO, Department of Energy Idaho Field Office (DOE-ID) DOE/ Idaho Operations Office, State of Idaho Department of Health and Welfare (IDHW), and United States Environmental Protection Agency Region 10 decision-makers. In addition, their decisions must be justified to public stakeholders. CERCLA and the EPA guidance identify the criteria and subcriteria for technology screening and remedial alternative evaluation. The goal of this effort is to support CERCLA decisionmakers by developing and using a CERCLA-based decision analysis methodology for screening remedial technologies and evaluating remedial alternatives for the INEEL Waste Area Group (WAG) -7, Operable Unit (OU) 13/14 Subsurface Disposal Area (SDA) Feasibility Study (FS). The purpose of the Toffler Associates effort is to support the WAG 7-13/14 Feasibility Study Team with an objective and transparent decision tool for technology screening and remedial alternative evaluation. This report documents the decision model.

\section{CERCLA-Based Decision Analysis Methodology}

A methodology for modeling, structuring, scoring and evaluating remedial alternatives for CERCLA sites, in general, was developed previously (Parnell et al., 1999). For a major Superfund site cleanup, the methodology (Figure 1) begins by working with site technical and management personnel to quantify the CERCLA criteria based on CERCLA, the Environmental Protection Agency (EPA) CERCLA guidance, the contaminants of principal concern (COPC), and the unique challenges of the site. The resultant model is comprised of evaluation measures, value functions, criteria weights, and a mathematical method for combining alternative scores on each of these measures to accurately represent how consistent a remedial alternative is compared to the law (CERCLA). We validate this model with state and EPA regulators. Once remedial alternatives have been developed, the model uses life cycle cost data, implementation data, and performance data to compare these alternatives. The value-focused modeling of CERCLA allows us to use decision analysis techniques to perform sensitivity analysis for modeling assumptions and remedial alternative scoring. In addition, our method can easily incorporate the analysis of key site characterization and performance uncertainties. As new technology effectiveness and cost data 
become available, the analysis can be periodically updated during the RI/FS process to provide remedial alternative evaluation products to DOE, state, and EPA decision-makers to support key decision milestones.

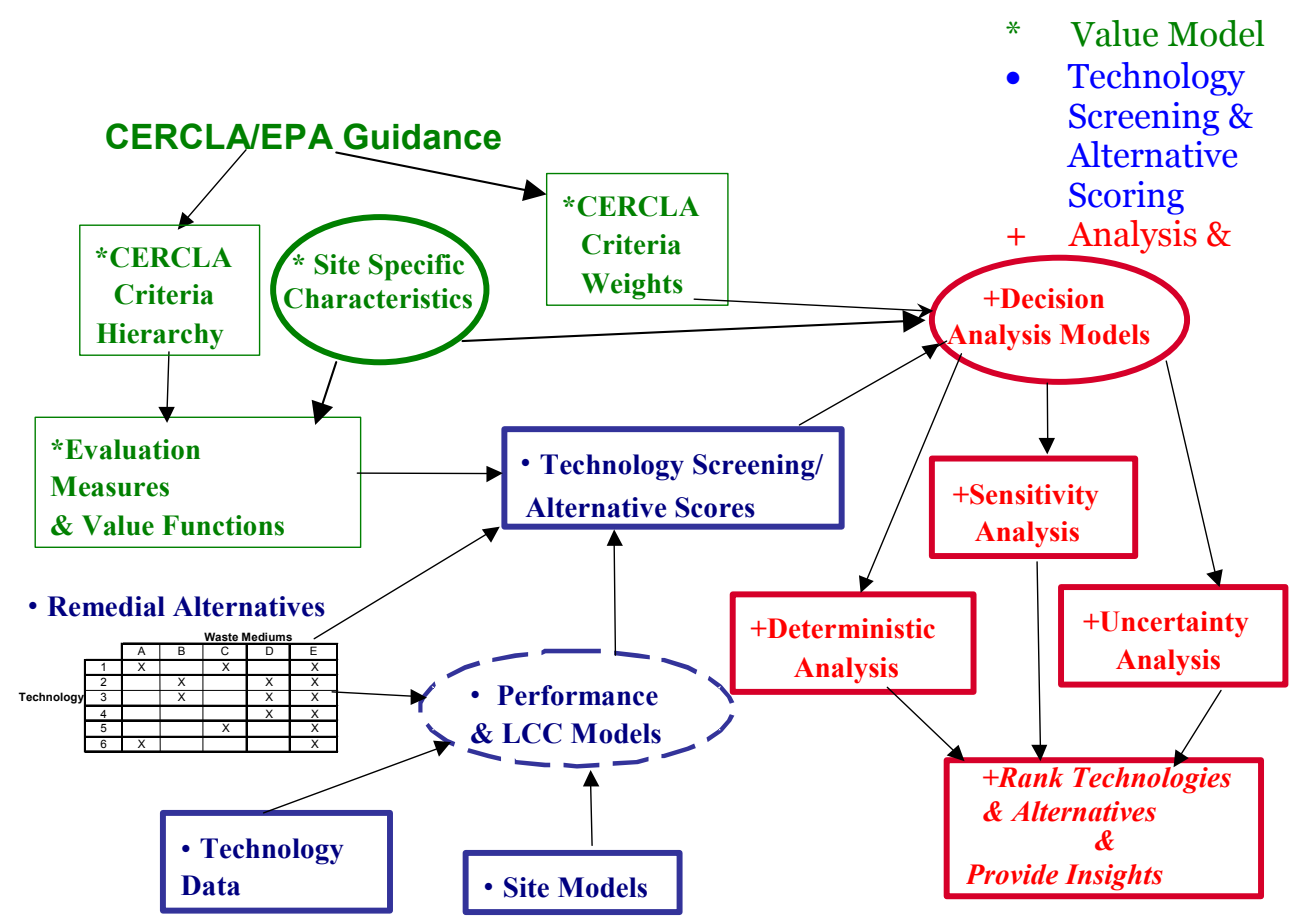

Figure 1. CERCLA-Based Decision Analysis Methodology

Working with INEEL/LMITCO, DOE-ID, State of Idaho, and EPA Region 10 decision-makers, we had previously developed an SDA-specific, CERCLA-based multiobjective decision analysis model based on the CERCLA criteria (Grelk et al., 1998). Beginning at a meeting of key decision-makers in May 1999, we reviewed and refined this decision analysis model. For each criterion, we developed evaluation measures and value functions to capture how well a technology or a remedial alternative meets each of the CERCLA criteria. Next, we reviewed each evaluation measure and value function with the Feasibility Study team to ensure that data could be cost-effectively obtained. We refined the evaluation measures and value functions based on team feedback. Next, we reviewed the changes with the key decision-makers. This value model will be the decision analysis algorithm for the SDA Site Analysis Model being developed by INEEL. This document describes the CERCLAbased decision analysis model developed for the SDA technology screening and remedial alternative evaluation. Each CERCLA criterion, sub criterion, evaluation measure, and value function is described. The rationale for each measure is also included. The team also used CERCLA and SDA site specific characteristics to adjust the weights throughout the model reflecting the appropriate relative importance of the criteria, the subcriteria, and the various contaminants. 


\section{Goals}

The overall goal of the Toffler Associates effort is to support the WAG 7-13/14 FS Team with an objective and transparent decision support tool (see Figure 1). The first goal of this study is to support CERCLA decisionmakers (INEEL/LMITCO, DOE/ Idaho Operations Office, State of Idaho, and EPA Region 10) by developing a CERCLA-based decision analysis methodology for technology screening for the INEEL Waste Area Group (WAG) -7, Operable Unit (OU) 13/14 Subsurface Disposal Area (SDA) Feasibility Study. The second goal is to support the decision-makers by modifying the CERCLA-based methodology for remedial alternative evaluation.

\section{Waste Assumptions}

To make the model operational, we have made several assumptions about the SDA waste forms.

1) The value model should address Contaminants of Principal Concern (COPC) and other contaminants as specified below and summarized in Table 1:

a) Principal threats are identified as Carbon Tetrachloride and Actinides

b) COPCs are principal threats as well as non-principal but risk driving threats (with risk $\geq 10^{-5}$ ) which include non-principal but risk-driving threats radionuclides as well as nitrates and methylene chloride

c) Other contaminants $\left(10^{-5} \geq\right.$ risk $\geq 10^{-7}$ or hazard index $\left.>0.1\right)$

Table 1. Contaminant Categories

\begin{tabular}{|l|l|l|}
\hline Principal Threats & $\begin{array}{l}\text { Risk Driving } \\
\text { Non-Principal Threats }\end{array}$ & Non-risk Drivers \\
\hline $\mathrm{CCl}_{4}(6 . \mathrm{E}-04 / \mathrm{HI} 10)$ & $\mathrm{C}-14(6 . \mathrm{E}-04)$ & Ac-227 (5.E-07) \\
\hline $\begin{array}{l}\mathrm{Np}-237 /(\mathrm{Pu} 240) \\
(2 . \mathrm{E}-04)\end{array}$ & $\mathrm{I}-129(2 . \mathrm{C}-04)$ & $\mathrm{Cl}-36$ (7.E-06) \\
\hline $\mathrm{U}-234(2 . \mathrm{E}-04)$ & Tc-99 (2.E-04) & H-3 (7.E-07) \\
\hline $\begin{array}{l}\text { U-238 (6.E-04)/ } \\
\text { Total U (HI 10) }\end{array}$ & U-235 (1.E-05) & Pa-231 (5.E-07) \\
\hline & Nitrates (HI 4) & U-232 (1.E-07) \\
\hline & $\begin{array}{l}\text { Methylene chloride } \\
(4 . E-05 / H I ~ 0.2)\end{array}$ & U-233 (1.E-06) \\
\hline & & U-236 (8.E-06) \\
\hline
\end{tabular}

2) The relative importance of remediating the contaminants listed in Table 1 varies according to the contaminant's category. The Feasibility Study Team developed the following relative importance weights to 
communicate the contaminants' relative importance. These weights will be used within the quantitative decision model.

Table 2. Weights for contaminant categories

\begin{tabular}{|c|c|c|}
\hline $\begin{array}{l}\text { Contaminant Category } \\
\text { Specific Contaminants }\end{array}$ & $\begin{array}{l}\text { Category } \\
\text { Weight }\end{array}$ & $\begin{array}{c}\text { Specific } \\
\text { Contaminant } \\
\text { Weight }\end{array}$ \\
\hline Principal threats & $70 \%$ & \\
\hline $\mathrm{CCL}_{4}$ & & $2 / 3$ \\
\hline $\begin{array}{l}\text { Actinides } \\
(\mathrm{U}-234, \mathrm{U} 238, \mathrm{~Np}-237, \text { Tot } \mathrm{U})\end{array}$ & & $1 / 3$ \\
\hline Other COPCs & $25 \%$ & \\
\hline $\begin{array}{l}\text { Nitrates \& } \\
\text { Methylene Chloride }\end{array}$ & & $2 / 3$ \\
\hline $\begin{array}{l}\text { Other Rads } \\
\text { (C-14,I-129,Tc-99,U-235) }\end{array}$ & & $1 / 3$ \\
\hline Other Contaminants & $5 \%$ & \\
\hline $\begin{array}{c}\text { Rads (Ac-227,H-3, Cl-36, } \\
\text { Pa-231, U-232,U-233,U-236) }\end{array}$ & & 1.0 \\
\hline & $100 \%$ & \\
\hline
\end{tabular}

\section{INEEL SDA Terminology}

The SDA Feasibility Study Team has organized the CERCLA tasks into three phases.

- Phase 1: Planning phase. This report is prepared under Phase 1.

- Phase 2: Technology screening phase. Approximately 100 technologies will be screened and evaluated in this phase.

- Phase 3: Evaluation of remedial alternatives. The best technologies from Phase 2 will be used to develop about five remedial alternatives. The collection of specified TPOs needed at one site to accomplish the remedial objectives is referred to as a technology train. The collection of specified trains, one for every site within the SDA, is a remedial alternative. The remedial alternatives will be evaluated in this phase.

In the description of the value model and measures, we specify which measures are appropriate for technology evaluation and which are appropriate for remedial alternative evaluation. In evaluating single technologies, often a typical site is modeled containing waste forms and contaminants that are appropriate for the technology being evaluated. When evaluating remedial alternatives, the performance of the remedial alternatives must be determined across all sites. 


\section{CERCLA CRITERIA}

The purpose of this document is to provide an objective and transparent rationale for the technology screening and remedial alternative evaluation in the Feasibility Study for the INEEL Subsurface Disposal Area. The document contains a value model hierarchy, tailored for the SDA, based upon the criteria identified in the National Contingency Plan (NCP) and the EPA Guidance which, together are the primary guidance documents for the Comprehensive Environmental Response and Compensation Liability Act (CERCLA). For each criterion, we define an evaluation measure that we will use for technology screening - in Phase 2 - and remedial alternative evaluation - in Phase 3. According to CERCLA and the NCP, there are nine specified criteria, as depicted below in Figure 2 (40 CFR S300.430.(e)(9)(iii)):

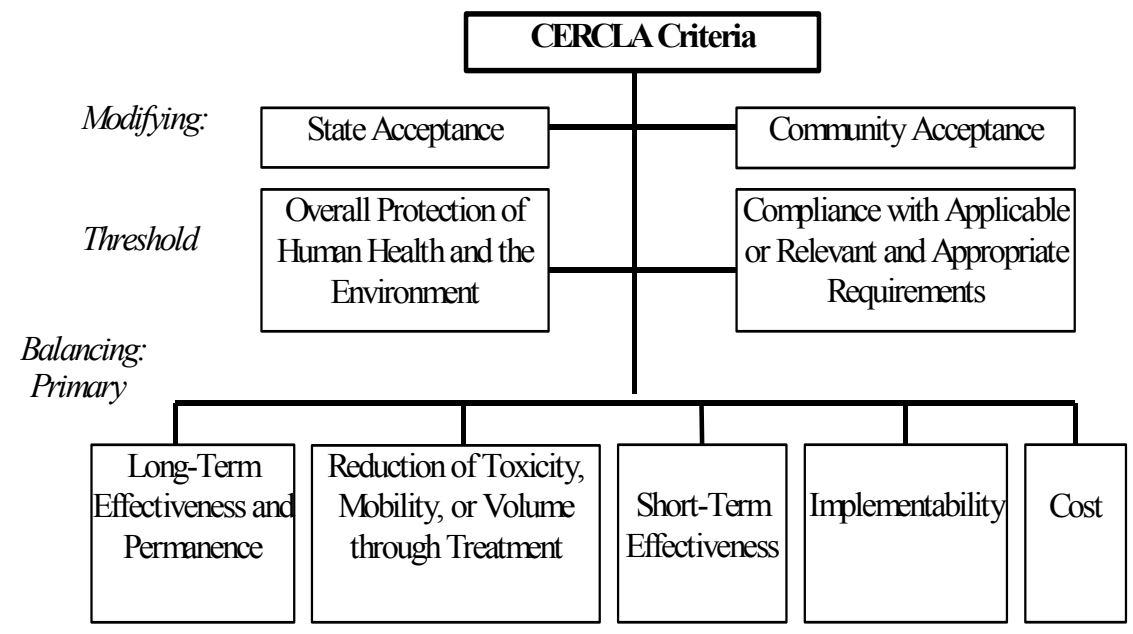

Figure 2. CERCLA Criteria

Using the NCP and EPA guidance, we have identified subcriteria and evaluation measures that allow us to quantitatively evaluate how a technology or a remedial alternative performs for each of the five balancing criteria. By applying weights to these evaluation measures, we emphasize the relative importance of each measure, thus achieving the best balance of the five Primary Balancing Criteria. The details of the value model are described in the remainder of this document. Scoring of the technologies and remedial alternatives will provide a ranking based on the criteria, subcriteria, weights, evaluation measures, and value functions. The model also allows a full sensitivity analysis that can be used to evaluate the effects of evaluation measure scores and changes to weights on the ranking of the technologies and remedial alternatives.

\section{Modifying and Threshold Criteria:}

The CERCLA criteria are divided into the following three distinct groups: Modifying Criteria, Threshold Criteria, and Primary Balancing Criteria (40 CFR S300.430 (f)(1)). The Modifying Criteria, State and Community Acceptance, are not explicitly included in the multiobjective decision analysis. The Modifying Criteria should be considered after the Record of Decision (ROD) has been released to the public for review. The Threshold Criteria, consisting of the Overall Protection of Human Health and the Environment, and Compliance with Applicable or Relevant and Appropriate Requirements (ARARs), are threshold objectives that all remedial alternatives must 
meet in order to be eligible for selection. Therefore, in order for a remedial alternative to be considered in this analysis, it must have met the Threshold Criteria.

\section{CERCLA Value Model Using Balancing Criteria}

After we introduce some key multiobjective decision analysis terminology, we describe the SDA CERCLA Balancing Criteria and subcriteria with associated evaluation measures, value functions, and weights. For each evaluation measure, a value of ten indicates the best possible outcome for that measure, while a value of zero indicates the worst possible outcome. This value model will be used to quantitatively compare each technology and remedial alternative to determine which provides the greatest value for the CERCLA-based measures. 


\section{MULTIOBJECTIVE DECISION ANALYSIS}

The CERCLA-based decision analysis method uses the technique of multiobjective decision analysis (Kirkwood, 1997). The details of the application of this methodology to CERCLA environmental remediation applications are described in Parnell, et. al., 1999. The next two sections describe the benefits of this approach and introduce the evaluation measure and value function terminology used in this report.

\section{CERCLA-Based Decision Analysis Benefits}

Our decision analysis approach has several major benefits to CERCLA decision-makers (Parnell et al., 1999). Benefits are as follows:

Objective, Systematic Process. Our process is an objective, systematic analysis process that directly uses the CERCLA criteria and EPA guidance to develop a quantitative model to evaluate the technologies and the remedial alternatives. Since all information is available to all participants, no individual can bias the results. As new information becomes available from the remedial investigation (RI), the analysis results can be systematically updated.

Robust Analysis Technique. Many analysis methodologies focus on unique technology characteristics. Since our decision analysis methodology evaluates the performance of remedial alternatives against the CERCLA criteria, the methodology is robust enough to credibly evaluate existing and innovative technologies.

Traceable Analysis Results. The decision analysis results are traceable - we can "peel back" the results and identify the modeling and scoring assumptions that drive the results. Traceability increases the understanding of the remedial alternative's evaluation and, therefore, the credibility of the analysis results.

Better Alternatives. Decision analysis provides quantitative feedback to the technologists on the effectiveness of their remedial alternatives. Using this feedback, we can design new remedial alternatives (better combinations of technologies) that have higher performance scores on the CERCLA criteria.

Sensitivity Analysis. Sensitivity analysis can be performed to any modeling assumption or remedial alternative score. The excellent sensitivity analysis capabilities can provide important insights to site decision-makers, regulators, and community stakeholders.

Uncertainty Analysis. Significant uncertainties may exist about the site characterization and the effectiveness of innovative technologies. Our decision analysis methodology can analyze uncertainties about site characterization and remedial alternative effectiveness.

Framework for Regulator and Public Comment. The above benefits should give the regulators and the public more confidence in the selected remedy. In addition, the sensitivity analysis capabilities can be directly used to show how sensitive the selection of the remedial alternative is to any modeling assumption or score advocated by any stakeholder

\section{Evaluation Measure Terminology}

Evaluation measures are categorized in two dimensions. 
- Natural or Constructed. A natural measure is in common use. For example, the amount of dollars is a natural measure for cost. Grades (A, B, C, etc.) are an example of a constructed scale. Specific performance levels must be described to map a student's performance to the letter grades used in most academic programs.

- Direct or Proxy: A direct measure focuses on the criterion. For example, the amount of dollars is a direct measure of cost. If a direct measure is not available, a proxy measure is used. A proxy measure focuses on an important related measure. For example, for technology screening, the number of subsystems of a technology may be used as a proxy for reliability. It might not be cost-effective to perform reliability calculations for a large number of technologies considered in the screening process. However, for remedial alternative evaluation, the direct measure of reliability would probably be used.

In this work we tried to identify measures in the following order:

1. Natural, direct measures,

2. Constructed, direct measures,

3. Natural, proxy measures, and

4. Constructed, proxy measures.

For each evaluation measure, we identify the type of evaluation measure using one of the above four types.

\section{Value Function Terminology}

Value functions measure returns-to-scale on the evaluation measure. The worst possible level of the evaluation measure is given a value of 0 and the best possible evaluation measure level is given a value of 10 . The decisionmakers identified the shapes of the value functions. Four general shapes were used:

- Linear: Constant returns to scale,

- Concave: Diminishing returns to scale,

- Convex: Increasing returns to scale, and

- S-curve: Slowly increasing returns up to a critical value, rapid returns-to-scale near the critical value, then diminishing returns after the critical value.

Once the decision-makers specified the shape of the curve, the values for key levels of the evaluation measures were assessed.

\section{Example Format}

\section{I Evaluation Measure with Explanation - This heading will contain the specific Criterion or Sub criterion from the CERCLA documents}

(40 CFR S300.430 (e)(9)(iii)(D)(3)) and (EPA/540/G-89/004, 6.2.3.4) These are the specific reference sections and paragraphs from the congressional Federal Register or EPA Guidance, respectively, that explain the criterion 
or sub criterion in CERCLA being discussed. We include a quick explanation of what CERCLA is aiming at with this criterion. We also add notes or key assumptions about the criterion.

\section{I.A. This is the name of one of the subcriteria under the above criterion}

2.I.A.1 This Is The Name Of The Evaluation Measure

Type of Measure - Natural, Proxy (This describes the type of measure developed. See evaluation measure terminology in the introduction section).

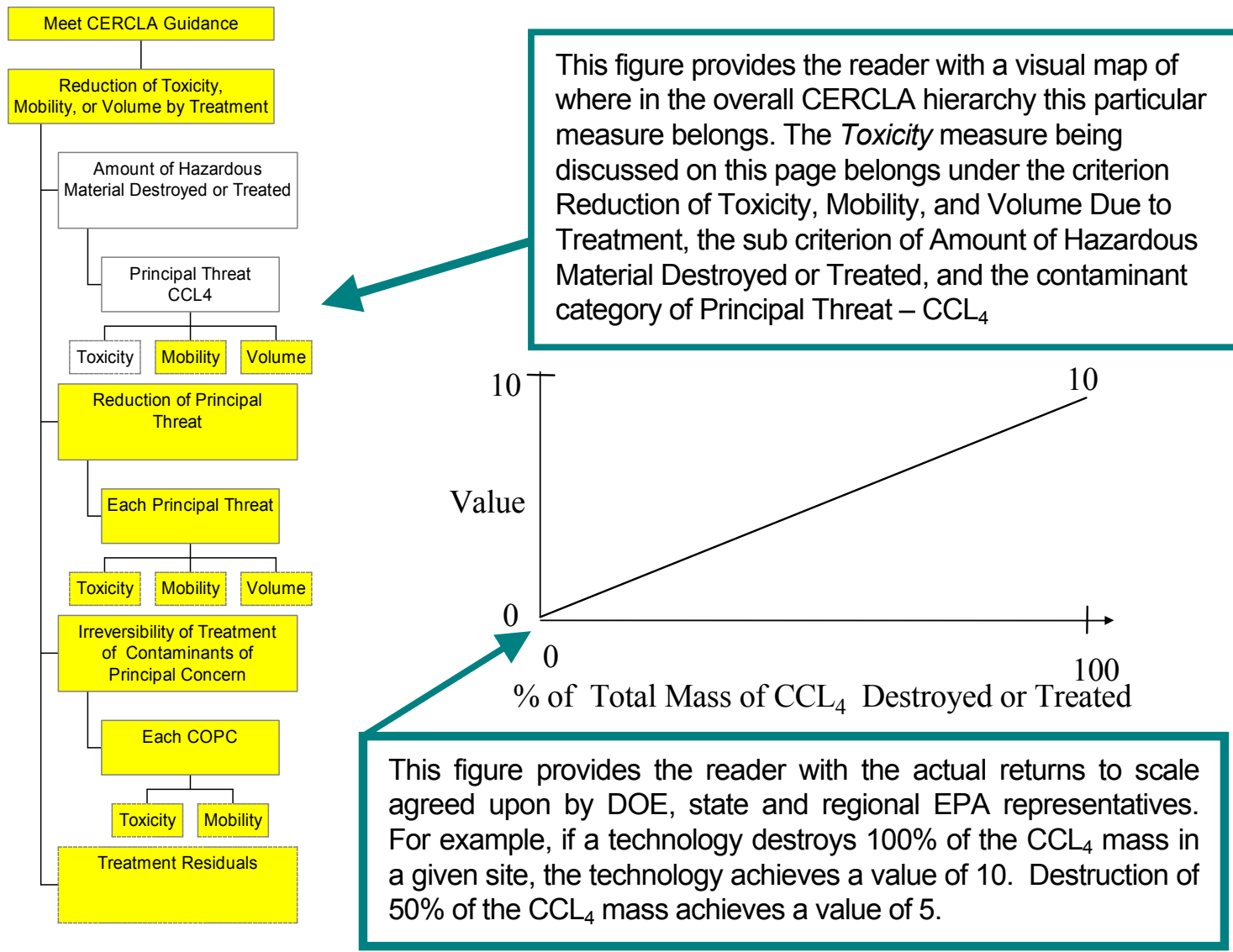

This paragraph explains the value function shown above. The curve shown above is linear with no internal objectives where the value may jump with a small increase in \% destroyed. Phase 2 Here we describe what differences, if any, there are in measuring a technology process option, in Phase 2 vs. a site technology train or complete remedial alternative in Phase 3. 


\section{CERCLA HIERARCHY AND EVALUATION MEASURES FOR INEEL SDA}

\section{Balancing Criteria 1: Long Term Effectiveness and Permanence}

(40 CFR S300.430 (e)(9)(iii)(F)) and (EPA/540/G-89/004, 6.2.3.3): “The evaluation of alternatives under this criterion addresses the results of a remedial action in terms of the risk remaining at the site after response objectives have been met. The primary focus of the evaluation is the extent and effectiveness of the controls that may be required to manage the risk posed by treatment residuals and/or untreated wastes. The following components of the criterion should be addressed in the evaluation for each alternative: magnitude of residual risk and adequacy and reliability of controls. The following section will discuss the quantification of these subcriteria.

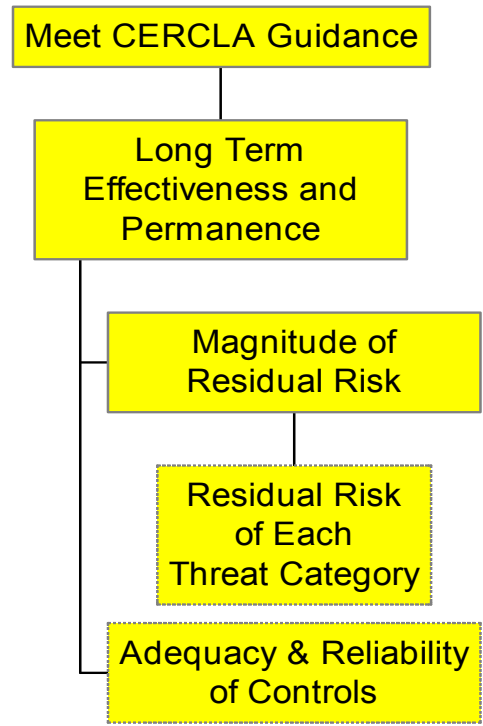

Figure 1.1 Long Term Effectiveness and Permanence Hierarchy

The criteria were equally weighted since CERCLA does not specifically differentiate between the importance of the two criteria.

\subsection{Magnitude of Residual Risk}

(40 CFR S300.430 (e)(9)(iii)(F)(1)) and (EPA/540/G-89/004, 6-8): "This factor assesses the residual risk remaining from untreated waste or treatment residual at the conclusion of remedial activities. The potential for this risk may be measured by numerical standards such as cancer risk levels or the volume or concentration of contaminants in waste, media, or treatment residuals remaining on the site. The characteristics of the residuals should be considered to the degree that they remain hazardous, taking into account their volume, toxicity, mobility, and propensity to bioaccumulate."

The evaluation measures within the Magnitude of Residual Risk criterion are weighted as a function of risk level. The Risk-driving principal threats receive a weight of .70, the Risk-driving non- 
principal threats receive a weight of .25 and, finally, the non-risk driving, non-principal threats receive a weight of .05 . Within Phase 2, principal threats, the measures associated with carbon tetrachloride $\left(\mathrm{CCL}_{4}\right)$ will be assigned a weight of $2 / 3$ and the actinides a weight of $1 / 3$. Within Phase 2 Risk-driving Non-principal threats, the measures associated with nitrates will be assigned a weight of $2 / 3$ and the other carcinogens will be assigned a weight of $1 / 3$. Phase 2 NonRisk driving, Non-principal threats, there exists only one category so each evaluation measure will receive all of the weight.

\section{I.A Residual Risk (Phase 2 model)}

This measure addresses the estimated resultant residual risk for each different category of contaminants.

\section{Type of Measure - Natural, Direct}

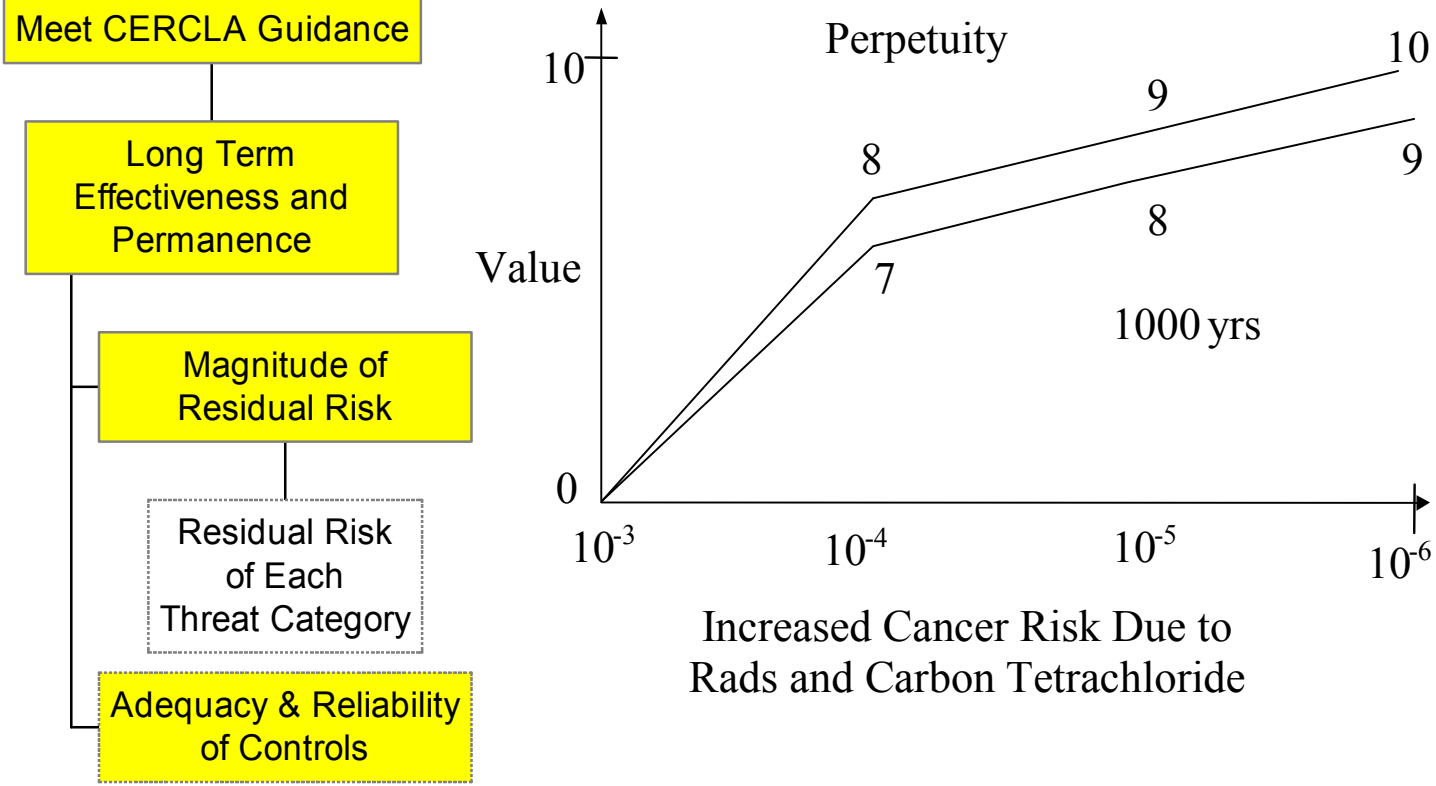

Phase 2: In phase two, since TPOs are being evaluated, individual measures of residual risk for each category of contaminant are used.

$\equiv$ principal threats: Two curves are shown which indicate a penalty of one value point for not - eving the stated level of risk for perpetuity (greater than 1,000 years). For both curves, a large part of value is gained by reaching $10^{-4}$ from the current $10^{-3}$ risk level.
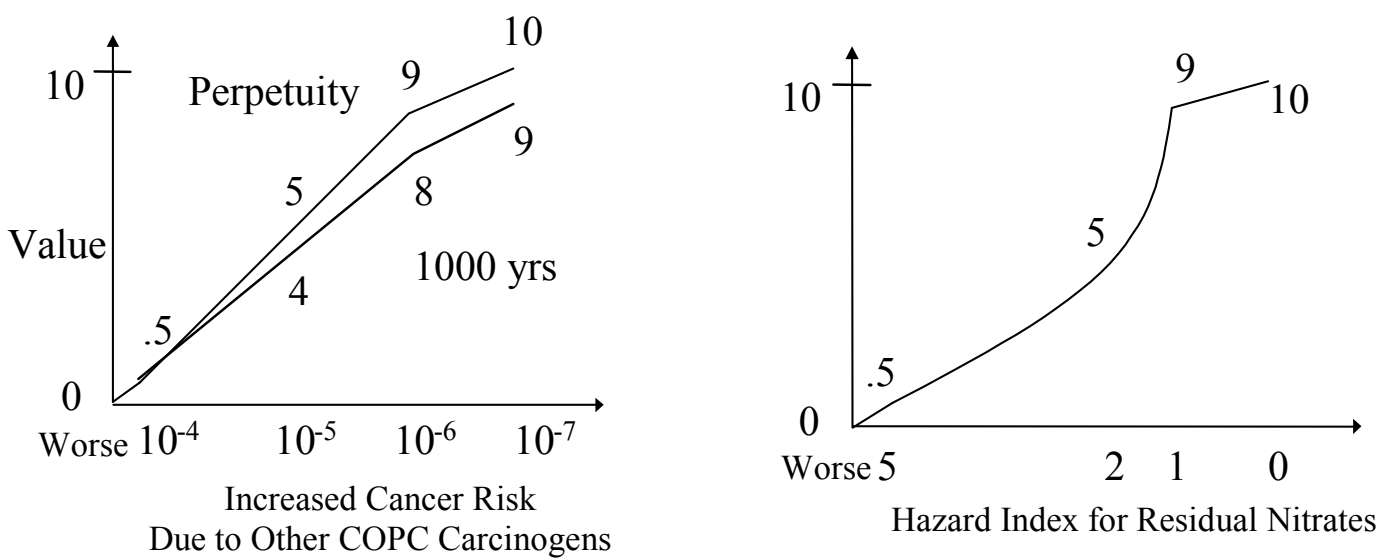
For Risk Driving Non-principal Threats: In the first measure, the level of $10^{-6}$ additional cancer risk is a point of departure for other carcinogens and therefore receives almost all the value -9 . The riskdriving, non-principal threats are currently at a lower level of risk than the principal threats. Methylene chloride is included only in the other carcinogen measure since its current hazard risk number is already below 1.0 and its risk level is estimated at $10^{-4}$.

The second measure is only for Nitrates. The current hazard index for Nitrates is 4.0 and the point of departure for the hazard index is 1.0. Little value is gained until the achieved level approaches 1.0.

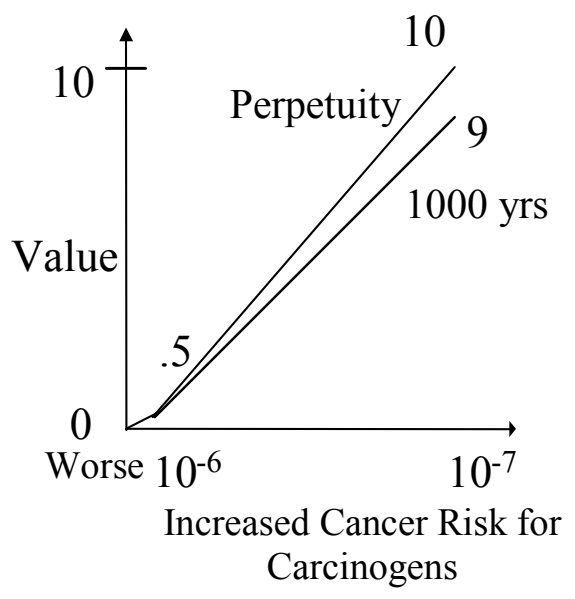

For Non-Risk Driving, Non-principal Threats: The final measure for Phase 2, Residual Risk, is for non-risk driving, non-principal threat carcinogens. These contaminants are already at $10^{-6}$ or lower and may be reduced to as low as $10^{-7}$.

1.I.A Residual Risk (Phase 3 model)

Phase 3: In this phase, the additional cancer deaths due to residual radioactive contaminants and carbon tetrachloride are evaluated in the first measure. Two curves are shown which illustrate a penalty of one value point for not achieving the stated level of risk for perpetuity (greater than 1,000 years). The actual penalty will vary linearly between one point (zero years) to zero points ( $>1,000$ years). For both curves, the greatest amount of value is gained by reaching $10^{-4}$ from the current $10^{-3}$ risk level.

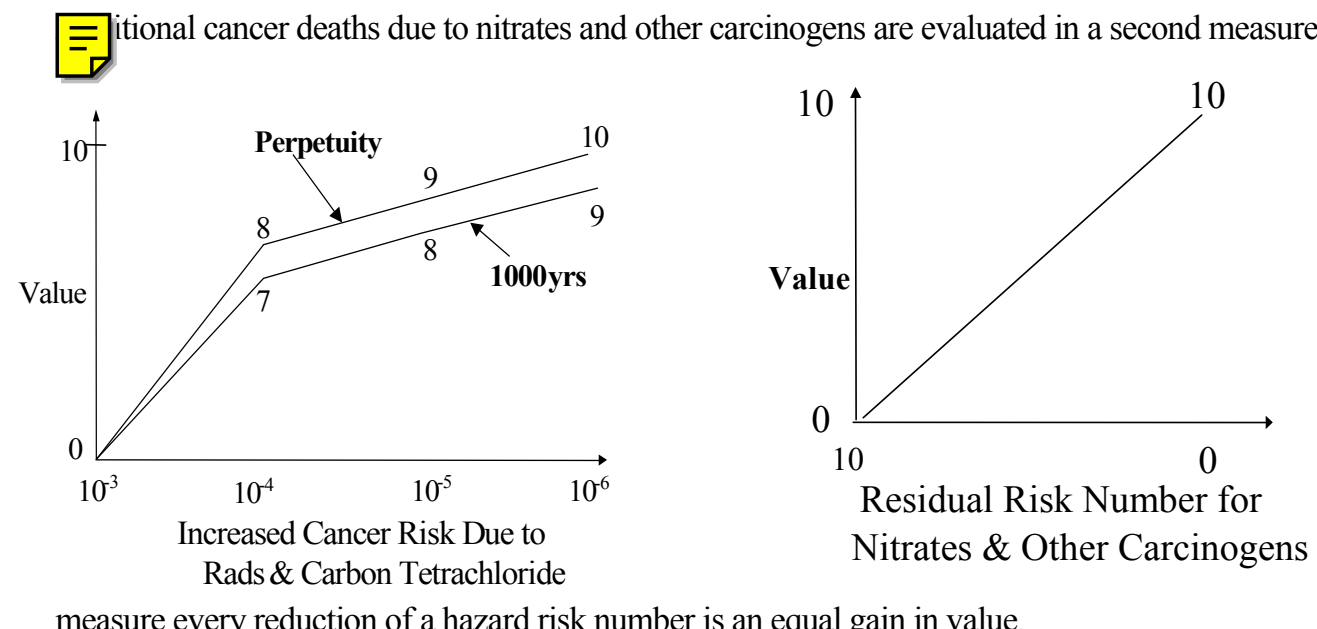


Notes: The addendum to the Work Plan assumes a cap is installed over the entire SDA. The cap assumption affects the identification of which contaminants are COPCs. The contaminants that are identified solely with surface pathways are not included in the COPCs. Only groundwater pathway specific contaminants are included. The team has organized the contaminants into three categories based upon the their associated levels of risk (Table 1.). 


\section{II. Adequacy \& Reliability of Controls}

(40 CFR S300.430 (e)(9)(iii)(C)(2)) and (EPA/540/G-89/004, 6-8,9): The guidance addresses the adequacy and suitability of controls used to manage treatment residuals or untreated wastes that remain at the site. It also addresses the potential need for replacement of technical components, magnitude of threats or risks should the remedial action need replacement, and degree of confidence that controls adequately handle potential problems.

Type of Measure - Constructed, Proxy

\section{Meet CERCLA Guidance}

Long Term

Effectiveness and

Permanence

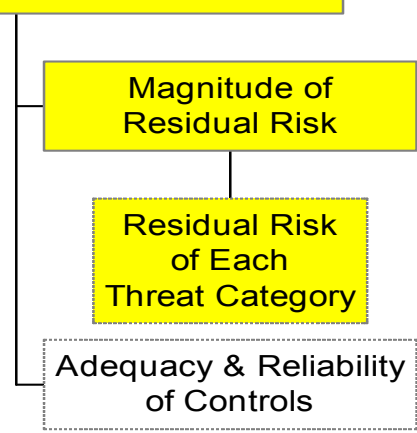

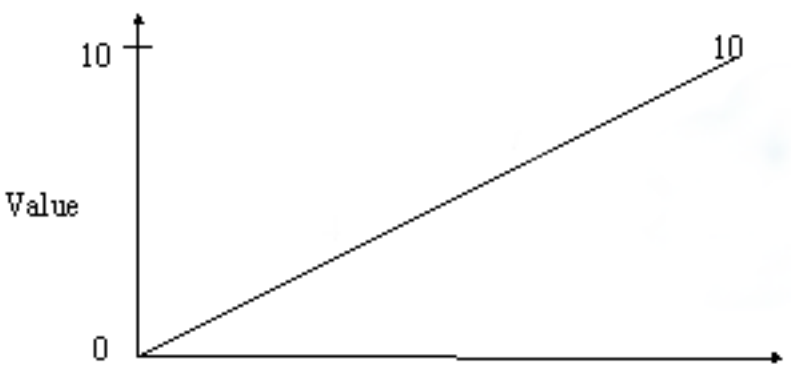

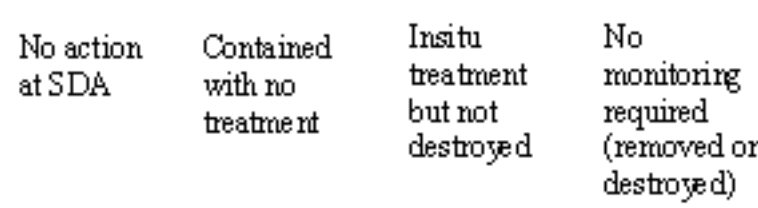

This measure focuses on the condition of the waste after treatment since the status of the waste will determine how suitable the controls are and how reliable the technological solution may be. The FS team constructed increasing value categories since no natural measure was available. Phase 2 values are obtained as shown. In Phase 3, the highest value of the TPOs in a train is the value of the train. There is an implied assumption that there is no effect of the choice of a TPO on the level of the other TPOs. 


\section{Balancing Criteria 2: Reduction of Toxicity, Mobility, Or Volume Through Treatment}

(40 CFR S300.430 (e)(9)(iii)(D)) and (EPA/540/G-89/004, 6.2.3.4) This criterion addresses the statutory preference for selecting remedial actions that employ treatment technologies that permanently and significantly reduce toxicity, mobility, or volume (TMV) of the hazardous substances as their principal element. This preference is satisfied when treatment is used to reduce the principal threats at a site through destruction of toxic contaminants, reduction of the total mass of toxic contaminants, irreversible reduction in contaminant mobility, or reduction of total volume of contaminated media. The hierarchy below addresses these concerns by evaluating a technology process option (TPO) or a remedial alternative categorized by the appropriate contaminants. This structure was selected for the hierarchy to:

- Provide visibility on contaminants

- Simplify value functions by singling out preferences with appropriate contaminants

- Allow us to simplify the hierarchy by deleting unnecessary evaluation measures

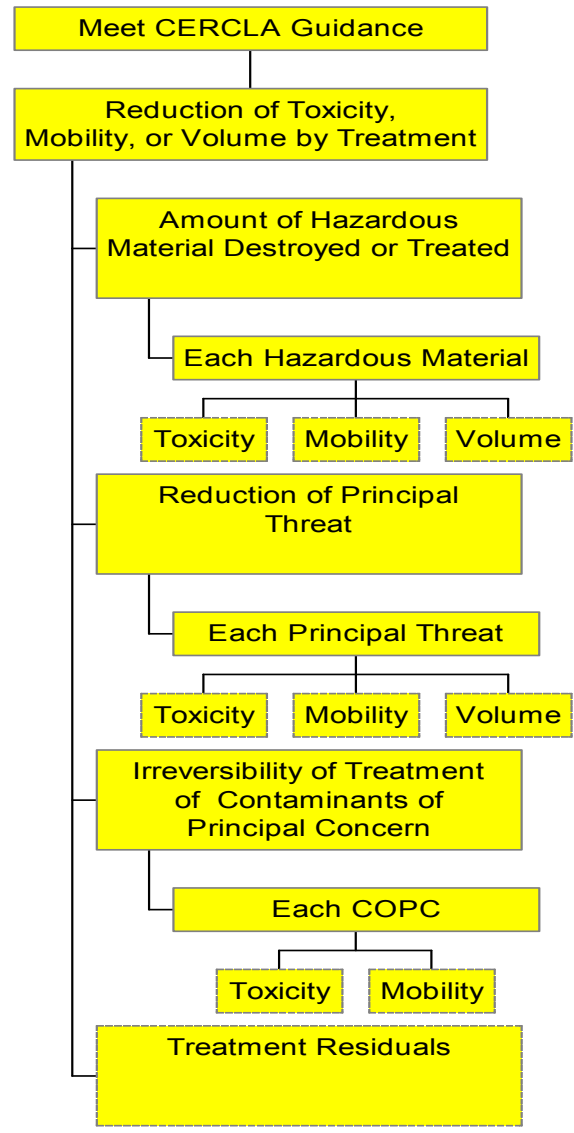

Figure 2.1. Reduction of Toxicity, Mobility, or Volume Through Treatment 
The full hierarchy is shown below in Figure 2.2. This expansion of the Reduction of TMV hierarchy emphasizes some key points:

- Toxicity is not used for radiological contaminants

- Volume is not a required or suitable metric for irreversibility at this site.

- One measure is needed for treatment residuals.

Because the subcriteria will be measured by contaminant category, a weighting system must be used to allow the aggregation under each sub criterion. The table below indicates the tri-agency preferences for each of the categories of contaminants. 


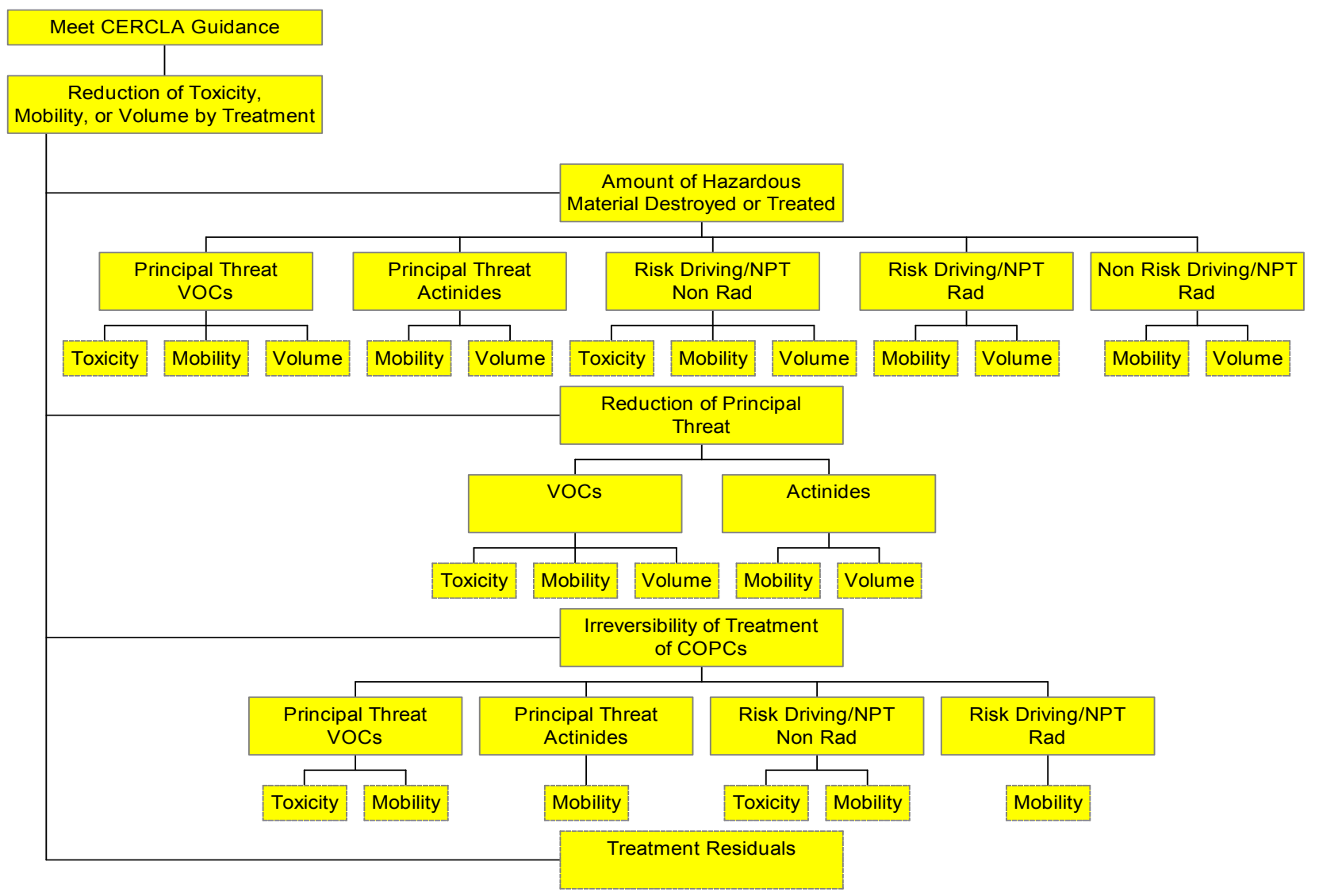

Figure 2.2 Expanded Hierarchy for Reduction of Toxicity, Mobility, or Volume due to Treatment 


\section{DRAFT}

\section{I. The Amount of Hazardous Materials Destroyed or Treated}

(40 CFR S300.430 (e)(9)(iii)(D)(3)) and (EPA/540/G-89/004, 6.2.3.4) This sub criterion satisfies CERCLA's requirement to address the amount of hazardous material destroyed or treated. The three agencies determined this measure is applicable to the contaminants of principal concern and the non risk-driving contaminants listed in Table 1.

The weights for toxicity, mobility, and volume under the criterion are equal. The different Contaminants of Principal Concern (COPCs) as well as the non risk-driving contaminants are weighted according to Table 2.

2.I.A. The Amount of Carbon Tetrachloride with Reduced Toxicity, Mobility, or Volume

\section{I.A.1 Reduced Toxicity of $\mathrm{CCL}_{4}$ \\ Type of Measure - Natural, Proxy}

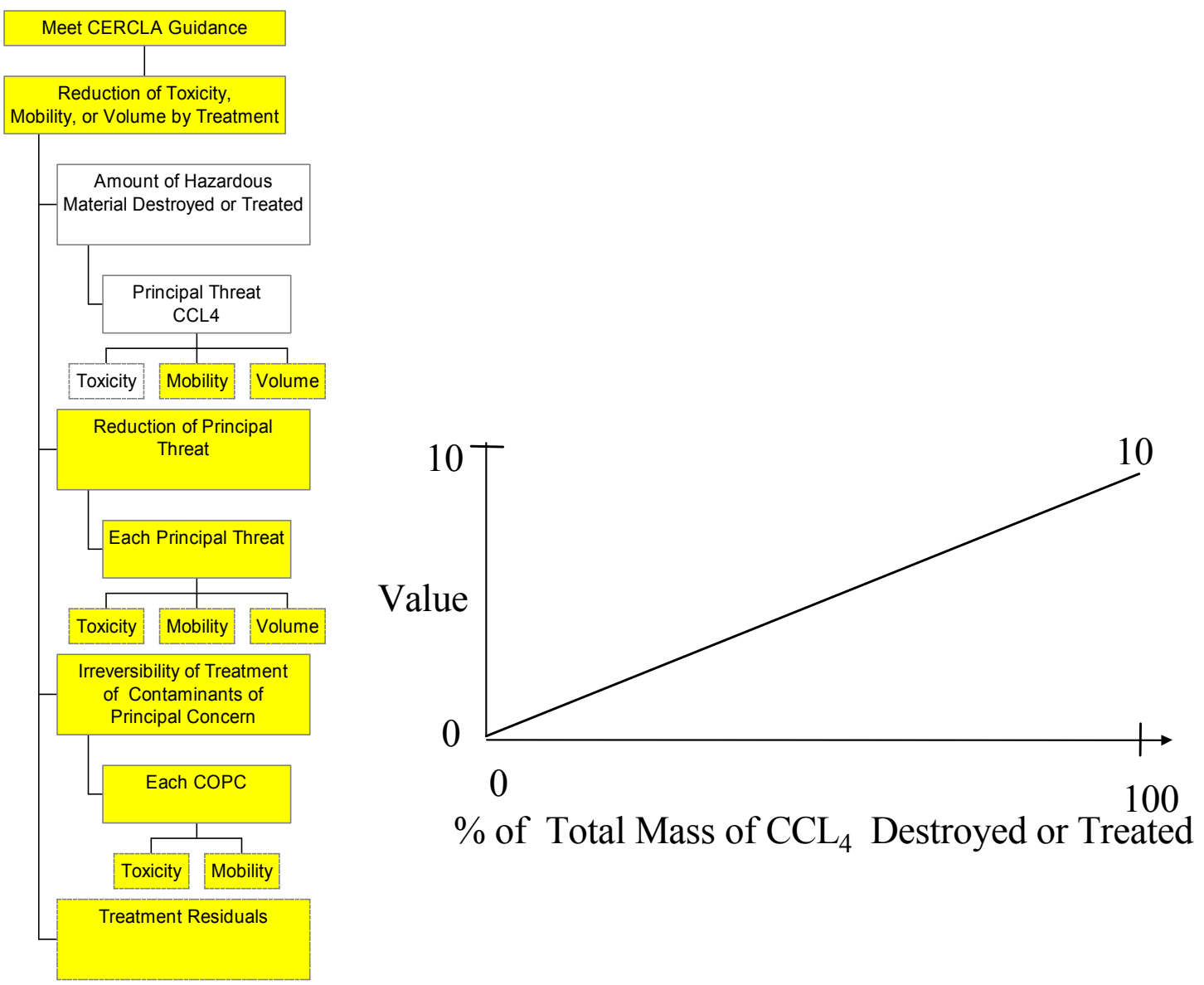

Percent contaminant mass is used as a proxy for toxicity. The measure will be used for each of the non-rad contaminant categories. For Phase 2 this should be a direct estimate of the mass destroyed by a TPO based upon a typical site. For Phase 3, this will be the total calculated $\%$ of $\mathrm{CCL}_{4}$ destroyed or treated over the entire SDA. 


\section{DRAFT}

\section{I.A.2 Reduced Mobility of CCL4}

Type of Measure - Natural, Direct

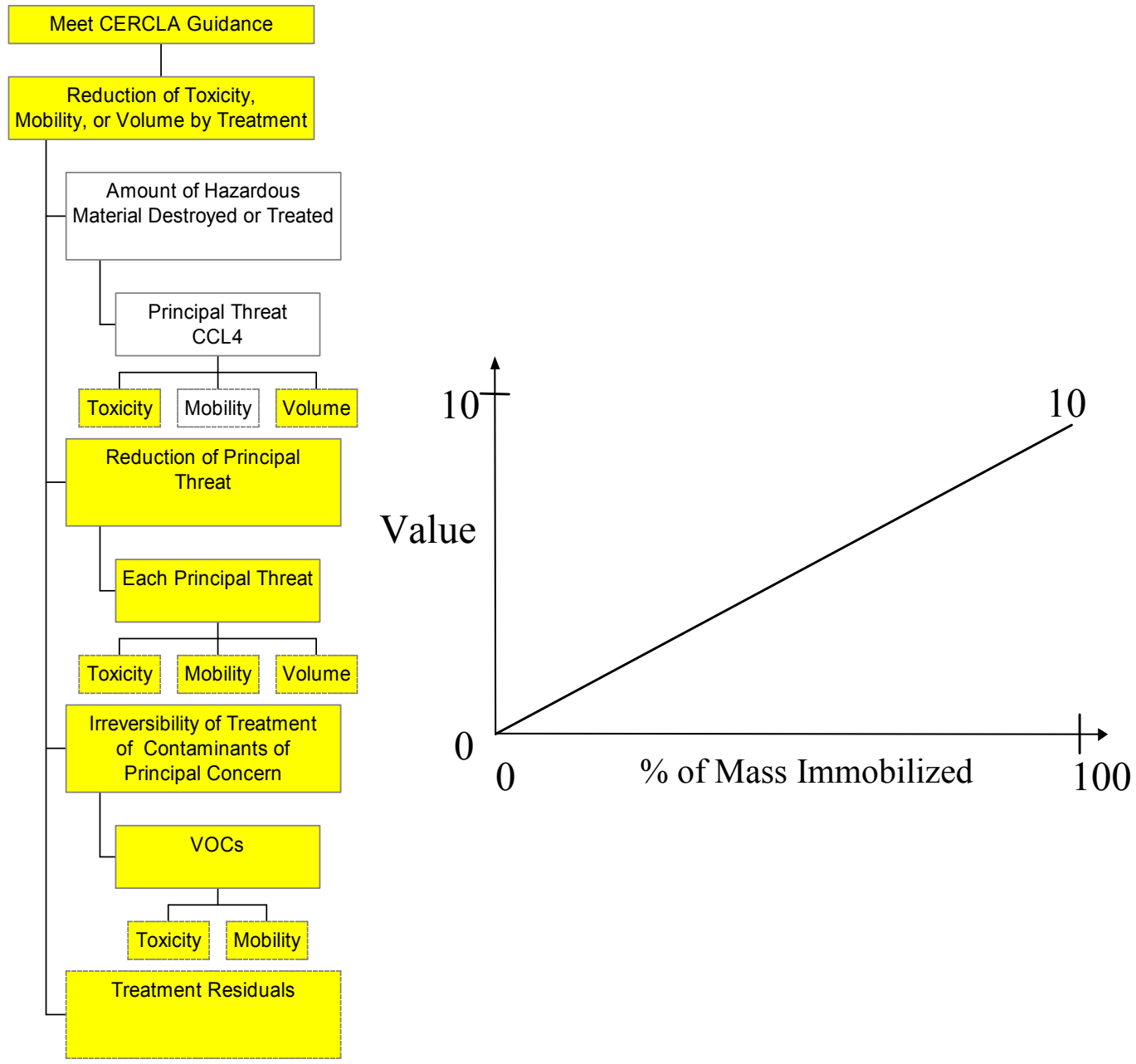

This measure focuses directly on the percent of contaminant mass immobilized. For Phase 2, this measure will be used to score each class of technologies at a typical site which has $\mathrm{CCL}_{4}$ contaminant. For Phase 3, this will be the calculated $\%$ of $\mathrm{CCL}_{4}$ immobilized throughout the SDA. 


\section{DRAFT}

\section{I.A.3 Reduced Volume of $\mathrm{CCL}_{4}$}

Type of Measure - Natural, Direct

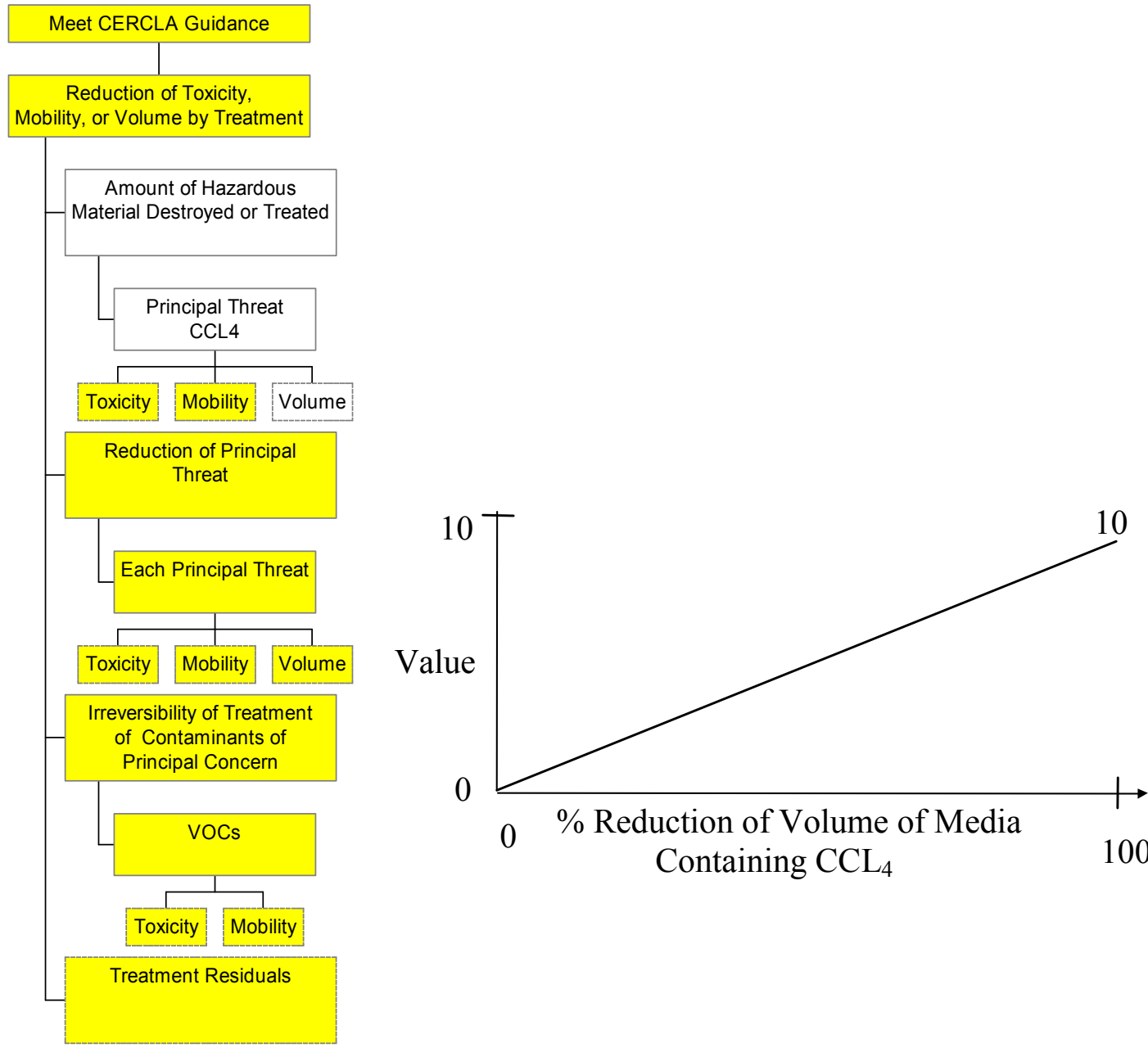

This measure is the \% reduction in the volume of the contaminated media. Reduction in volume may reduce the risk and the amount of final disposal required. For Phase 2, the reduction is easily calculated for a typical site. For Phase 3, this will be \% reduction of the volume of the $\mathrm{CCL}_{4}$ contaminated media throughout the SDA. 


\section{DRAFT}

2.I.B. The Amount of Actinides with Reduced Toxicity, Mobility, or Volume

2.I.B.1 Reduced Mobility of Actinides

Type of Measure - Natural, Direct

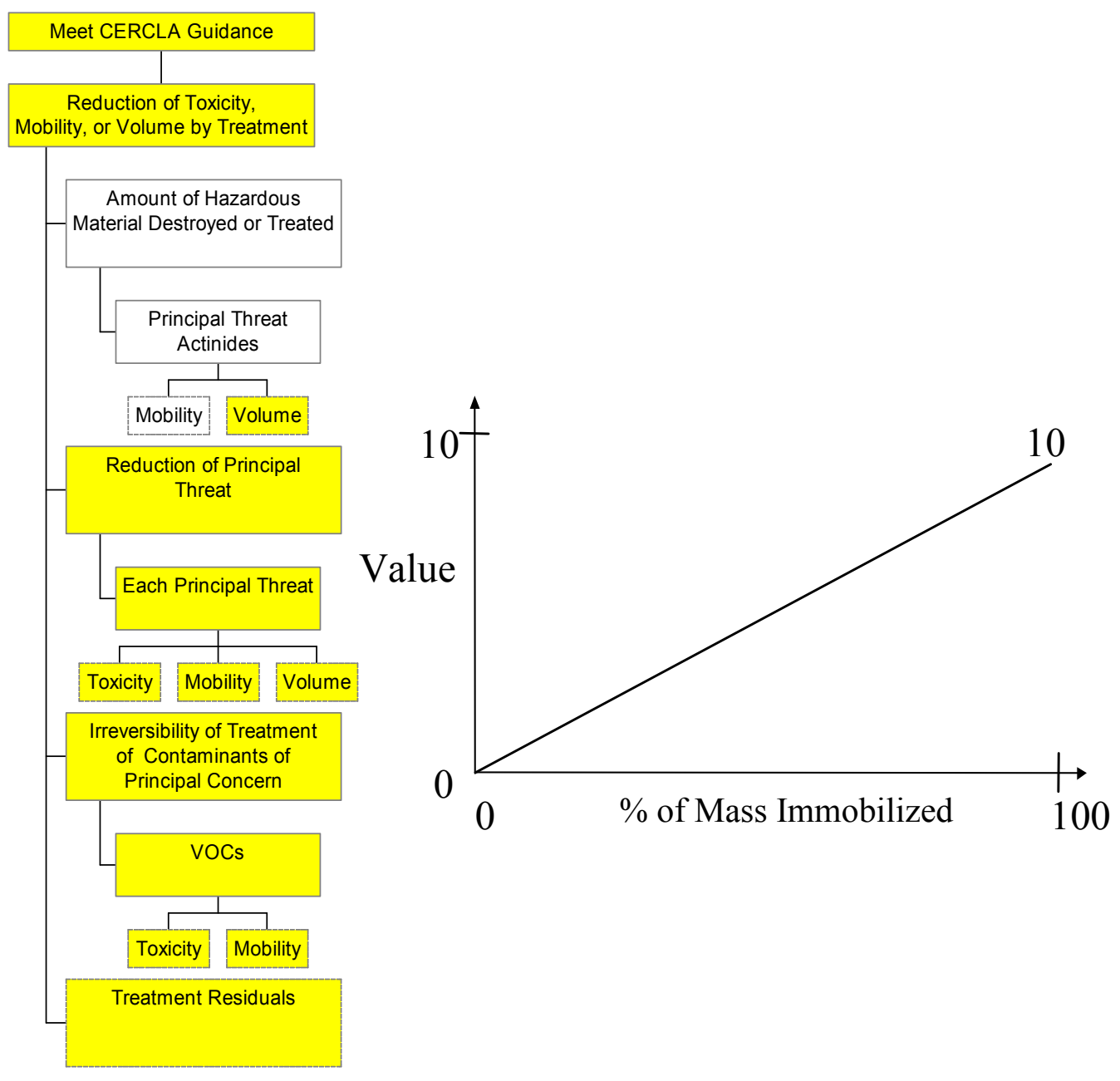

This measure focuses directly on the percent of contaminant mass immobilized. For Phase 2, this measure will be used to score each class of technologies, and the percentages will be averaged. For Phase 3, this will be the total $\%$ of each actinide mass immobilized throughout the SDA. All three actinides are equally weighted to yield an average $\%$ immobilized. 


\section{DRAFT}

\subsection{B.2 Reduced Volume of Actinides}

Type of Measure - Natural, Direct

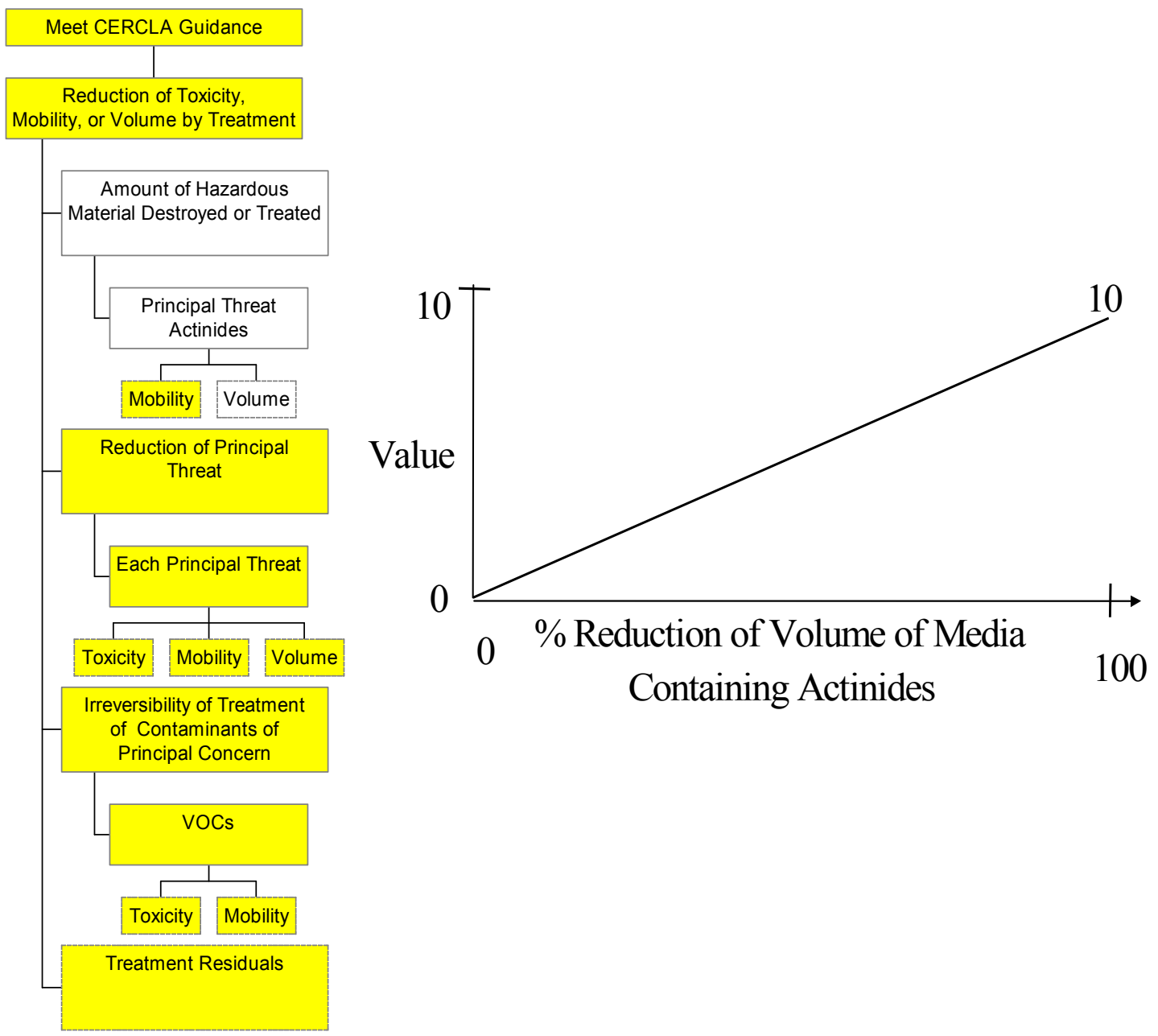

This measure is the \% reduction in the volume of the contaminated media. Reduction in volume may reduce the risk and the amount of final disposal required. For Phase 2, the reduction is easily calculated for a typical actinide contaminated site. For Phase 3, this will be \% reduction of the volume of the Actinides contaminated media throughout the SDA. All three actinides are equally weighted to yield an average $\%$ reduction of volume. 


\section{DRAFT}

2.I.C. The Amount of Risk-Driving/NPT VOCs with Reduced Toxicity, Mobility, or Volume 2.I.C.1 Reduced Toxicity Of Risk-Driving/NPT (Nitrates \& Methylene Chloride) Type of Measure - Natural, Proxy
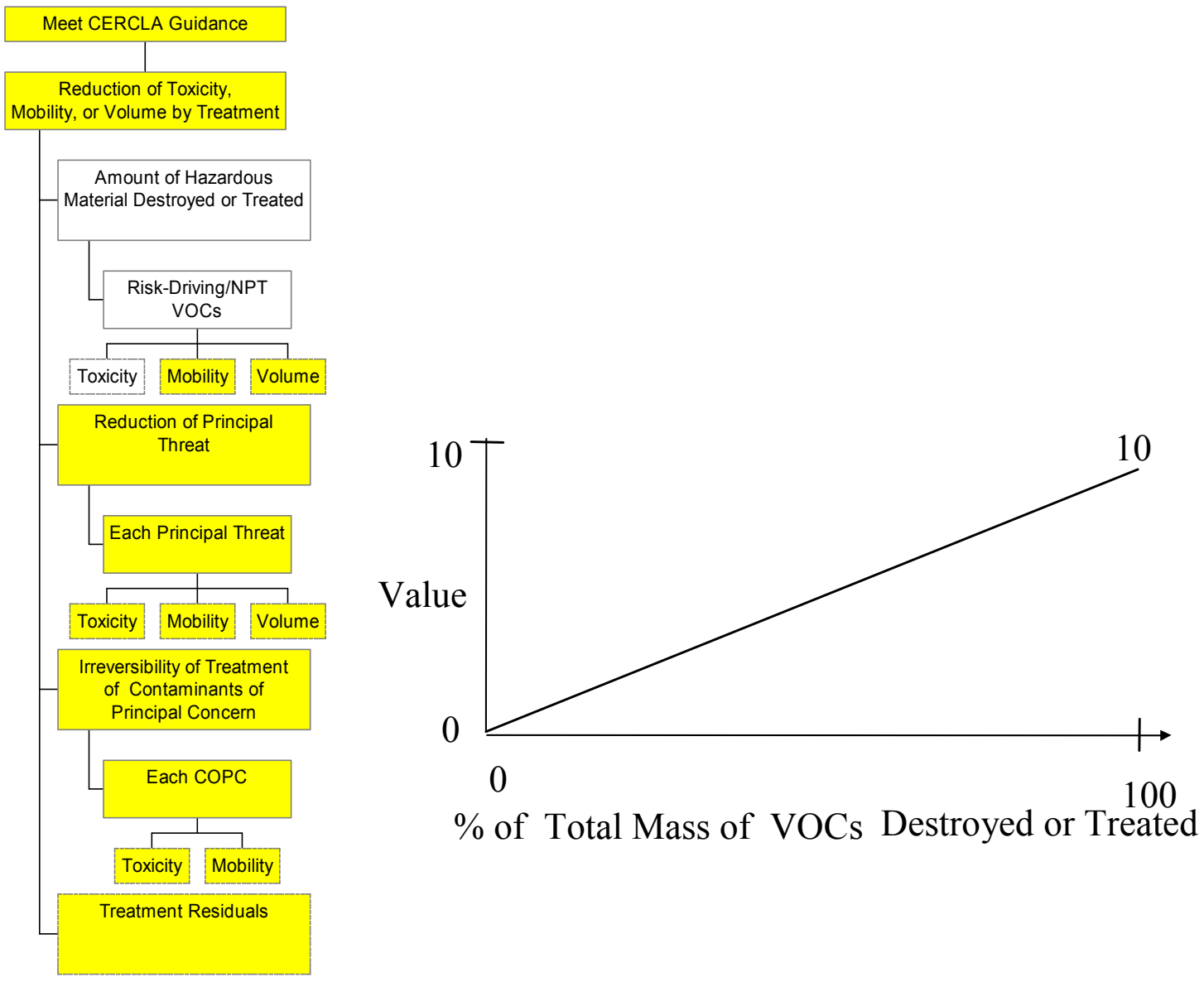

Percent contaminant mass is used as a proxy for toxicity. The measure will be used for each of the non-rad contaminant categories. For Phase 2 this should be a direct estimate based upon a typical site. For Phase 3, this will be the total estimate \% of Risk-Driving/NPT VOCs (nitrates \& methylene chloride) destroyed or treated over the entire SDA. 


\section{DRAFT}

2.I.C.2 Reduced Mobility of Risk-Driving/NPT VOCs (Nitrates \& Methylene Chloride)

Type of Measure - Natural, Direct
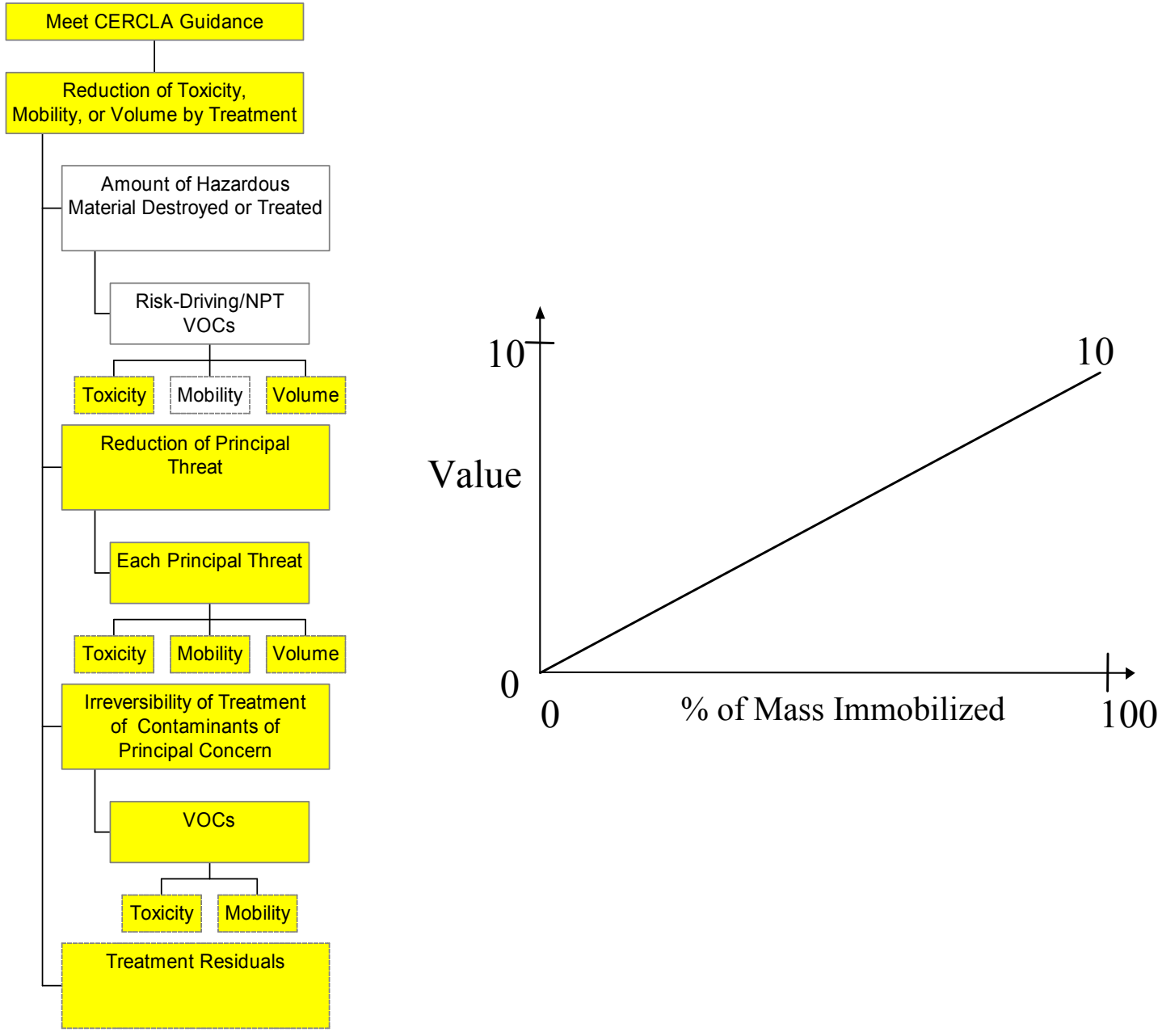

This measure focuses directly on the percent of contaminant mass immobilized. For Phase 2, this measure will be used to score each class of technologies. For Phase 3, this will be the average $\%$ of Risk-Driving/NPT VOCs (nitrates \& Methylene chloride) mass immobilized throughout the SDA. 


\section{DRAFT}

\section{I.C.3 Reduced Volume of Risk-Driving/NPT VOCs (Nitrates \& Methylene Chloride)}

Type of Measure - Natural, Direct

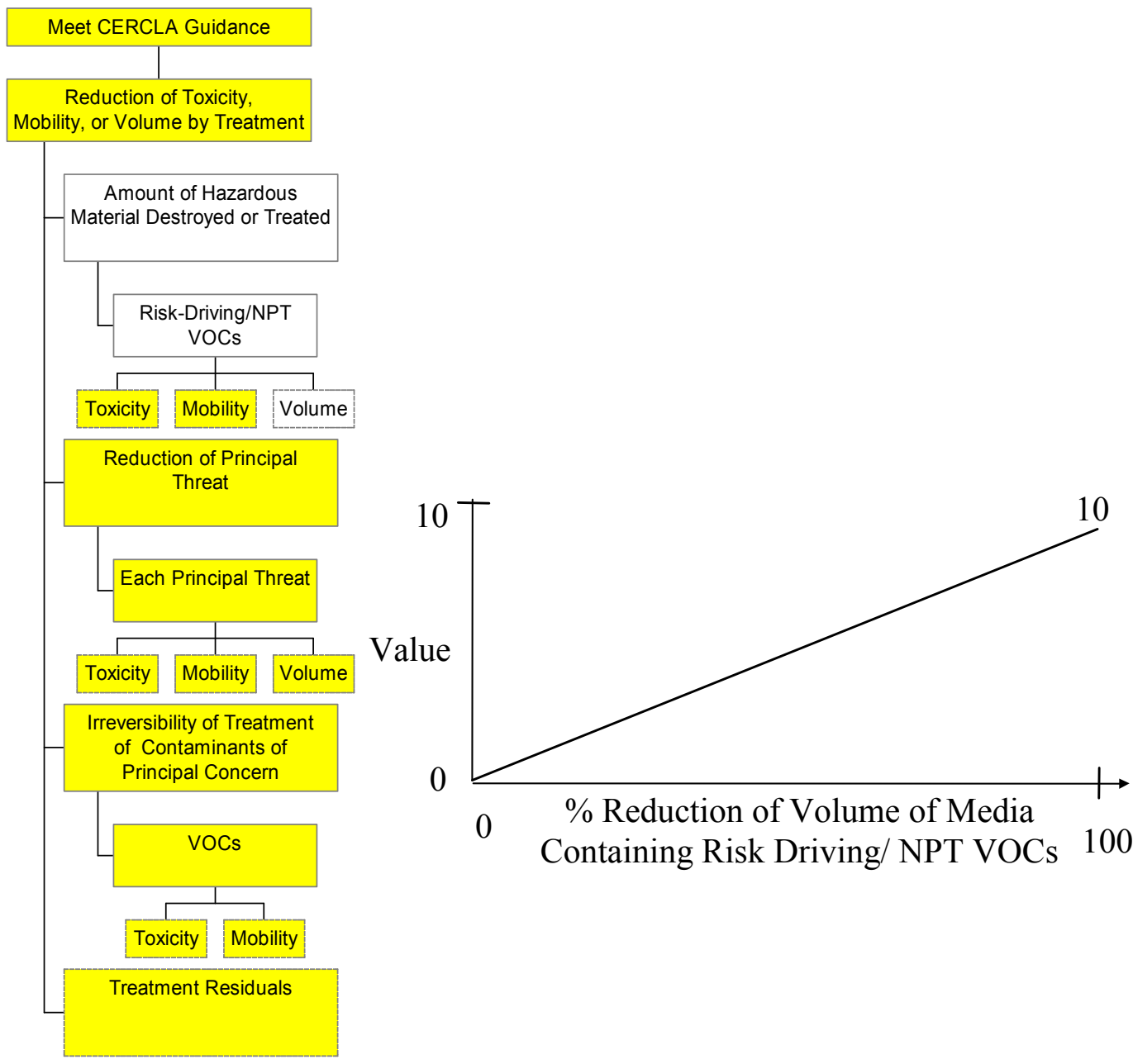

This measure is the \% reduction in the volume of the contaminated media. Reduction in volume may reduce the risk and the amount of final disposal required. We calculate the volume reduction for each contaminant and weight each contaminant equally. For Phase 2, the reduction is easily calculated for a typical site, and then averaged over the different contaminants. For Phase 3, this will be an average \% reduction of the volume of the Risk-Driving/NPT VOCs contaminated media throughout the SDA. 


\section{DRAFT}

2.I.D. The Amount of Risk-Driving/NPT Radiological Contaminants with Reduced Toxicity, Mobility, or Volume

2.I.D.1 Reduced Mobility of Risk-Driving/NPT Rads

Type of Measure - Natural, Direct

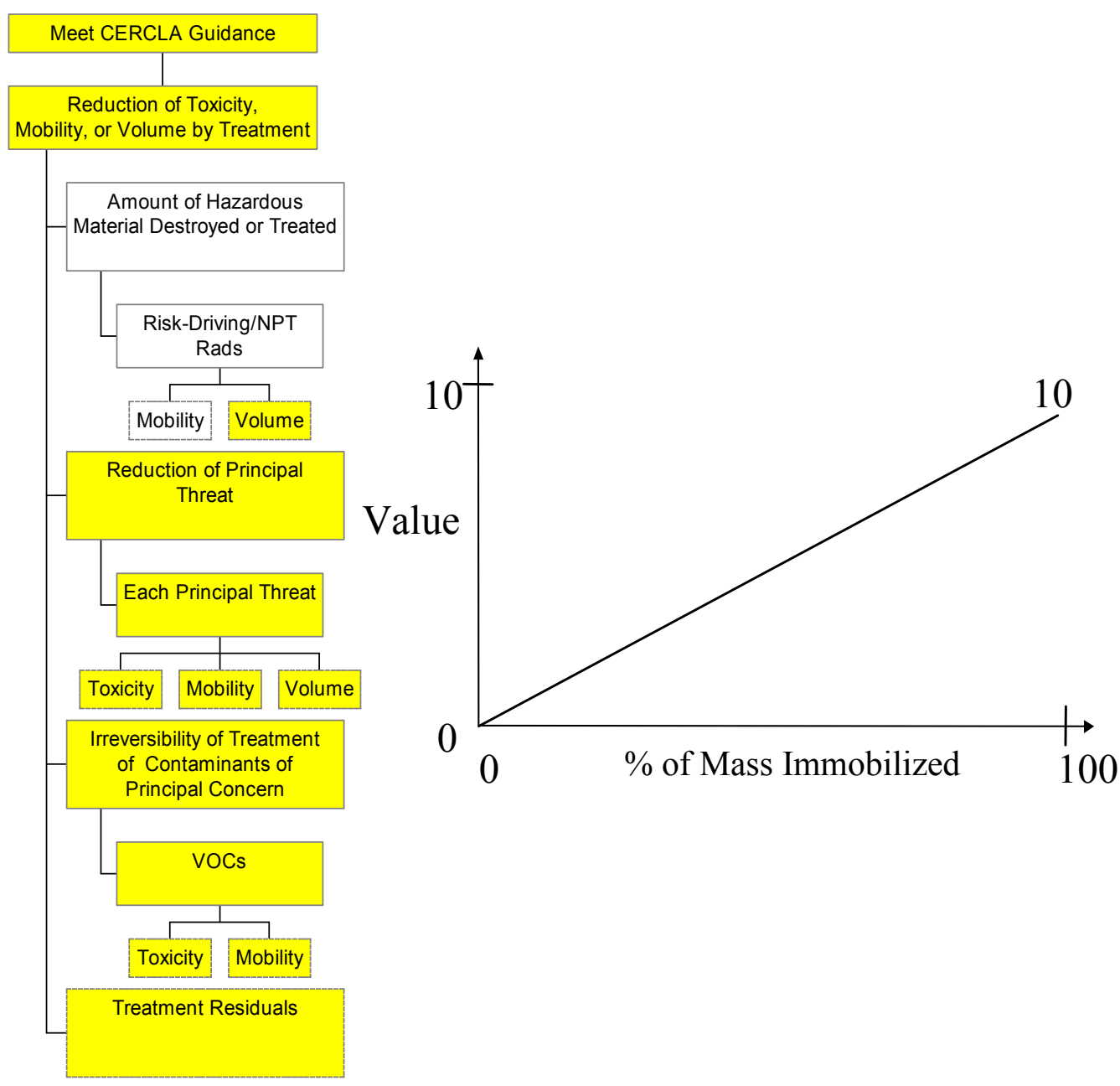

This measure focuses directly on the percent of Risk-Driving/NPT Rads mass immobilized. For Phase 2, this measure will be used to score each class of technologies for a typical site. For Phase 3, this will be the average \% of Risk-Driving/NPT Rads mass immobilized throughout the SDA. Each of the four Rad contaminants will be weighted equally. 


\section{DRAFT}

2.I.D.2 Reduced Volume of Risk-Driving/NPT Rads

Type of Measure - Natural, Direct

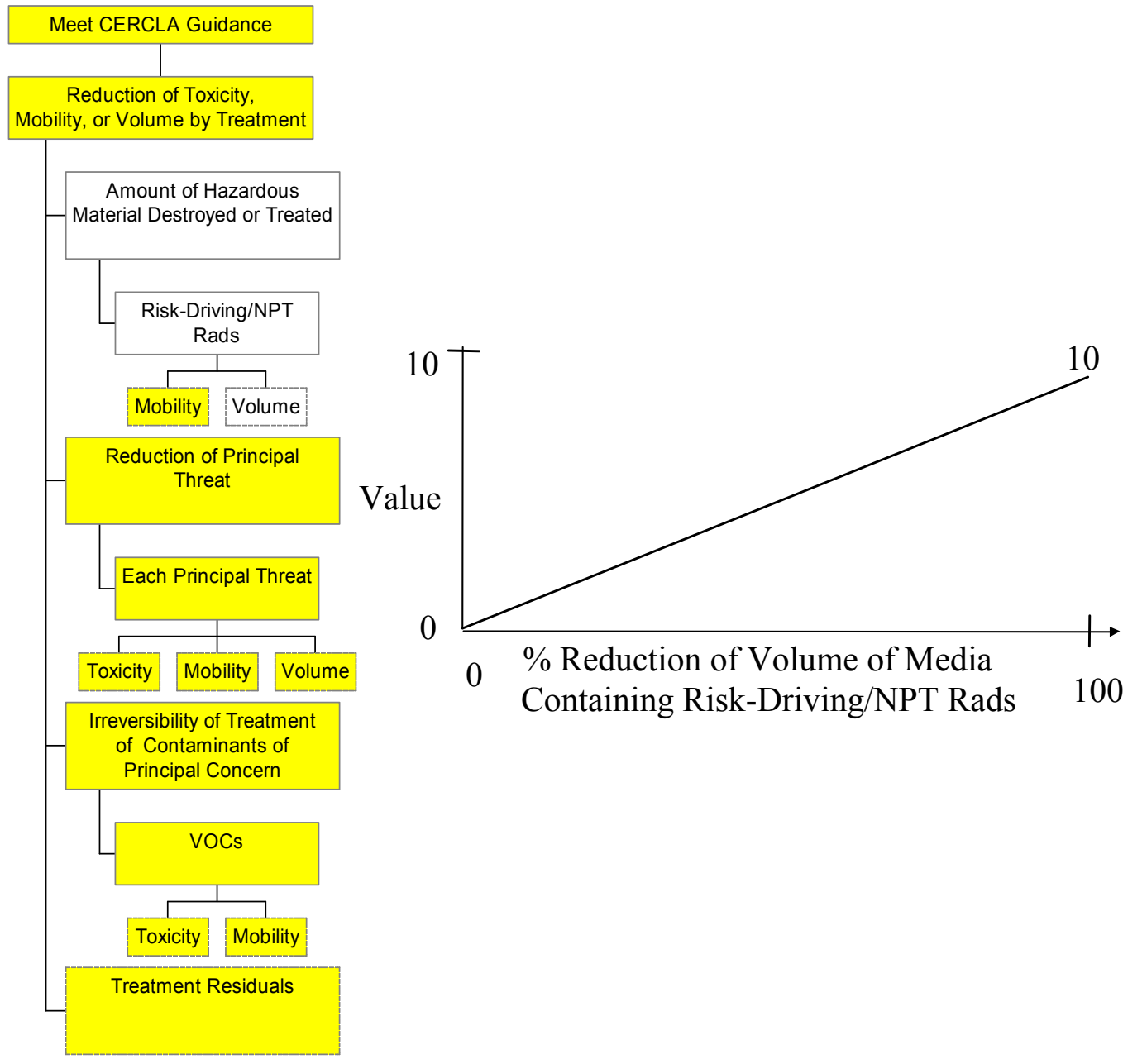

This measure is the \% reduction in the volume of the contaminated media. Reduction in volume may reduce the risk and the amount of final disposal required. For Phase 2, the reduction is easily calculated for a typical site by averaging the \% reduction of volume of each contaminant. For Phase 3, this will be \% reduction of the volume of the radiologically contaminated media throughout the SDA, again by equally weighting each of the 4 contaminants. 


\section{DRAFT}

2.I.E. The Amount of Non Risk-Driving/NPT Rads with Reduced Toxicity, Mobility, or Volume

2.I.E.1 Reduced Mobility of Non Risk-Driving Rads

Type of Measure - Natural, Direct

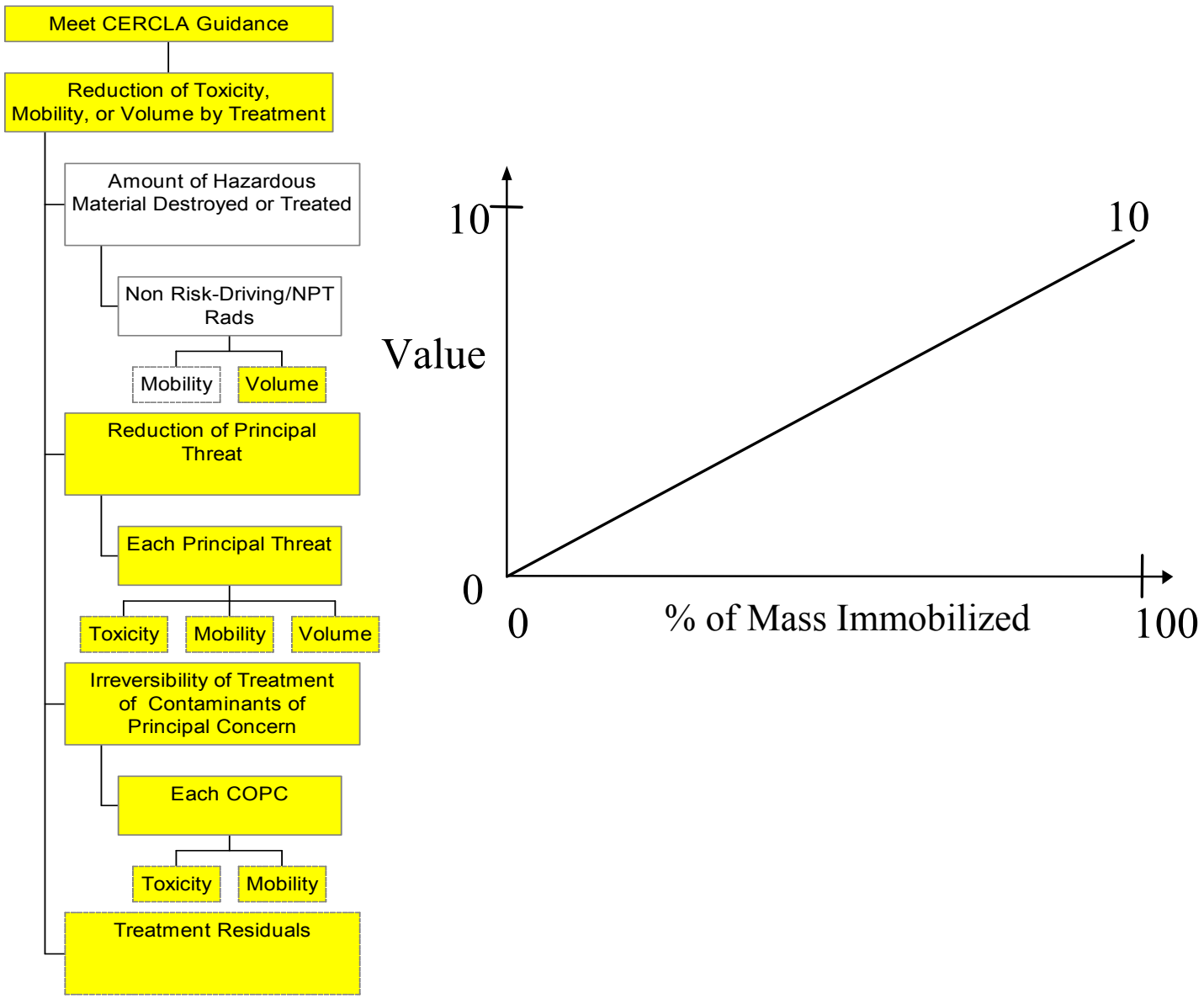

This measure focuses directly on the percent of contaminant mass immobilized. For Phase 2, this measure will be used to score each class of technologies by equally weighting each contaminant. For Phase 3, this will be the average of the $\%$ of non risk-driving/NPT Rads mass immobilized throughout the SDA. 


\section{DRAFT}

2.I.E.2 Reduced Volume of Non Risk-Driving/Non Principal Threat Rads

Type of Measure - Natural, Direct
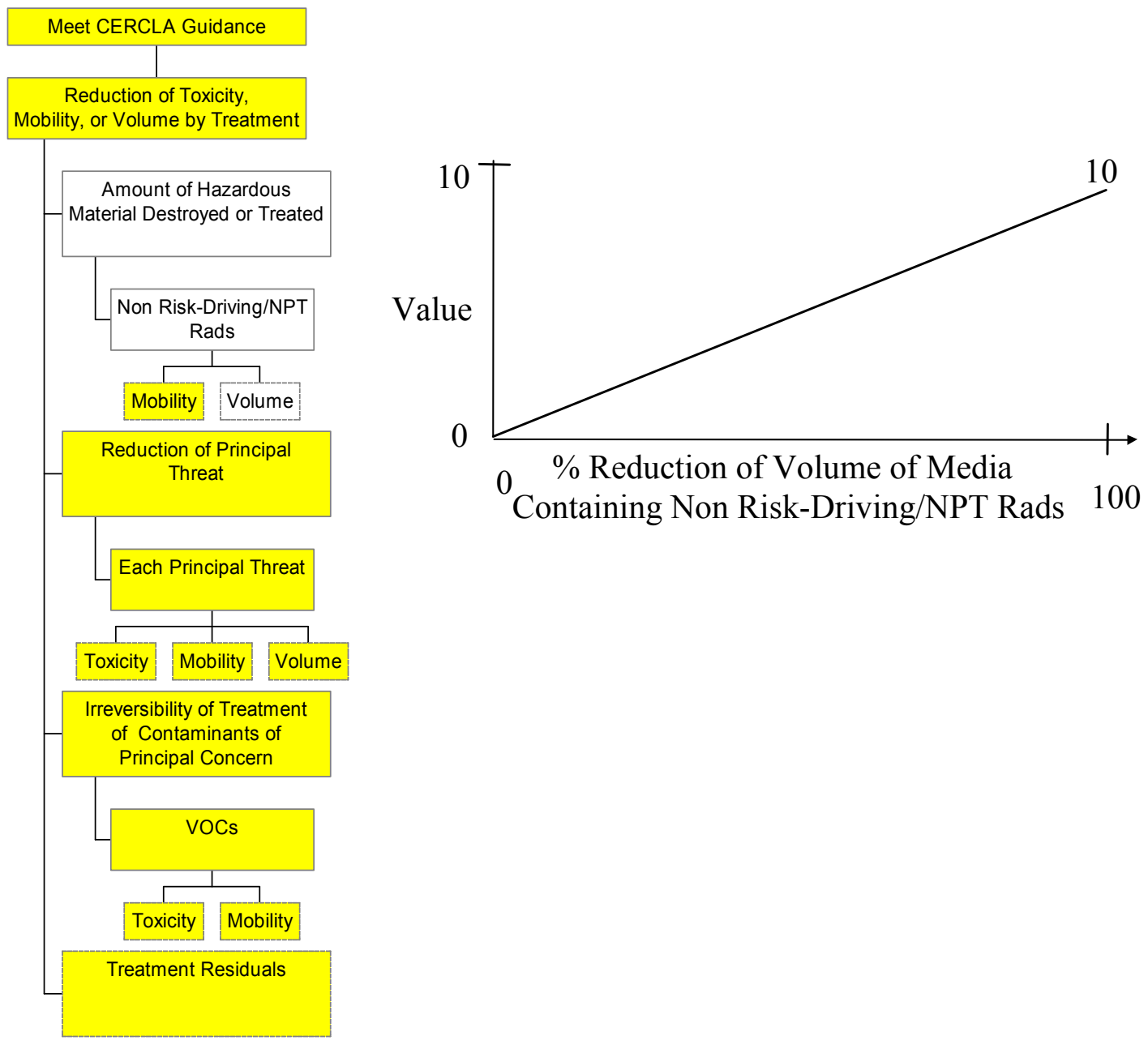

This measure focuses directly on the percent of contaminant mass immobilized. For Phase 2, this measure will be used to score each class of technologies by equally weighting all contaminants. For Phase 3, this will be the average \% of non risk-driving Rads volume of contaminated media throughout the SDA. 


\section{DRAFT}

\section{II. Amount of Principal Threat Treated to Reduce Toxicity, Mobility, or Volume.}

(40 CFR S300.430 (e)(9)(iii)(D)(3)) and (EPA/540/G-89/004, 6.2.3.4) This sub criterion satisfies CERCLA's requirement to address the degree of expected reduction in toxicity, mobility, or volume of the waste and the specification of which reductions are occurring. Only reductions in principal threats are measured in this sub criterion. The principal threats being reduced are found in Table 1.

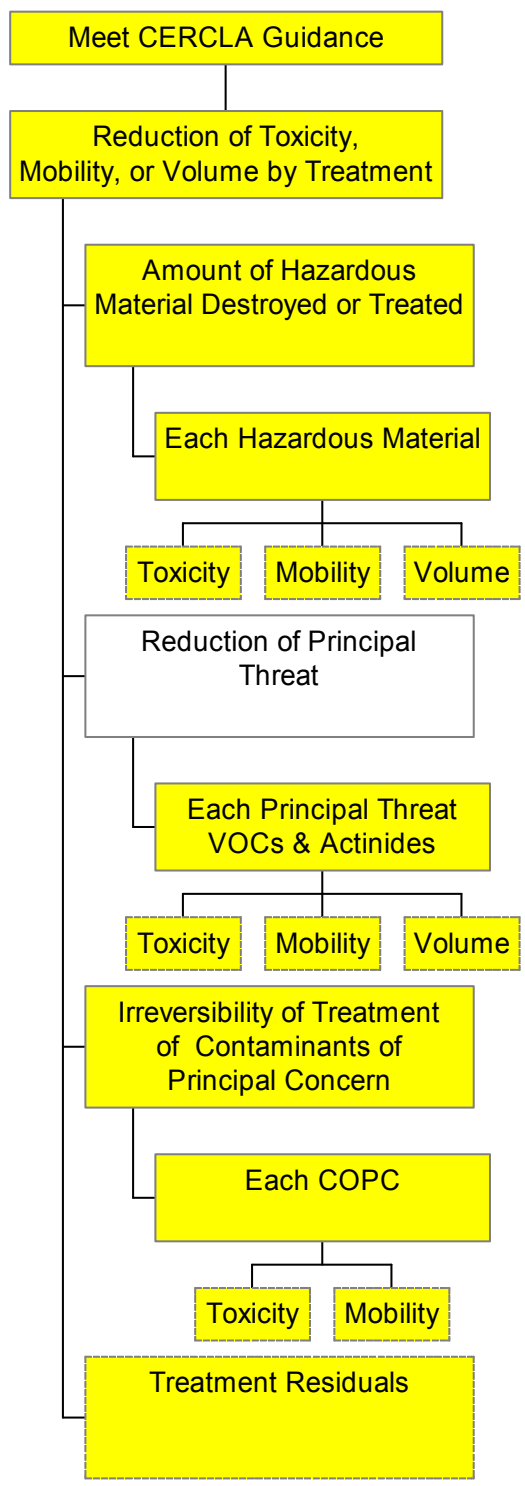




\section{DRAFT}

2.II.A. Amount of VOCs Treated to Reduce Toxicity, Mobility, or Volume

2.II.A.1 Reduction of Toxicity of Principal Threat VOCs

Type of Measure - Natural, Direct

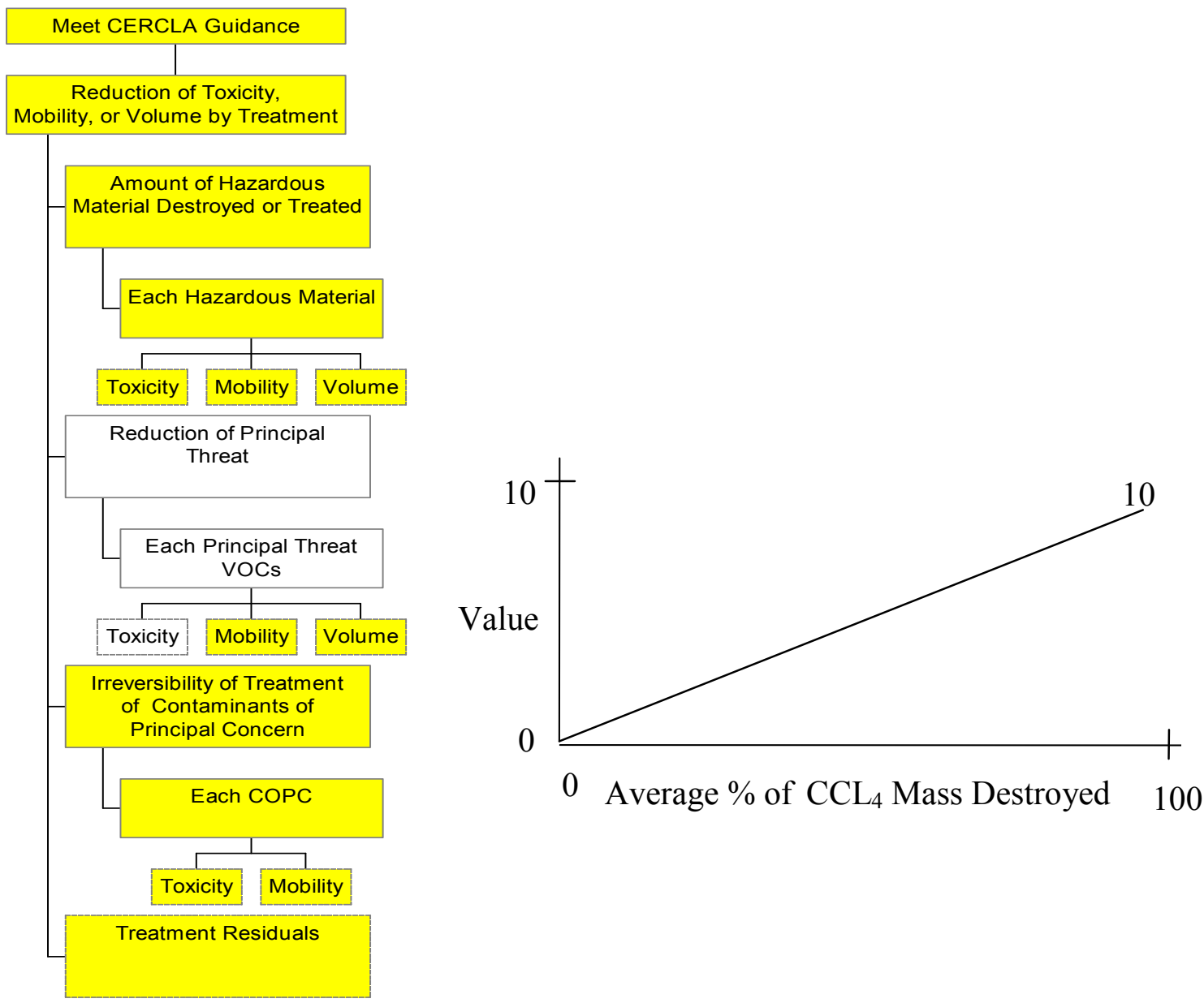

This is a measure of the reduction of toxicity of the $\mathrm{CCL}_{4}$. It is assumed that only destruction of $\mathrm{CCL}_{4}$ reduces its toxicity. For Phase $\mathbf{2}$ this should be a direct estimate based upon a typical site. For Phase 3, this will be an average $\%$ mass of $\mathrm{CCL}_{4}$ destroyed over the entire SDA. 


\section{DRAFT}

2.II.A.2 Reduction of Mobility of VOCs

Type of Measure - Natural, Direct

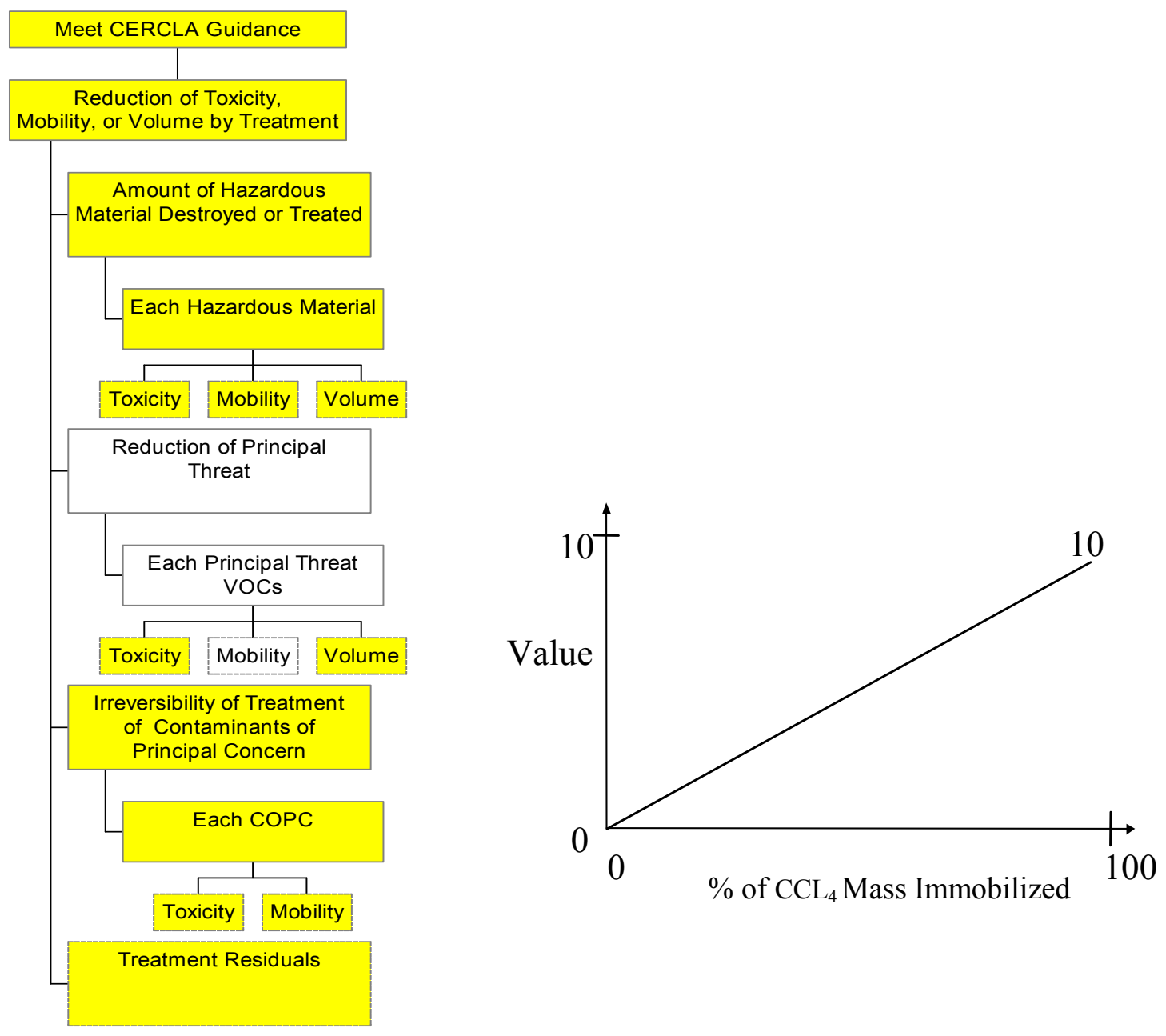

This is a measure of the reduction of mobility of $\mathrm{CCL}_{4}$. For Phase 2 this should be a direct estimate based upon a typical site. For Phase 3, this will be an average $\% \mathrm{CCL}_{4}$ mass immobilized over the entire SDA. 


\section{DRAFT}

\section{II.A.3 Reduction of Volume of Principal Threat VOCs}

Type of Measure - Natural, Direct

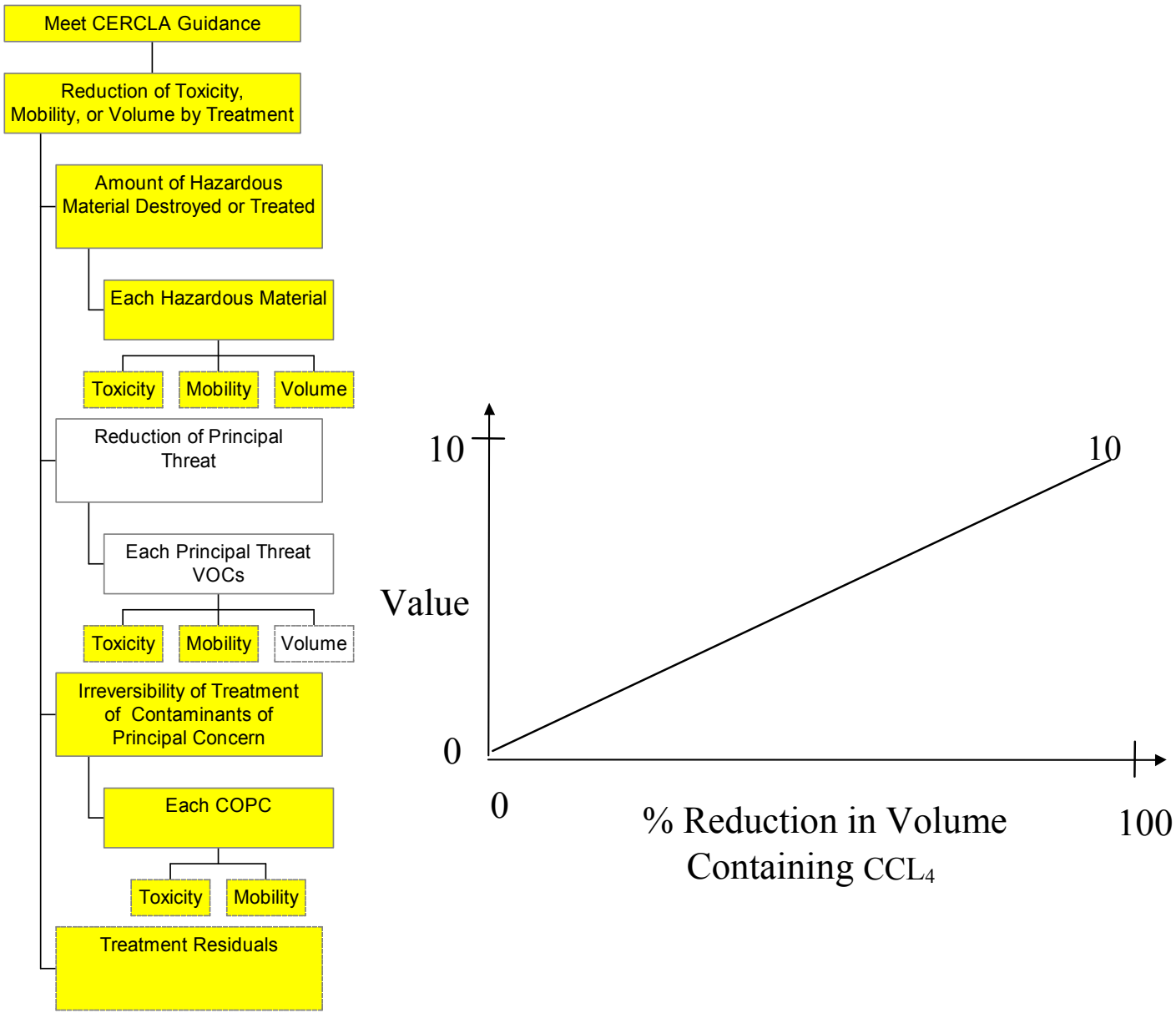

This measure is the \% reduction of volume of the contaminated media containing VOC's. Reduction in volume may reduce the risk and the volume for final disposal. For Phase 2 this should be a direct estimate based upon a typical site. For Phase 3, this will be an overall \% reduction in $\mathrm{CCL}_{4}$ contaminated media volume in the entire SDA. 


\section{DRAFT}

2.II. B. Amount of Actinides Treated to Reduce Toxicity, Mobility, or Volume

2.II.B.1 Reduction of Mobility of Principal Threat - Actinides

Type of Measure - Natural, Direct

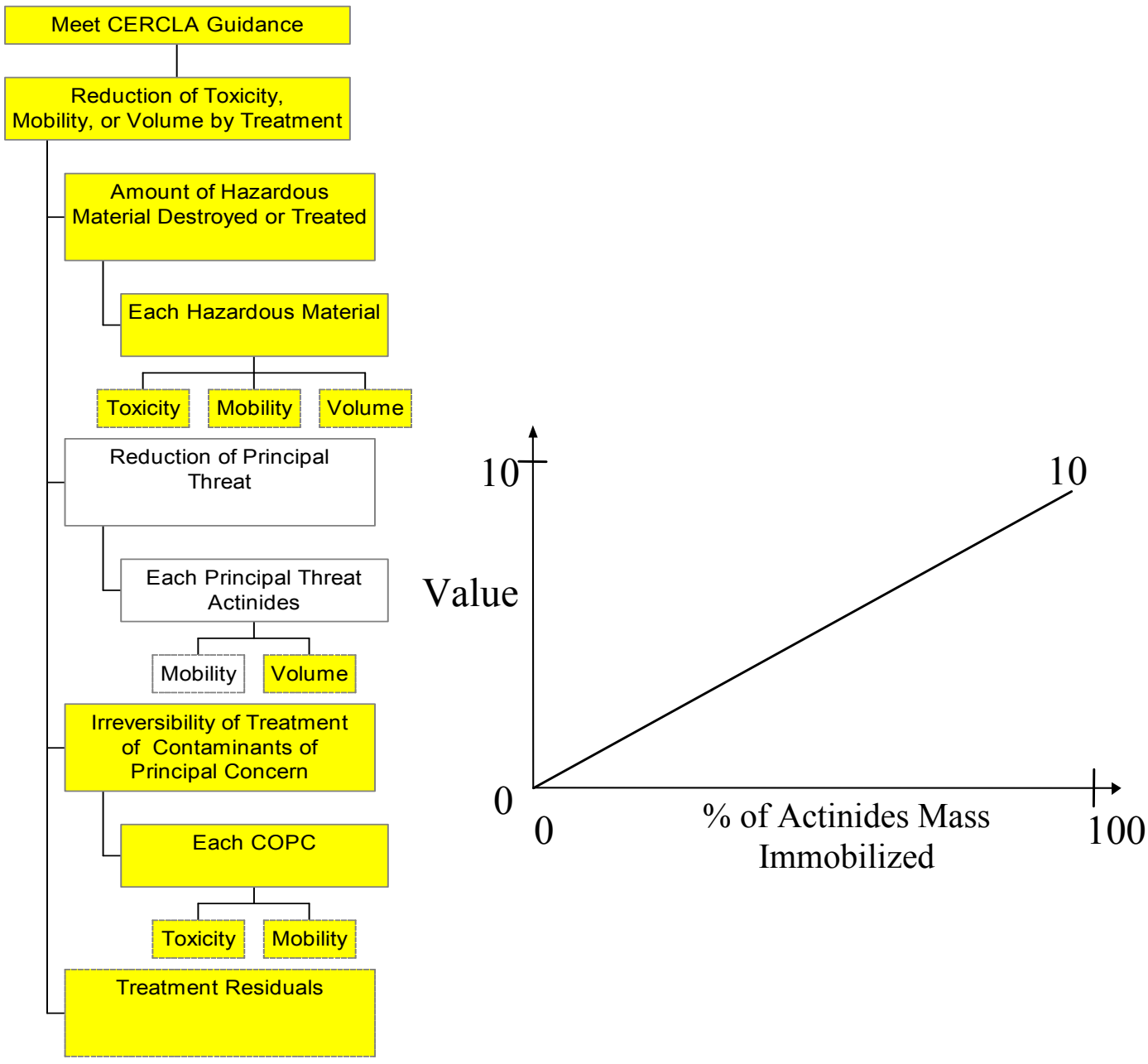

This is a measure of the reduction of mobility of the actinide component of the principal threats. For Phase 2 this should be a direct estimate based upon a typical site and a representative quantity of actinides. Each of the actinides are equally weighted. For Phase 3, this will be a $\%$ actinide mass immobilized over the entire SDA, again weighting each actinide equally. 


\section{DRAFT}

2.II.B.2 Reduction of Volume of Principal Threat - Actinides

Type of Measure - Natural, Direct

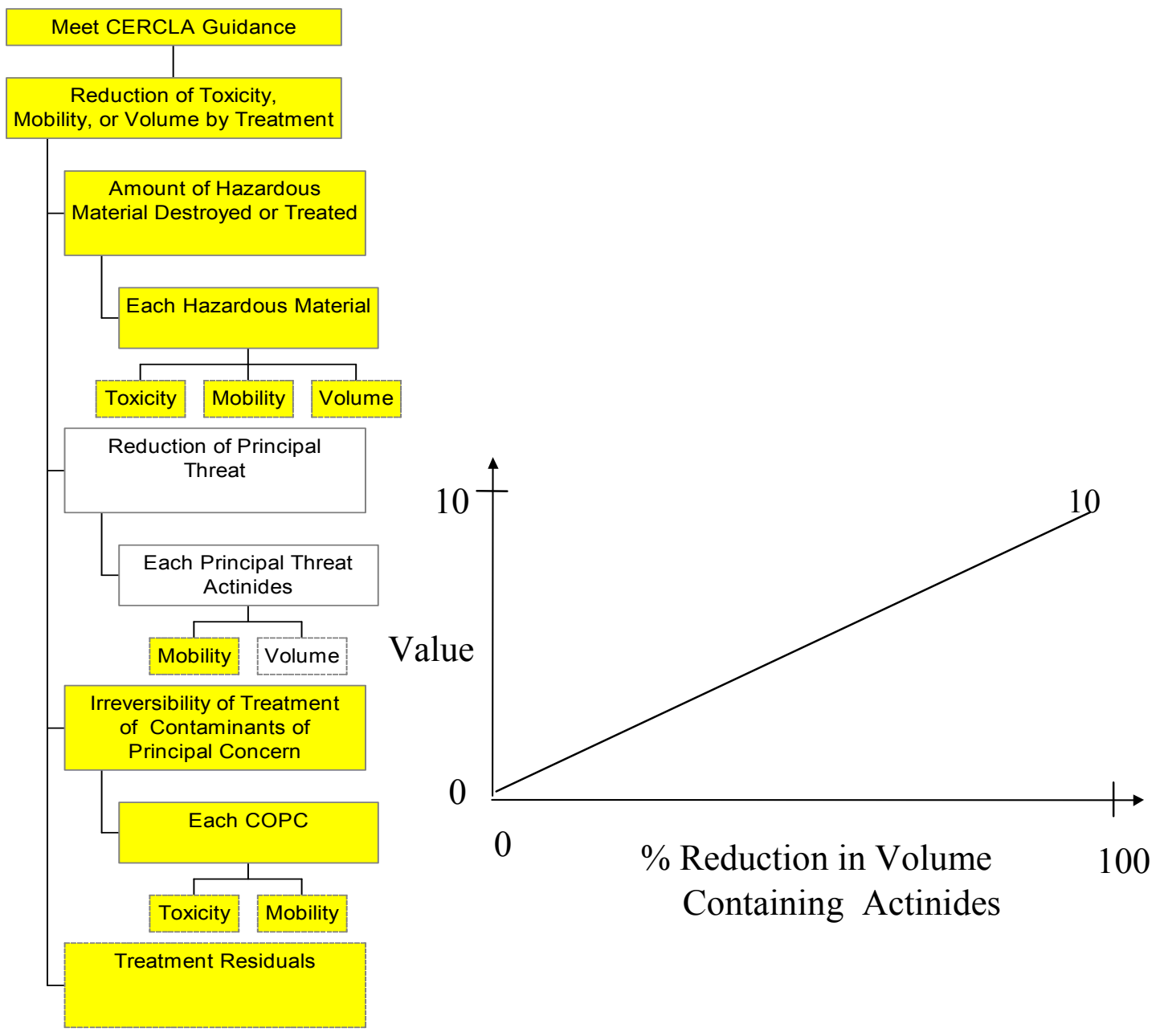

This measure is the $\%$ reduction of volume of the contaminated media containing actinides. Reduction in volume may reduce the risk and the volume for final disposal. If we have a $100 \%$ reduction in volume of actinides contaminated media, the value would be 10. For Phase 2, this should be a direct estimate based upon a typical site, giving all three actinides equal weight. For Phase 3, this will be an average \% reduction in actinide contaminated media volume over the entire SDA. 


\section{DRAFT}

\section{III. Irreversibility of Treatment of Contaminants of Principal Concern.}

(40 CFR S300.430 (e)(9)(iii)(D)(3)) and (EPA/540/G-89/004, 6.2.3.4) This sub criterion satisfies CERCLA's requirement to address the irreversibility of the reduction in contaminant mobility (and toxicity). The three agencies determined this measure to be applicable only to the contaminants of principal concern as listed in Table 1 . This sub criterion does not address the irreversibility of the reduction of contaminant volume.

The weights for Toxicity and for Mobility under the Irreversibility of Treatment criterion are equal.

The Contaminants of Principal Concern (COPCs) are weighted according to Table 2.

\section{III. A. Irreversibility of Treatment of VOC's}

2.III.A.1 Irreversibility of Reduction of Toxicity of Carbon tetrachloride $\left(\mathrm{CCL}_{4}\right)$

\section{Type of Measure - Constructed, Direct}

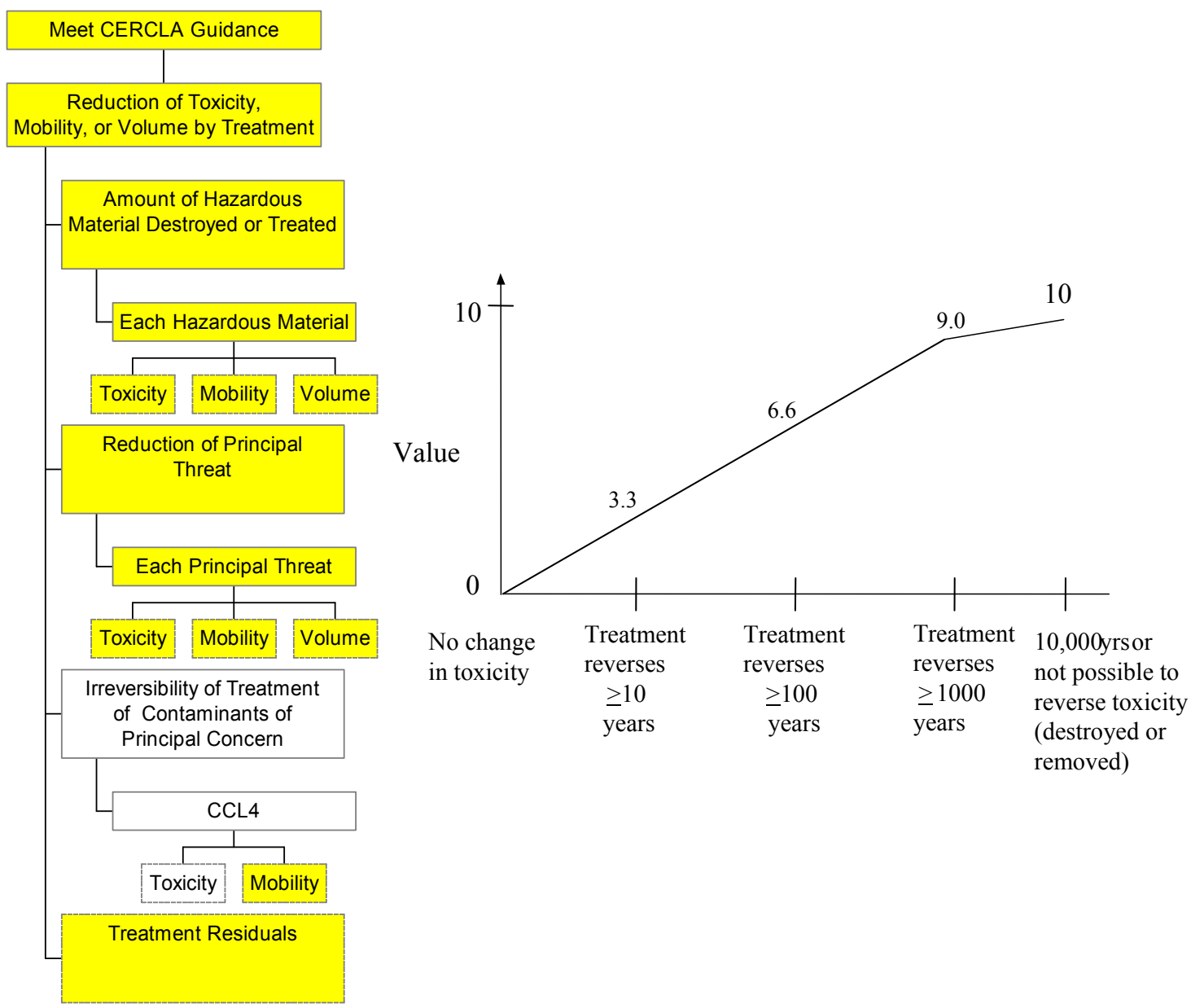

This evaluation measure focuses on the reversibility of the toxicity of the treated $\mathrm{CCL}_{4}$ due to natural consequences. The durability tests may provide more information for this measure. It was felt that at least 1000 years is a key goal to reach in irreversibility. For Phase $\mathbf{2}$ this should be a direct estimate based upon a typical site. For Phase 3, this will be the average value based upon the $\mathrm{CCL}_{4}$ reversibility time estimate for each site. The sites are averaged over the SDA. There is concern that there may be dependency between TPOs within a train - one technology process option may affect the original estimate of the reversibility of the $\mathrm{CCL}_{4}$ of another TPO in the train. 


\section{DRAFT}

2.III.A.2 Irreversibility of Reduction of Mobility of $\mathrm{CCL}_{4}$

Type of Measure - Natural, Direct

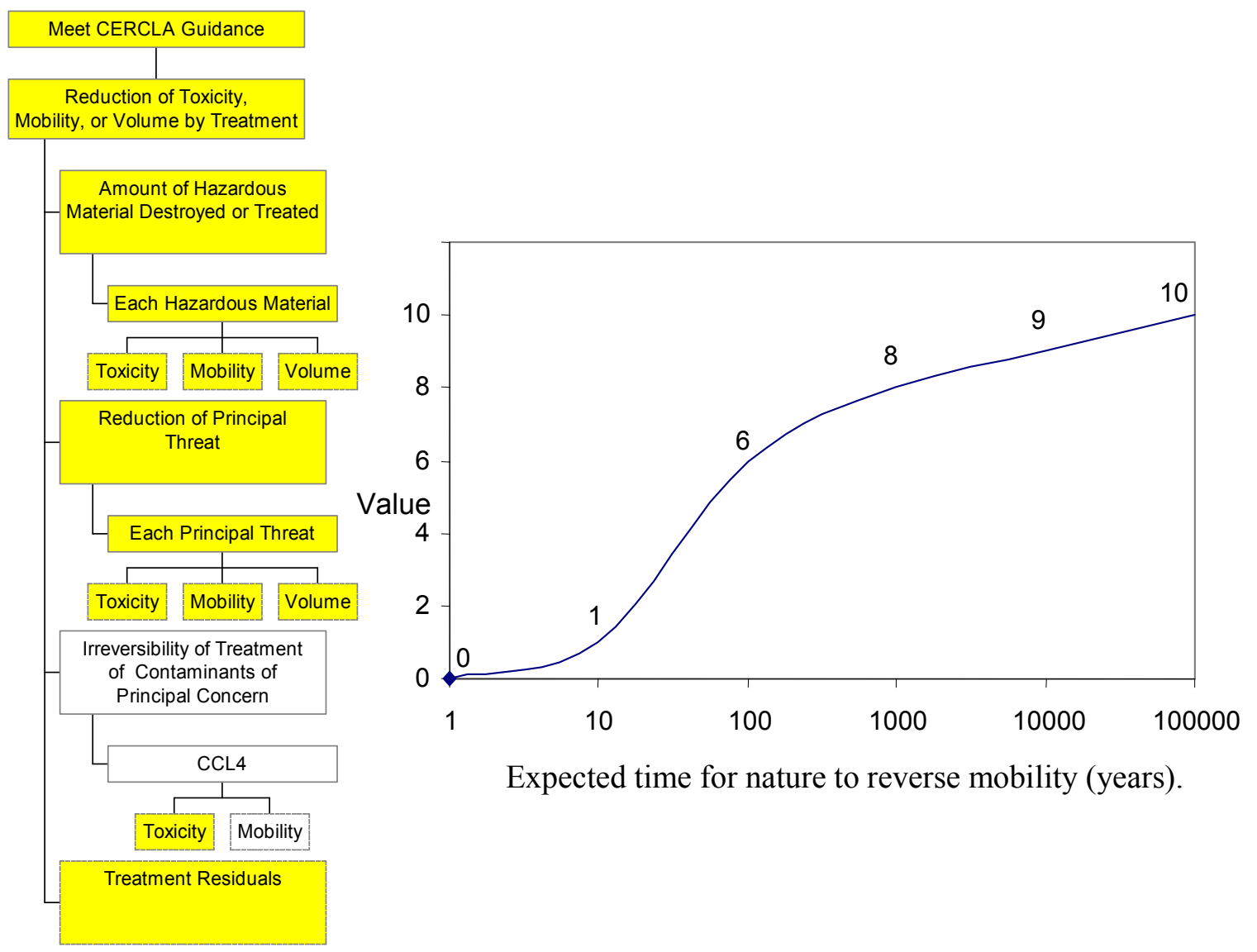

This evaluation measure refers to reversibility of the mobility of the Principal Threat $\mathrm{CCL}_{4}$ in the SDA due to natural consequences. For Phase 2, this measure will be used to score each class of technologies. For Phase 3, this will be the average site value for the SDA of the reversibility of the mobility of $\mathrm{CCL}_{4}$. 


\section{DRAFT}

\section{III. B. Irreversibility of Treatment of Actinides}

It is assumed that the toxicity of actinides cannot be reduced and therefore there is no reversibility of toxicity to consider.

\section{III.B.1 Irreversibility of Reduction of Mobility of Actinides}

Type of Measure - Natural, Direct

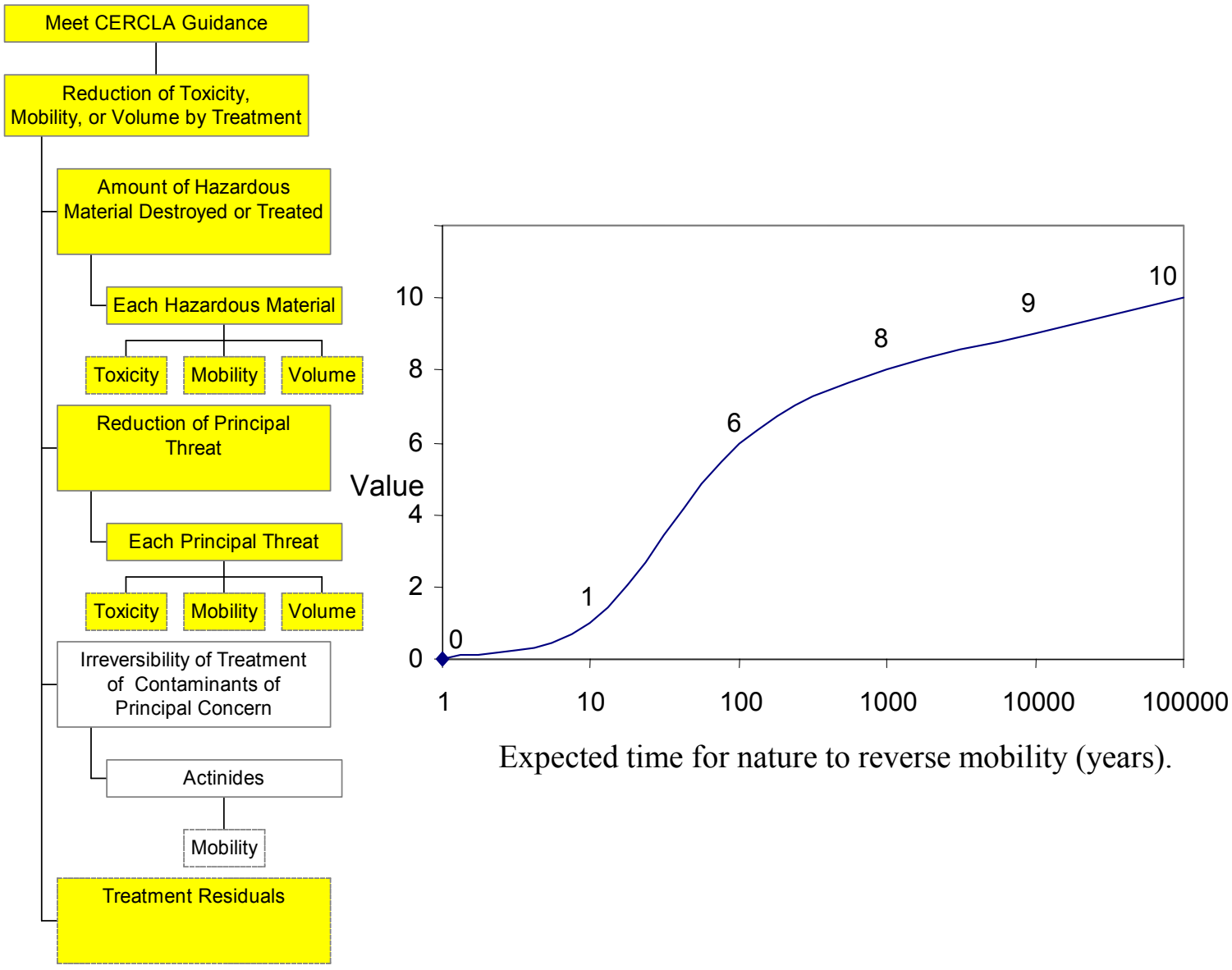

This evaluation measure refers to reversibility of the mobility of the Principal Threat - Actinides due to natural consequences. For Phase 2, this measure will be used to score each class of technologies. For Phase 3, this will be the average reversibility of the mobility of actinides, as measured in years, throughout the SDA. Each Principal Threat actinide will be weighted equally. 


\section{DRAFT}

\section{III. C. Irreversibility of Treatment of non-Rad (Nitrates \& Methylene Chloride)}

\section{III.C.1 Irreversibility of Reduction of Toxicity of Risk Driving/NPT VOCs}

Type of Measure - Constructed, Direct

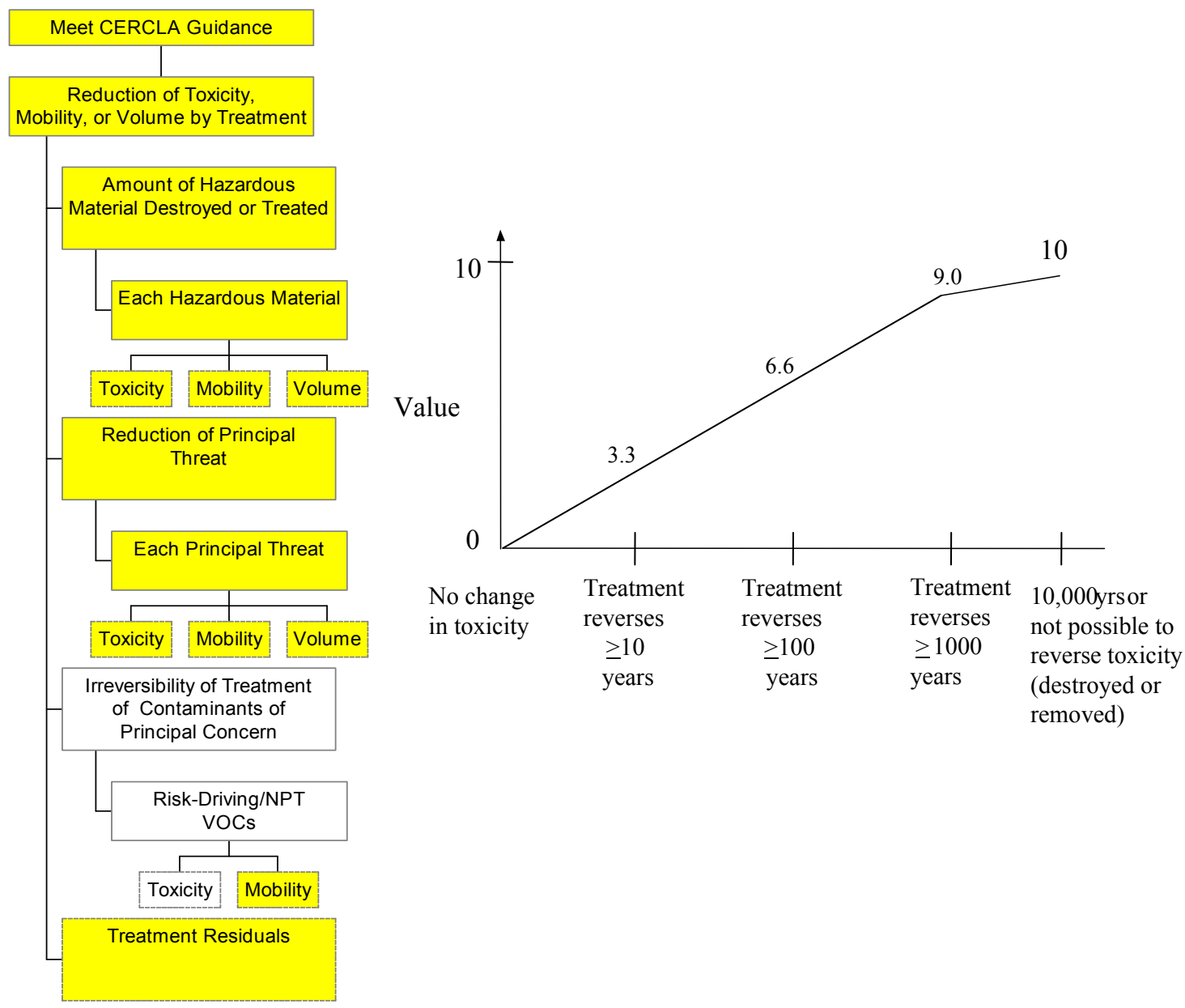

This evaluation measure focuses on the reversibility of the toxicity of the Risk Driving/NPT VOCs (nitrates \& Methylene chloride) at the SDA due to natural consequences. The durability tests may provide information for this measure. It was felt that 1000 years is a key goal to reach in irreversibility. For Phase $\mathbf{2}$ this should be a direct estimate based upon a typical site. For Phase 3, this will be the lowest average reversible time estimate for all Risk Driving/NPT VOCs (nitrates \& Methylene chloride) for each site and then averaged over the entire SDA. The two VOCs will be weighted equally. 


\section{DRAFT}

2.III.C.2 Irreversibility of Reduction of Mobility of Risk-Driving NPT non-Rad's

Type of Measure - Natural, Direct

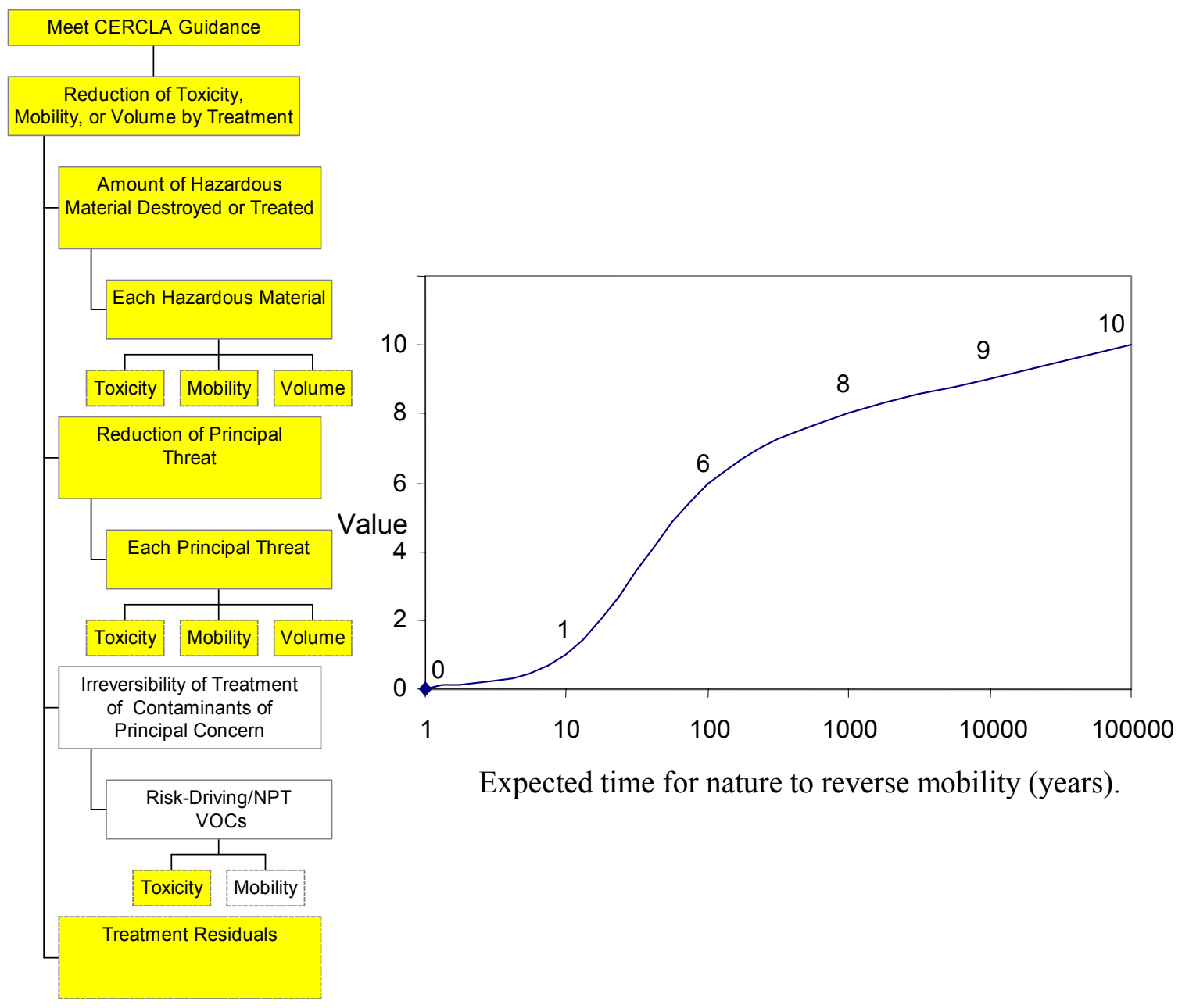

This evaluation measure refers to reversibility of the mobility of Risk Driving/NPT non-Rads (nitrates \& Methylene chloride) at the SDA due to natural consequences. For Phase 2, this measure will be used to score each class of technologies. For Phase 3, this will be the average reversibility of the mobility of Risk Driving/NPT non-Rads (nitrates \& Methylene chloride) throughout the SDA. The two non-Rads will be weighted equally. 


\section{DRAFT}

\section{III. D. Irreversibility of Treatment of Other COPC Radiological Contaminants}

It is assumed that the toxicity of radiological contaminants cannot be reduced and therefore there is no reversibility to consider.

\section{III.D.1 Irreversibility of Reduction of Mobility of Other COPC Rads}

Type of Measure - Natural, Direct

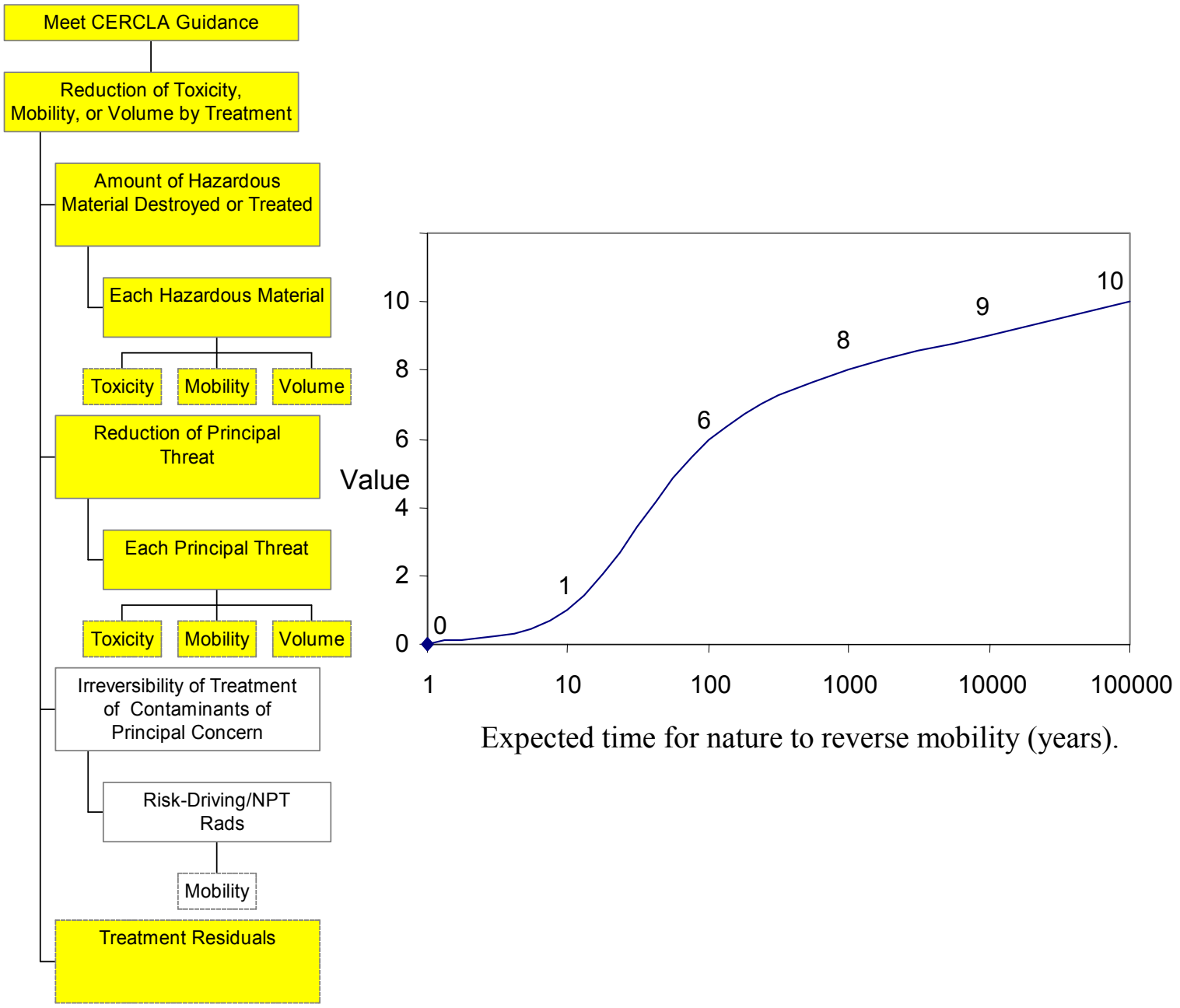

This evaluation measure refers to reversibility of the mobility of Risk-Driving/NPT Rads due to natural consequences. For Phase 2, this measure will be used to score each class of technologies with each radiological contaminant being weighted equally. For Phase 3, this will be the average reversibility of the mobility of Risk-Driving/NPT radiological contaminants throughout the SDA. Contaminants will be weighted equally. 


\section{DRAFT}

\section{IV. Amount of Treatment Residuals Remaining After Treatment.}

(40 CFR S300.430 (e)(9)(iii)(D)(3)) and (EPA/540/G-89/004, 6.2.3.4) This sub criterion satisfies CERCLA's requirement to address the quantity of treatment residuals remaining after treatment. This sub criterion directly addresses the toxic and non-toxic materials (secondary waste and treated waste product (in situ and ex situ)). An example of secondary waste is PPE. An example of in situ waste product is the glass monolith from ISV.

\section{Type of Measure - Constructed, Proxy}

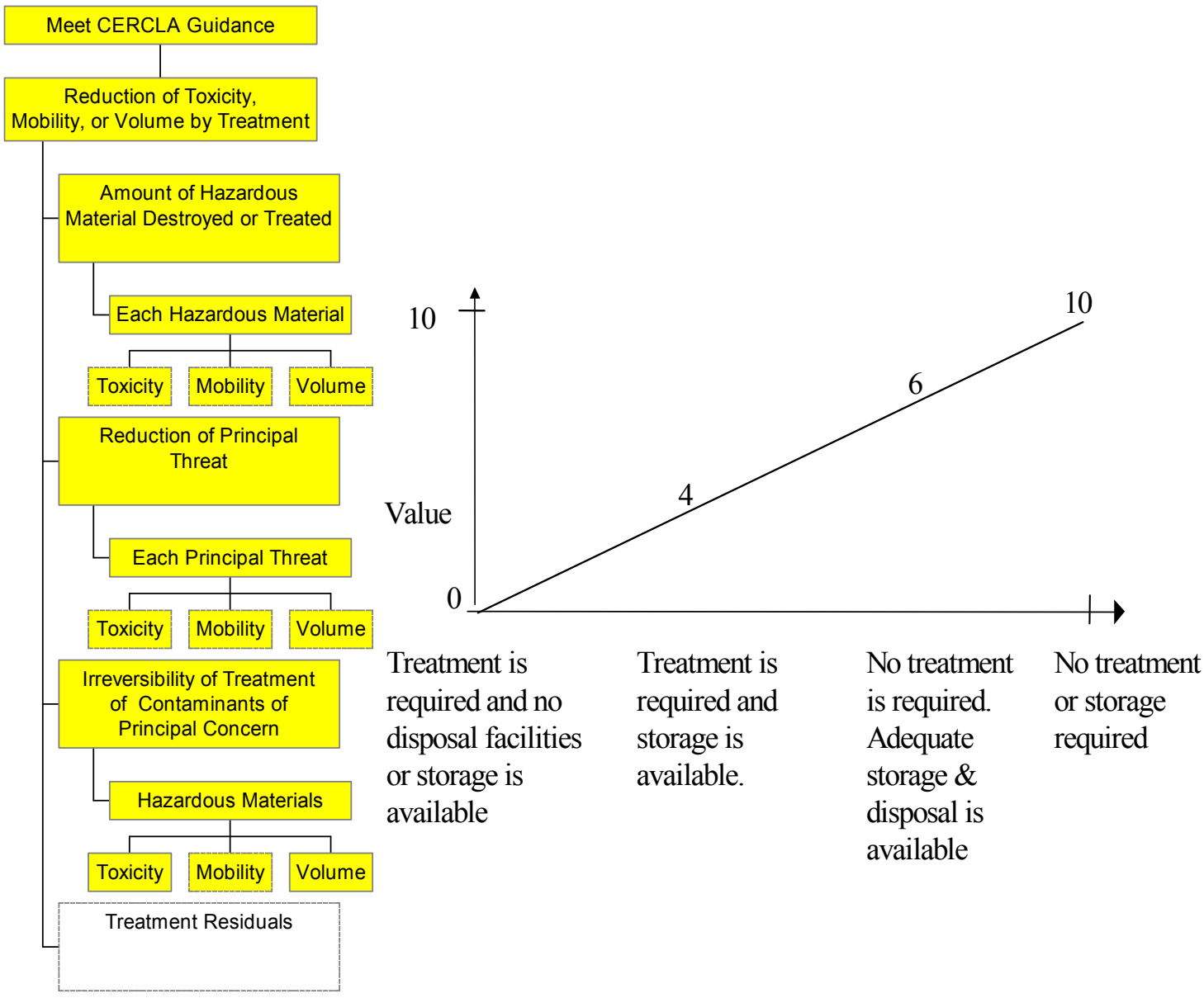

This measure uses treatment, storage and disposal activities as proxies for the impact of treatment residuals. For Phase 2, this measure will be used directly. For Phase 3, this will be the average value throughout the SDA due to the treatment, storage, and disposal activities required. 


\section{DRAFT}

\section{Balancing Criteria 3: Short Term Effectiveness}

(40 CFR S300.430 (e)(9)(iii)(E)) and (EPA/540/G-89/004, 6-9) "This evaluation criterion addresses the effects of the alternative during the construction and implementation phase until remedial response objectives are met. Under this criterion, alternatives should be evaluated with respect to their effects on human health and the environment during implementation of the remedial action. The following should be addressed as appropriate for each alternative: protection of the community during remedial actions, protection of workers during remedial actions, environmental impacts, and time until remedial response objectives are achieved." The four criteria were equally weighted since CERCLA does not specifically differentiate between the importance of the criteria.

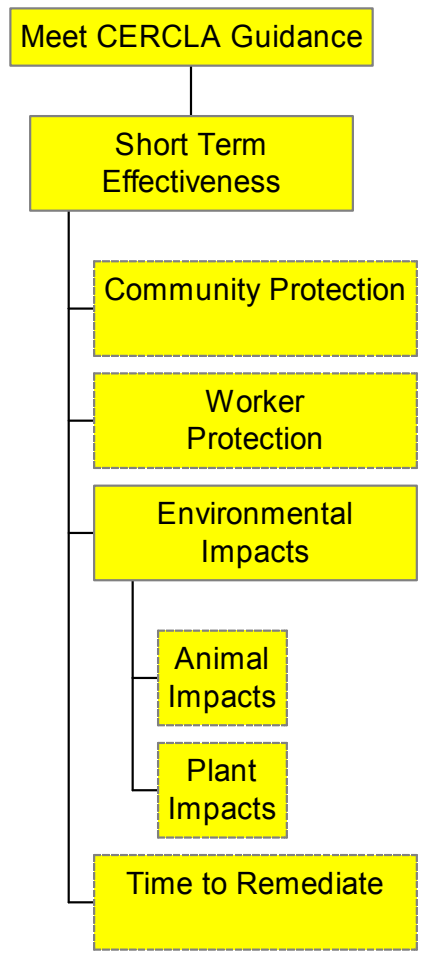

Figure 3.1 Short Term Effectiveness 


\section{DRAFT}

\section{I. Community Protection}

(40 CFR S300.430 (e)(9)(iii)(E)(1)) and (EPA/540/G-89/004, 6-9). This criterion satisfies CERCLA's requirement to address protection of the surrounding community during the remedial action. It addresses any risk that results from implementation of the proposed remedial action, such as dust from excavation, transportation of hazardous materials, or air-quality impacts from a stripping tower operation that may affect human health.

Type of Measure-Constructed, proxy

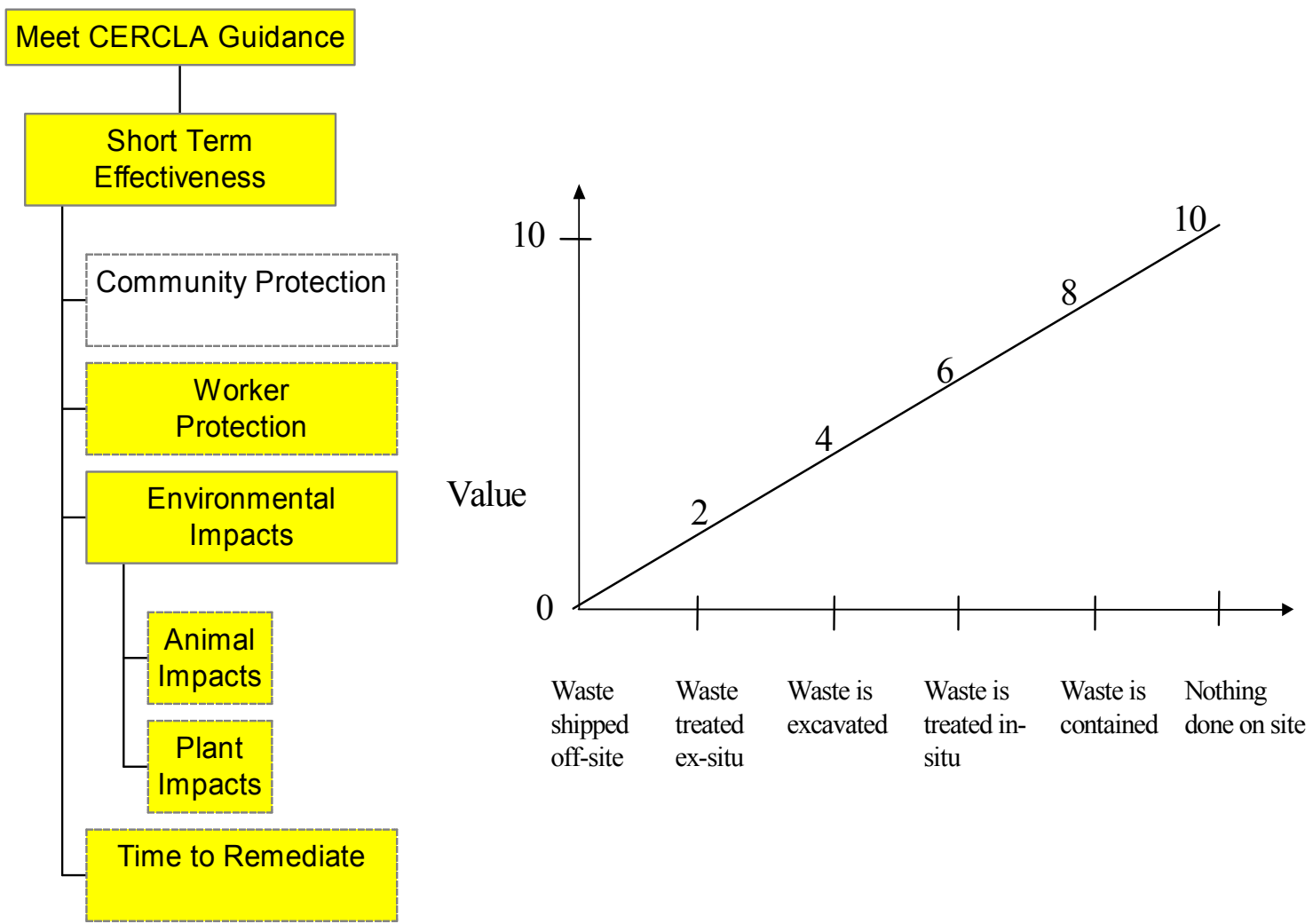

In Phase 2, this directly addresses the local community's perception of the potential exposure of the community during the remediation process. Shipping contaminated waste off-site is perceived as the highest potential for exposure of the community. Doing no treatment or excavation on-site would cause no new exposure potential for the community. For Phase 3, we should consider actual exposure risk instead of risk perception. Other measures to be considered are public HI, cancer risk, and safety analysis. A safety analysis will be performed for the five Feasibility Study alternatives and may be the best evaluation measure. The expected value of the community protection of the entire SDA is calculated. 


\section{DRAFT}

\section{II. Worker Protection}

(40 CFR S300.430 (e)(9)(iii)(E)(2)) and (EPA/540/G-89/004, 6-9). This sub criterion satisfies CERCLA's requirement to address protection of workers during the remedial action. "This factor assesses threats that may be posed to workers and the effectiveness and reliability of protective measures that would be taken."

Type of Measure - Constructed, Proxy

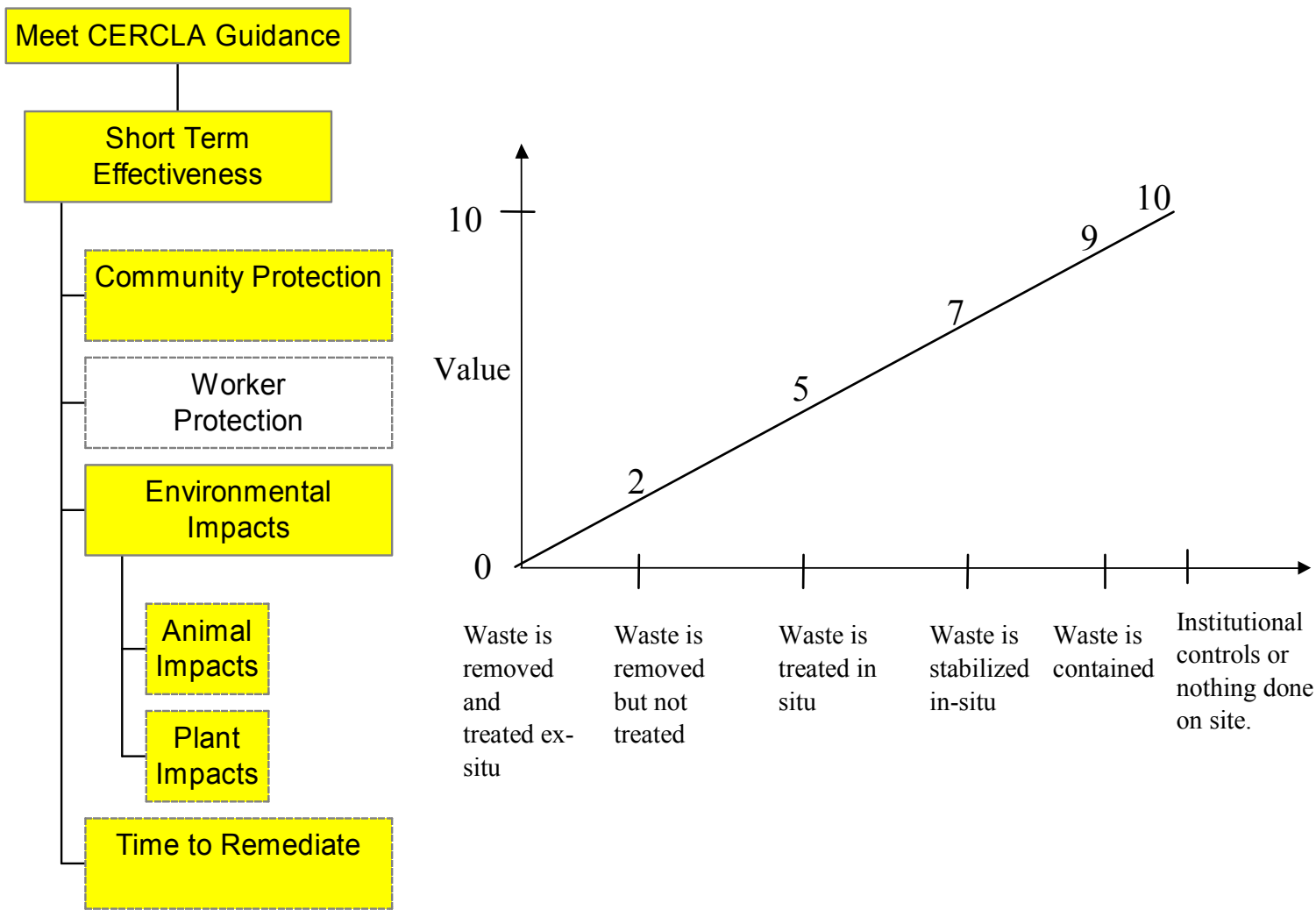

This measure, in Phase 2, directly addresses the perception of the potential exposure of the workers during the remediation process. Institutional controls cause no additional exposure of the workers. Removing waste and treating ex-situ is considered the highest potential exposure of the workers. For Phase 3, we should consider actual exposure risk instead of risk perception. Other measures to be considered are public HI, cancer risk, and safety analysis. A safety analysis will be performed for the five Feasibility Study alternatives which may provide the best evaluation measure. The expected value of the worker protection will be calculated for the entire SDA. 


\section{DRAFT}

\section{III. Environmental Impacts}

(40 CFR S300.430 (e)(9)(iii)(E)(3)) and (EPA/540/G-89/004, 6-9). This sub criterion satisfies CERCLA's requirement to address the potential for adverse environmental impacts that may result from the construction and implementation of a remedial alternative. The measure is broken into two categories, plants and animals. Each category has a constructed scale that captures the impact an alternative has on plants and animals.

\section{III.A. Animal Impact}

Type of Measure - Constructed, Direct
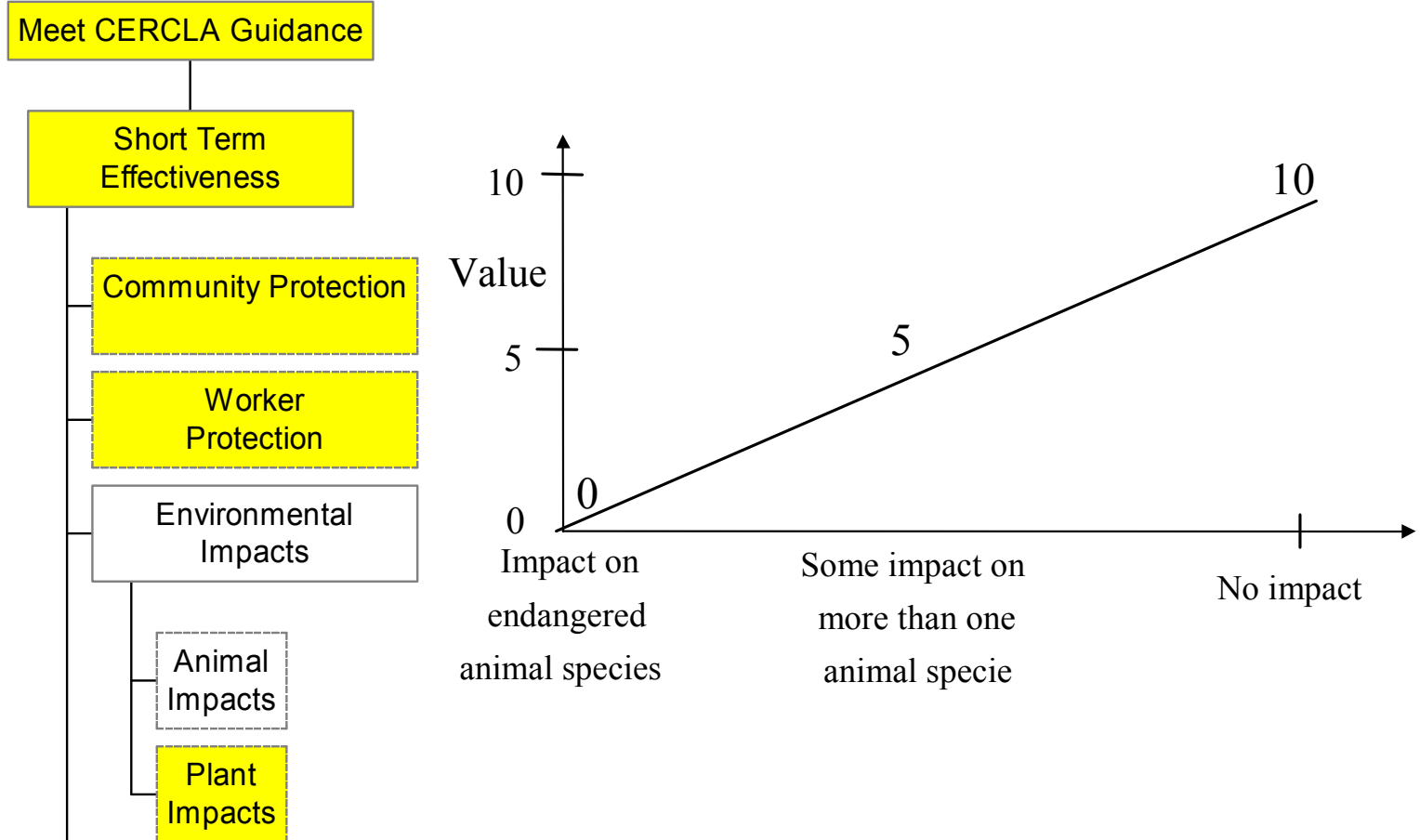

Time to Remediate

This measure directly addresses the animal impacts. It focuses on the most important issue -endangered animal species. The worst possible outcome is having an alternative that has an impact on endangered animal species. The best possible outcome is an alternative that has no impact on animals. Phase 2 may require a more subjective assessment of the impact for each TPO. For Phase 3, the Environmental Impact Statement (EIS) should give the FS alternatives more objective data. The most desirable level in a train will be the level scored for that train. Each site's value will then be averaged for the entire SDA. 


\section{DRAFT}

3.III.B. Plant Impact

Type of Measure - Direct, constructed

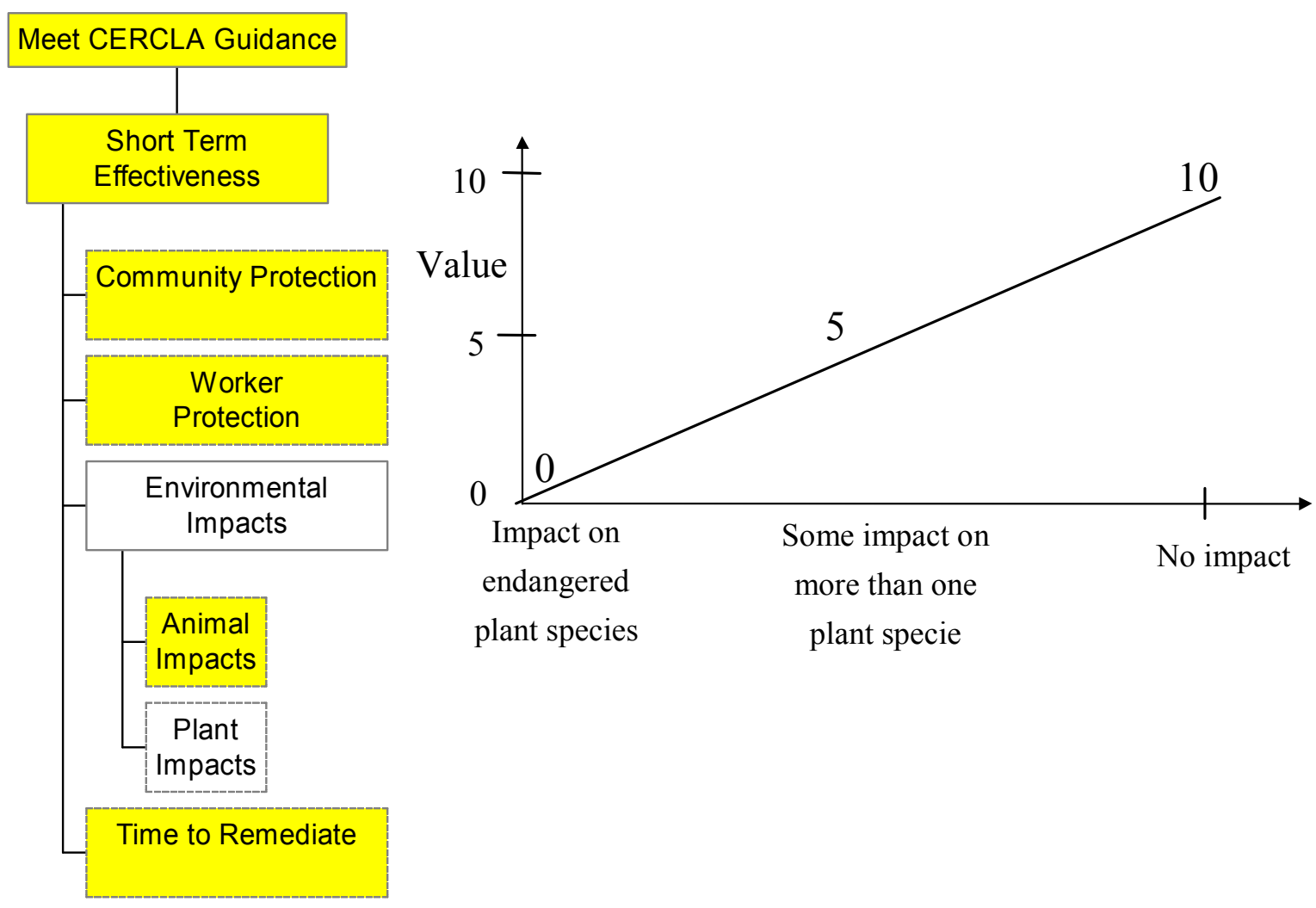

This measure directly addresses the plant impacts of the remedial alternative. It focuses on the most important issue -- endangered plant species. The worst possible outcome is having an alternative that has an impact on endangered plant species. The best possible outcome is an alternative that has no impact on plants. Phase 2 may require a more subjective assessment of the impact for each TPO. For Phase 3, the Environmental Impact Statement (EIS) should give the FS alternatives more objective data. The most desirable level in a train will be the level scored for that train. Each site's value will then be averaged for the entire SDA. 


\section{DRAFT}

\section{IV Time to Remediate}

(EPA/540/G-89/004, 6-9) and (40 CFR S300.430 (e)(9)(iii)(E)(4)). This sub criterion satisfies CERCLA's requirement to estimate the time required to achieve protection for the entire site.

Type of Measure - Direct, natural

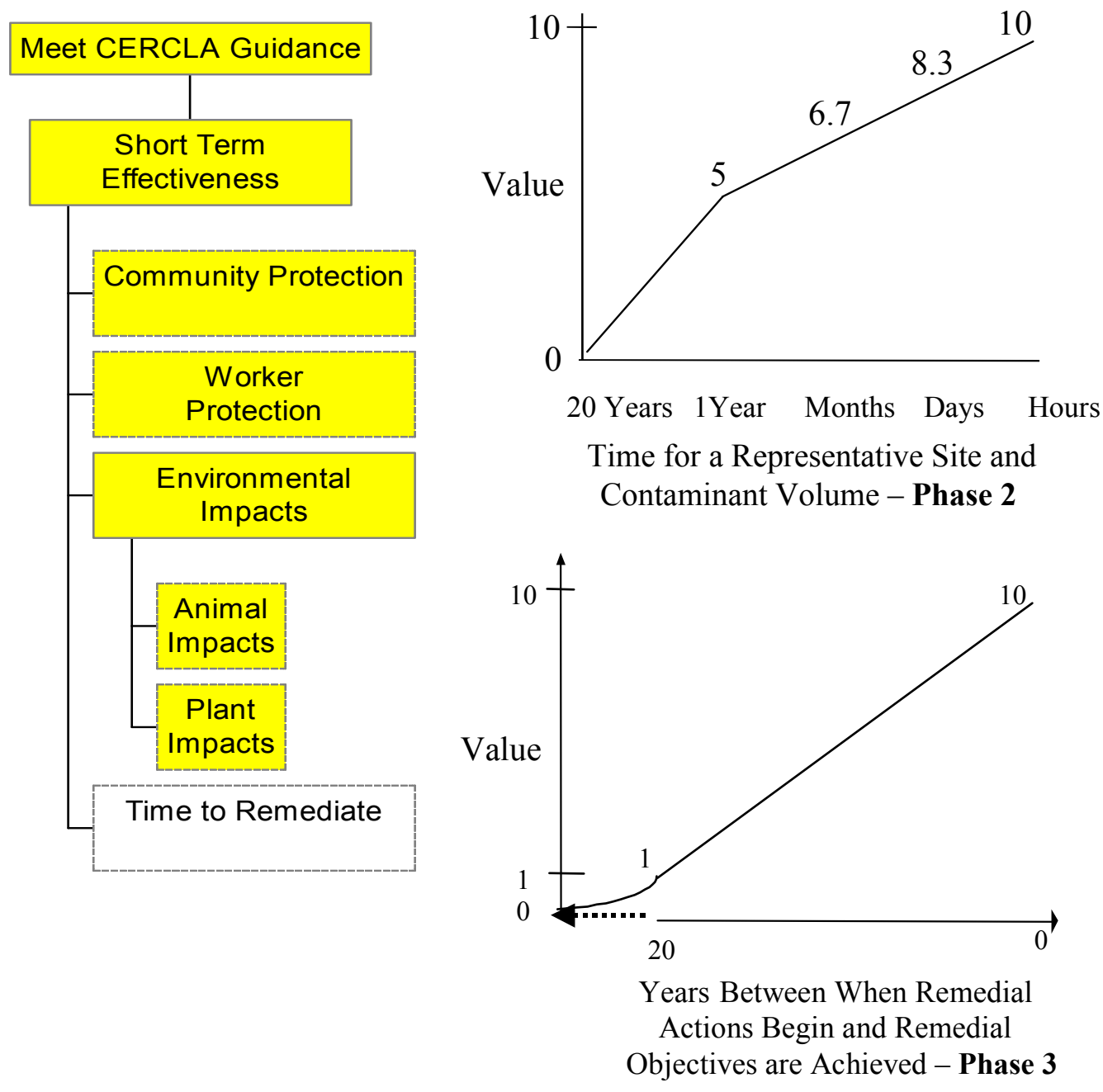

For Phase 2, this measure addresses the remediation time of the function that the technology is performing at a representative site to remediate a representative contaminant. For Phase $\mathbf{3}$, this measure addresses the time to meet the remedial response objectives for the SDA. Waste type and area are used to determine at each site the amount of waste being treated. As the remediation takes more than 20 years the value quickly decreases from one to zero. Remedial Actions begin with the approval of the ROD. 


\section{DRAFT}

\section{BALANCING CRITERIA 4: IMPLEMENTABILITY}

(40 CFR S300.430 (e)(9)(iii)(F)) and (EPA/540/G-89/004, 6.2.3.6): The implementability criterion addresses the technical and administrative feasibility of implementing an alternative and the availability of various services and materials required during its implementation. This criterion involves analysis of the following factors: technical feasibility, administrative feasibility, and availability of services and materials. The criteria are equally weighted since CERCLA does not specifically differentiate between the importance of the three criteria; the evaluation measures are also evenly weighted. Since there is no distinction between the CPOCs in the Implementability criteria, each evaluation measure considers all contaminants.

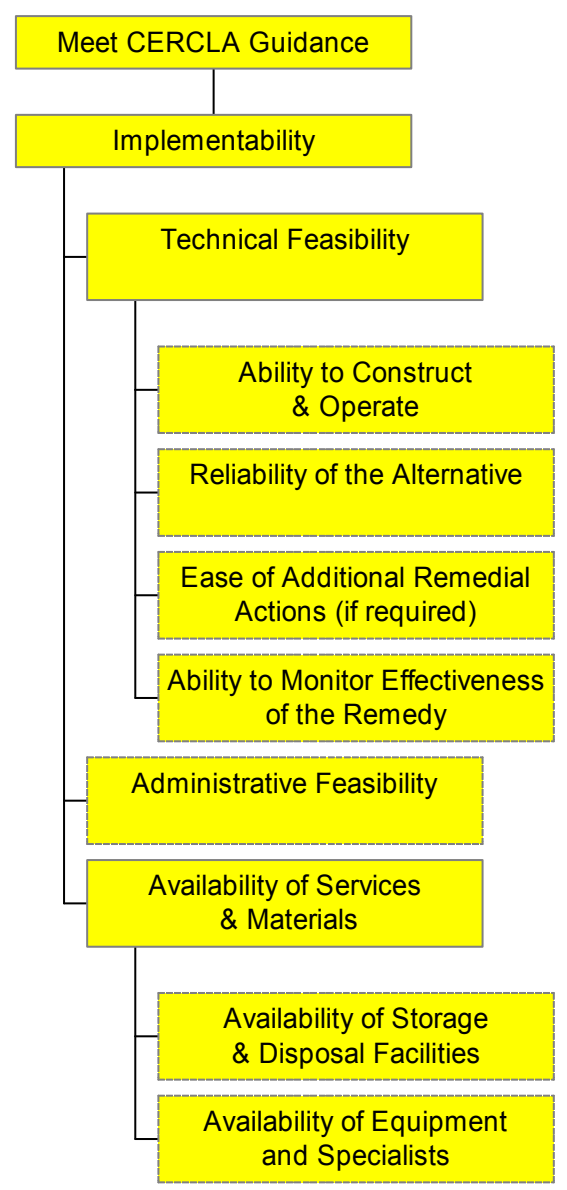

Figure 4-1 Implementability Hierarchy 


\section{DRAFT}

\section{I. Technical Feasibility}

(40 CFR S300.430 (e)(9)(iii)(F)(1)) and (EPA/540/G-89/004, 6.2.3.6): CERCLA further subdivides Technical Feasibility into the subcriteria presented in the preceding hierarchy (dotted-line boxes), including Ability to Construct \& Operate, Reliability of the Alternative, Ease of Additional Remedial Actions, and Ability to Monitor Effectiveness of the Remedy.

4.I.A. Technical Difficulties and Unknowns Associated with the Construction and Operation of a Technology

Type of Measure - Proxy, natural
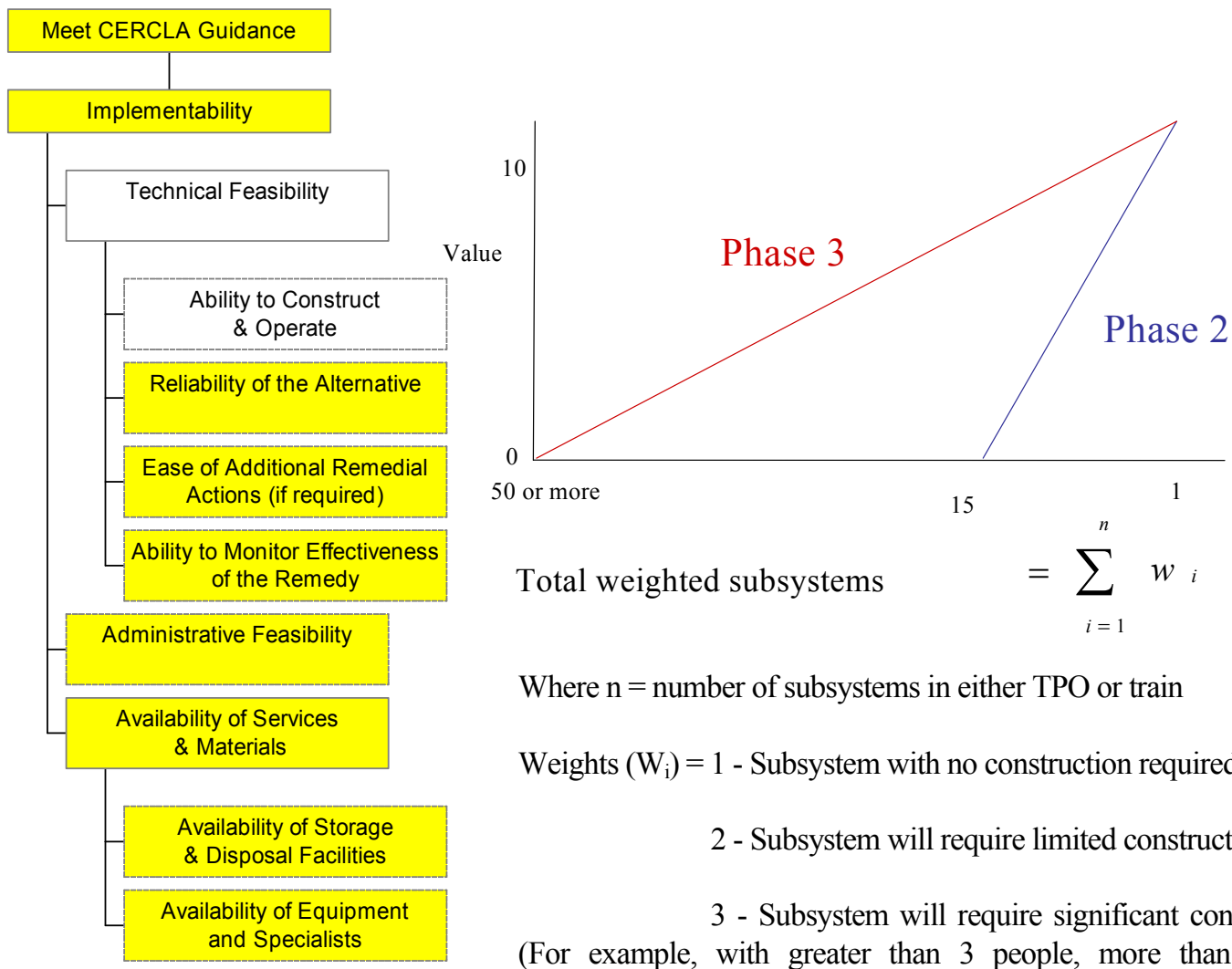

Where $\mathrm{n}=$ number of subsystems in either TPO or train

Weights $\left(\mathrm{W}_{\mathrm{i}}\right)=1$ - Subsystem with no construction required on site

2 - Subsystem will require limited construction on site.

3 - Subsystem will require significant construction on site

(For example, with greater than 3 people, more than two pieces of construction support equipment and will take more than one week.)

This measure addresses the number and the difficulty of construction of the subsystems as a proxy for how difficult the system will be to construct and operate. We are assuming that the integration difficulty is related to the number of subsystems. A subsystem is the first functional breakdown of the TPO. In Phase 2 the total number of subsystems for Phase 2 ranges only from 1 to 15 since only a single TPO is being scored. In Phase 3 the total number of subsystems for Phase 3 ranges from 1 to 50 or more since a site may contain multiple TPOs. The INEEL team felt that 50 subsystems would be a very difficult system to construct and operate at one site. The expected value represents the value of the average number of subsystems per site. 


\section{DRAFT}

4.I.B. Reliability of the Alternative

This sub-criterion satisfies CERCLA's requirement to address the likelihood that technical problems associated with implementation will lead to schedule delays.

Type of Measure - Constructed, Proxy

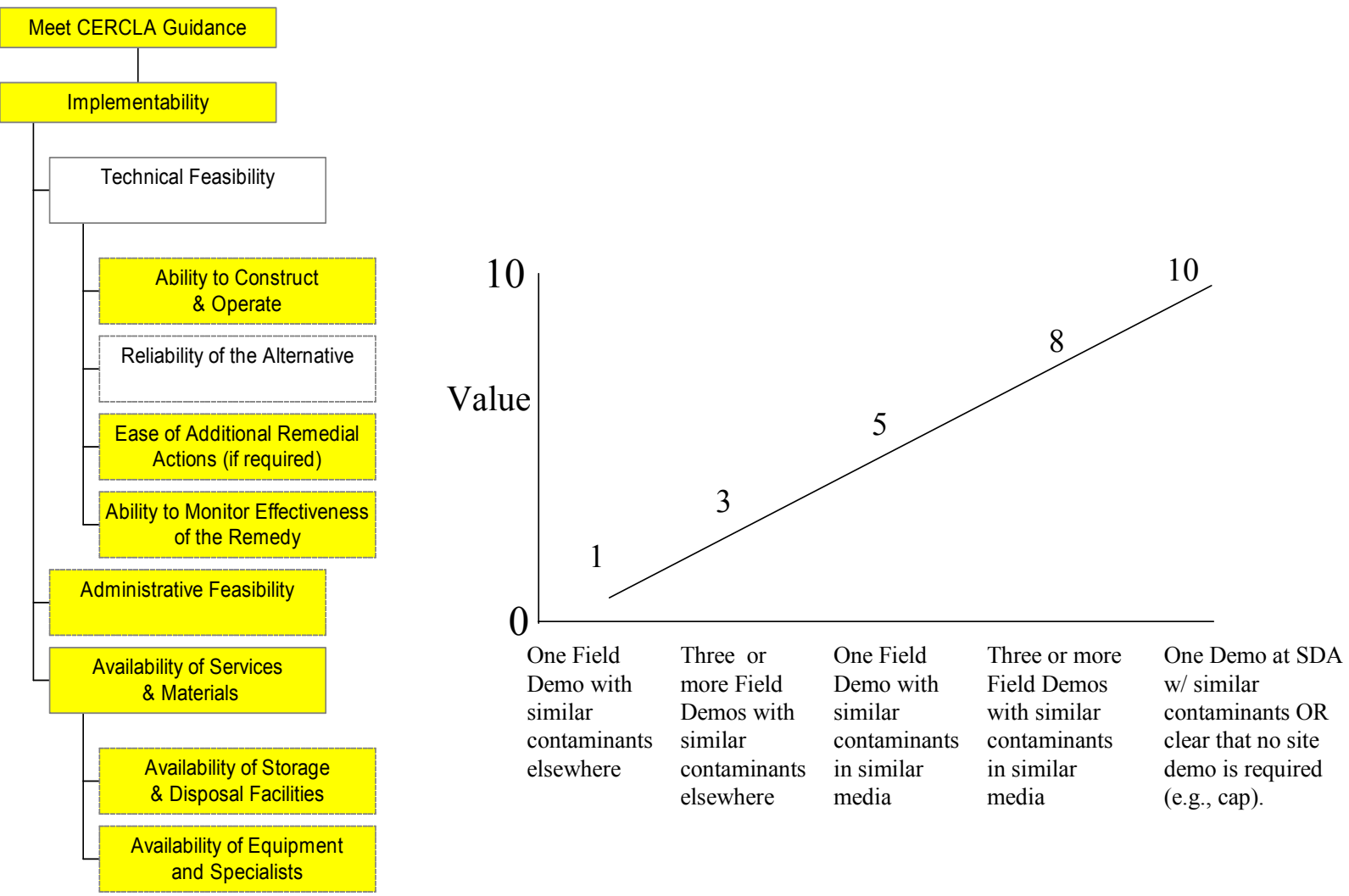

The FS team constructed this measure believing that successful demonstrations of a technology are a good proxy for that technology's (or train's) schedule reliability. In Phase 2, a single TPO is evaluated. In Phase 3, each TPO will be averaged throughout the SDA to yield an average value for a remedial alternative. 


\section{DRAFT}

\section{I.C. Ease of Additional Remedial Actions (if required)}

\section{Type of Measure - Direct, constructed}
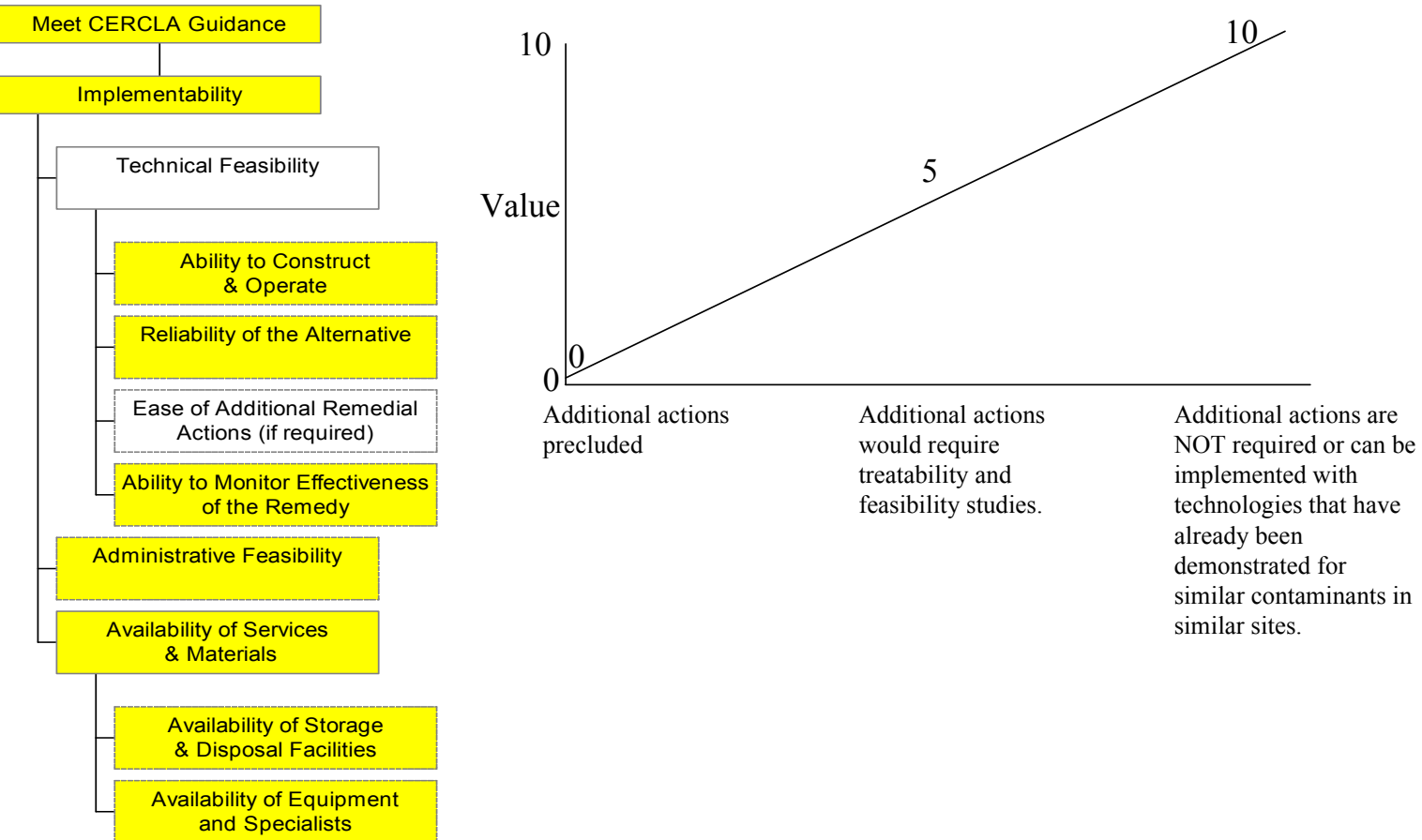

This measure addresses how difficult it would be to perform additional remedial actions if required. For each TPO in Phase 2, the experts will assign one of the above categories. In Phase 3, each train will be evaluated as the lowest value of the TPOs that comprise the train. The likely future interim remedial actions will have to be identified and their difficulty of implementation assessed. 


\section{DRAFT}

\section{I.D. Ability to Monitor the Effectiveness of the Remedy}

\section{Type of Measure - Constructed, Direct}
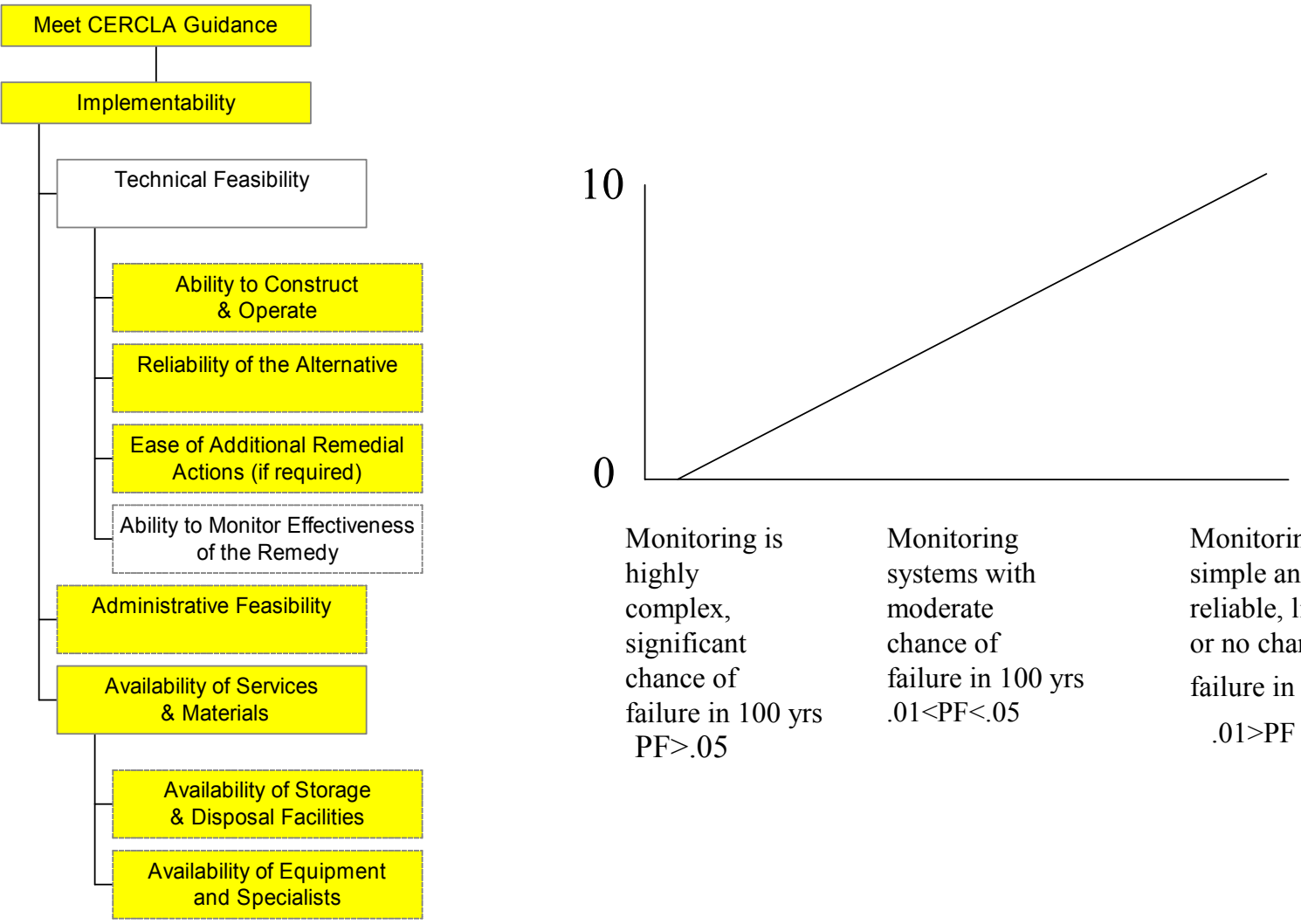

Monitoring is

highly

complex,

significant

chance of

failure in $100 \mathrm{yrs}$

$\mathrm{PF}>.05$
Monitoring

systems with

moderate

chance of

failure in $100 \mathrm{yrs}$

$.01<\mathrm{PF}<.05$
Monitoring is simple and reliable, little or no chance of failure in $100 \mathrm{yrs}$ $.01>\mathrm{PF}$

This measure applies to monitoring for the entire SDA. Monitoring includes groundwater and airborne pathways. This measure addresses how difficult it would be to perform monitoring. PF is the probability of failure of the monitoring. This measure applies to evaluation of alternatives in Phase $\mathbf{3}$ but does not apply for the TPOs being evaluated in Phase 2. Community preference mandates a zero value for any alternative that does not include monitoring. The average value is calculated over the entire SDA by using the estimated probability of success for each train. 


\section{DRAFT}

\section{II. Administrative Feasibility}

(40 CFR S300.430 (e)(9)(iii)(F)(1)) and (EPA/540/G-89/004, 6.2.3.6): This sub criterion satisfies CERCLA's requirement for addressing the ability to obtain approval and coordinate with other offices and agencies.

Type of Measure - Constructed, Direct

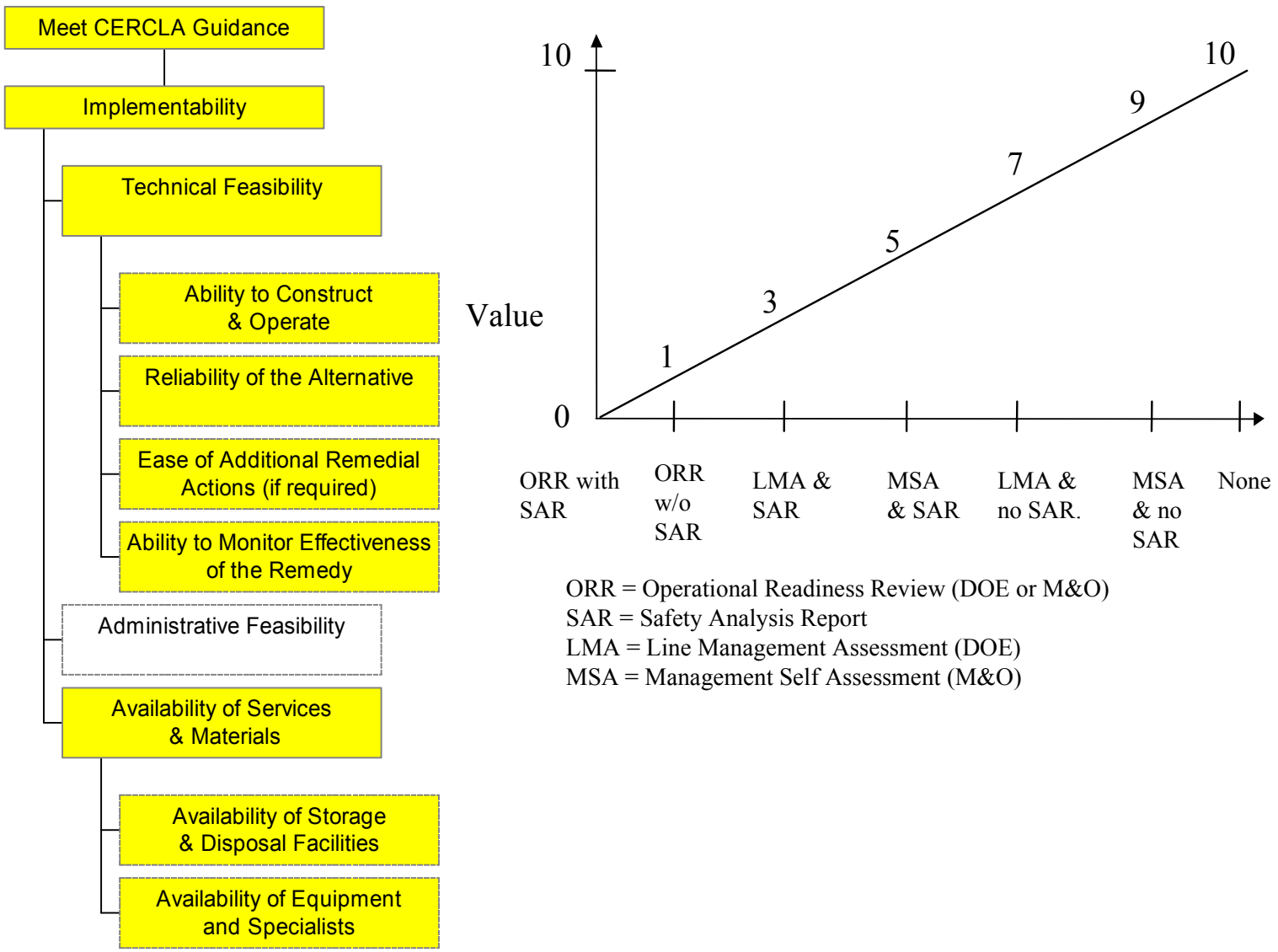

This measure directly addresses the administrative feasibility by the level of review and approval required. Both the TPOs in Phase $\mathbf{2}$ and the full remedial alternatives in Phase $\mathbf{3}$ are appropriately measured using the above scale. Review and approval evaluation is on a site basis and averaged for the SDA. 


\section{DRAFT}

\section{III. Availability of Services \& Materials}

(40 CFR S300.430 (e)(9)(iii)(F)(1)) and (EPA/540/G-89/004, 6.2.3.6): This sub criterion addresses the availability of treatment storage capacity and disposal services, availability of necessary equipment and specialists, and the availability of prospective technologies, including the potential for obtaining competitive bids. This sub criterion is broken into two categories addressing the issues just mentioned.

4.III.A. Availability of Storage and Disposal Facilities

Type of Measure - Constructed, Direct

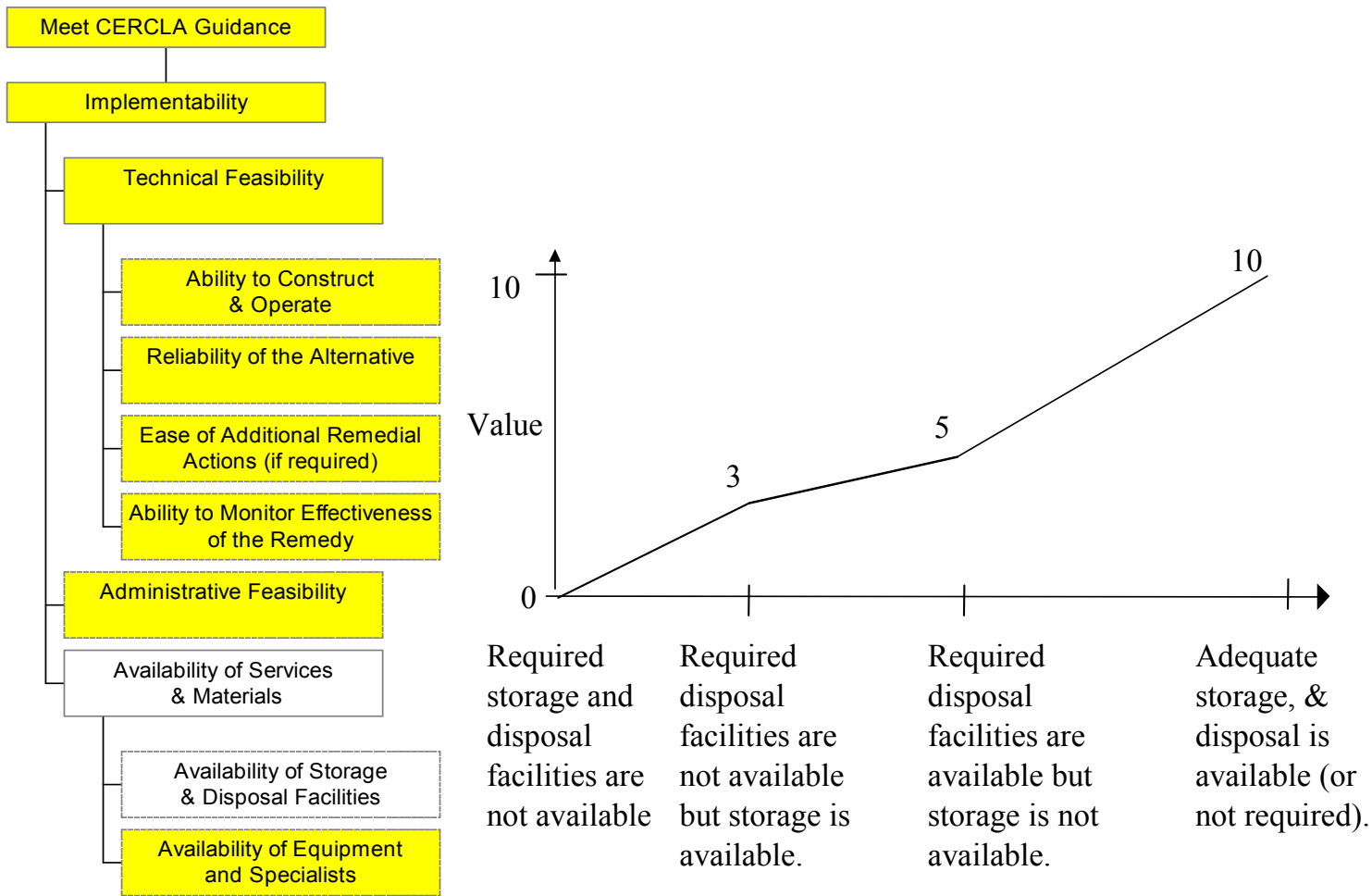

This measure directly addresses the immediate availability of storage and disposal facilities for alternatives that require them. It is recognized that storage facilities may be built, given enough time and money. The measure assumes that storage is required before waste disposal facilities can be used. Some remedial alternatives do not require storage or disposal. This measure applies directly to a TPO for Phase 2. For Phase 3, the lowest value category is the assigned level for the site. The remedial alternative value is just the average value over all the sites in the SDA. 


\section{DRAFT}

4.III.B. Availability of Equipment and Specialists

Type of Measure - Constructed, Direct

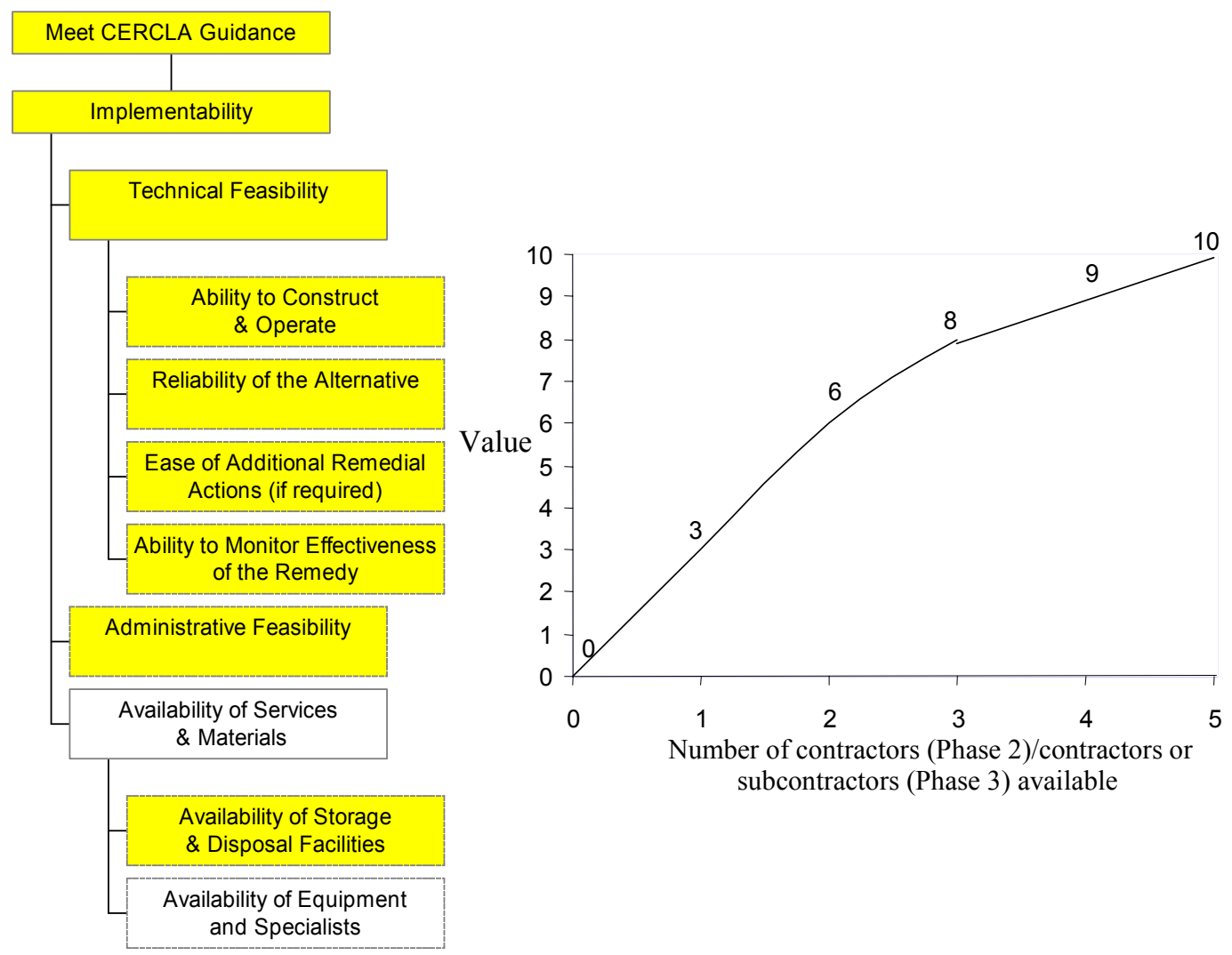

More contractors (subcontractors) indicate the existence of more companies that have the expertise to implement the evaluated TPO or remedial alternative. More companies, therefore, mean there is less risk of the technological capability not being available. For Phase 2, this measure uses the number of contractors as a proxy for the availability of equipment and specialists. For Phase 3, we include subcontractors as the proxy since a remedial alternative may include many TPOs for the entire SDA. The lowest number of contractors for any one TPO becomes the level of the train. The average train over the SDA yields the remedial alternative value. 


\section{DRAFT}

\section{Balancing Criteria 5: Cost}

(40 CFR S300.430 (e)(9)(iii)(G)) and CERCLA states this criterion must account for capital cost, operations and management cost, and present worth (EPA/540/G-89/004, 6-10). These three measures are captured in a net present cost, NPC.

\section{Meet CERCLA Guidance

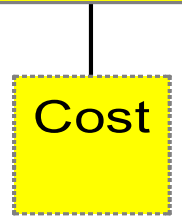

Figure 5.1 Cost

\section{Cost}

Type of Measure -Natural, Direct

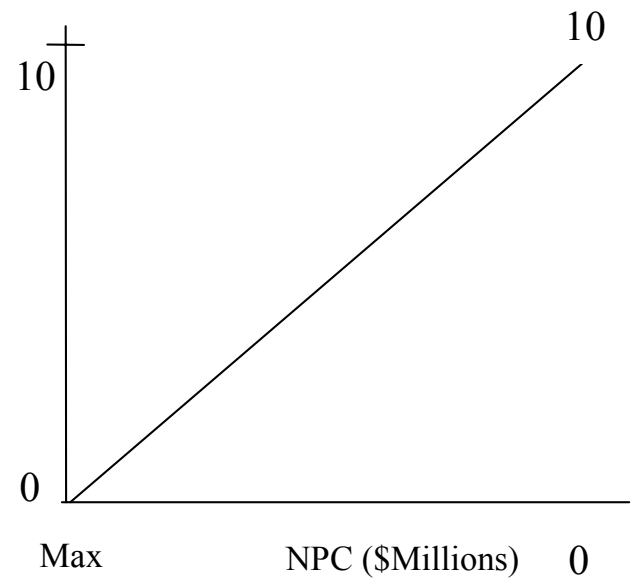

Phase 2

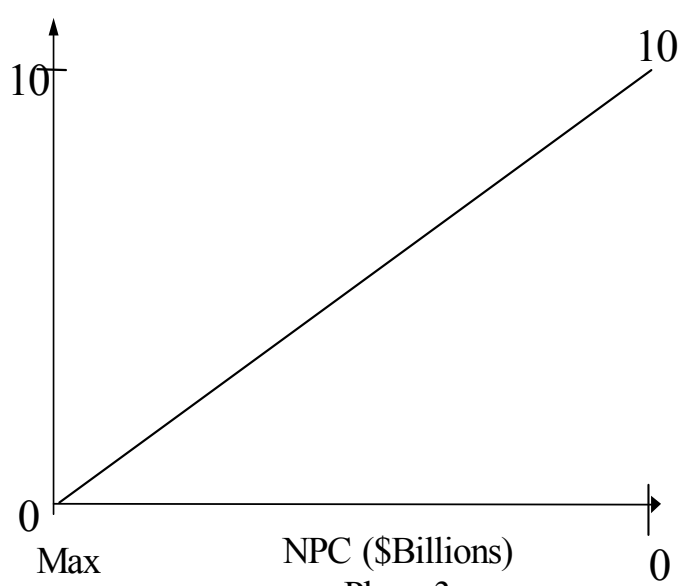

Phase 3

Cost for Phase 2 includes a rough estimate of capital and recurring costs for a single TPO. Performance estimate is based on a representative site and a contaminant volume of 10,000 yards. Cost per cubic yard is used in the calculations. The cost measure for Phase 2 indicates the lowest possible value assigned to the highest NPC of all TPOs evaluated.

Cost for Phase 3 is life cycle cost of the entire SDA project. This includes INEEL costs for treatment, transportation (includes cost to ship to WIPP), storage, and disposal. The cost measure indicates the lowest possible value for the highest NPC of the remedial alternatives. 


\section{DRAFT}

\section{SUMMARY}

This paper has described the CERCLA-based decision multiobjective analysis methodology that we have developed with INEEL/LMITCO, DOE-ID, State of Idaho, and EPA Region 10 decision-makers for INEEL technology screening and remedial alternative evaluation. For each criterion, we developed evaluation measures and value functions to capture how well a technology or a remedial alternative meets each of the CERCLA criteria. Next, we reviewed each evaluation measure and value function with the Feasibility Study team to insure that data could be cost-effectively obtained. We refined the evaluation measures and value functions based on team feedback. Next, the changes were reviewed and approved by the key decision-makers. This value model will be the decision analysis algorithm for the SDA Site Analysis Model being developed by INEEL. Each CERCLA criteria, subcriteria, evaluation measure, and value function are described.

The major value of the CERCLA-based multiobjective decision analysis methodology is the direct link of the CERCLA criteria to the ultimate decisions leading to the safest, most cost effective, and successful technology screening and remediation of radiological waste and other hazardous wastes at the INEEL SDA site. Since an objective, systematic process is used to define the value model and score the alternatives; the results are directly traceable and transparent for decision-maker use and stakeholder review. The methodology draws a clear line from the existing waste and hazards through transparent decisions clearly aimed at remediation, and to on-going and final actions to remediate SDA. The methodology documents good stewardship because it manifests these benefits:

1. An Objective, Systematic Process

2. A Robust Analysis Technique

3. Traceable Analysis Results

4. Better Alternatives

5. Sensitivity Analysis

6. Uncertainty Analysis

7. A Framework for Regulator and Public Discourse 


\section{DRAFT}

References

DOE, (U.S. Department of Energy). Office of Environmental Guidance, RCRA Corrective Action and CERCLA Remedial Action Reference Guide, EH-231, 1994

Environmental Protection Agency. Remediation Technologies Screening Matrix. EPA/542/B-94/013.

October 1994.

Grelk,B. J., Kloeber, J. M., Jackson, J. A., Parnell, G. S., and Deckro, R. F., “Quantifying CERCLA Using Site Decision Maker Values," Remediation, Spring 1998, pp. 87-105

Kirkwood, C. W., Strategic Decision Making: Multiobjective Decision Analysis with Spreadsheets, Belmont, California: Duxbury Press, 1997

Office of the Federal Register, National Archives and Records Service, "Federal Register, Rules and Regulations," 40 CFR Part 300, Vol. 55, No. 46, March 1990

Parnell, G., Jackson, J., Kloeber, J., and Deckro, R. Improving DOE Environmental Management: Using CERCLA- Based Decision Analysis for Remedial Alternative Evaluation in the RI/FS Process, Technical Report, VCU-MAS-99-1, Department of Mathematical Sciences, Virginia Commonwealth University, April 15, 1999

42 United States Code, Sections 9600-9613. Code for Comprehensive Environmental Response, Compensation, and Liability Act (CERCLA), 1988

United States Environmental Protection Agency (EPA), Guidance for Comprehensive Environmental Response, Compensation, and Liability Act, Interim Final, EPA/540/G-89/004, October 1988. 